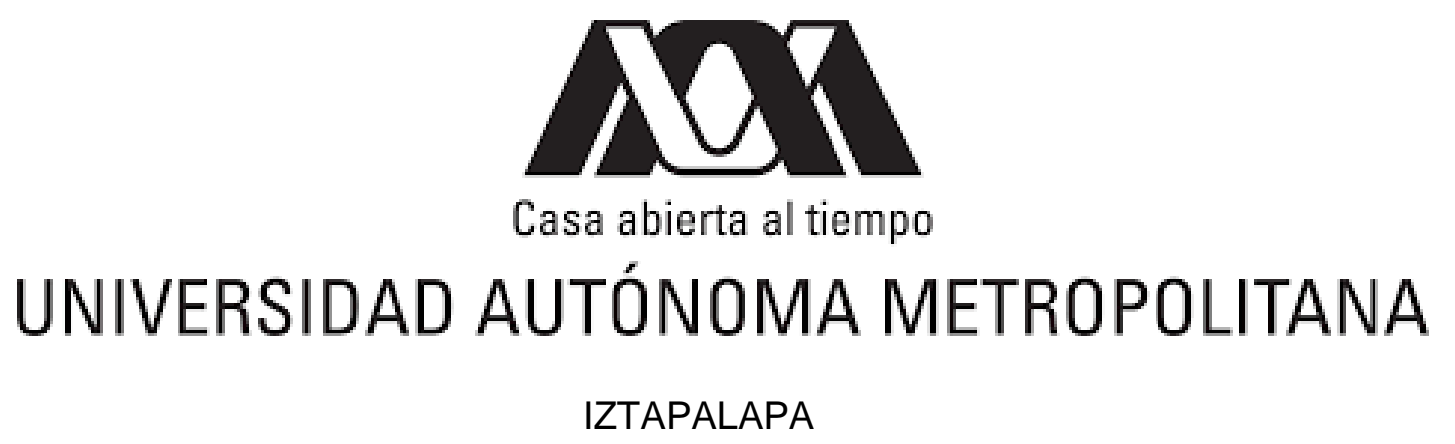

DIVISIÓN DE CIENCIAS BIOLÓGICAS Y DE LA SALUD

DOCTORADO EN CIENCIAS BIOLÓGICAS Y DE LA SALUD

EVALUACIÓN DEL PAPEL DE LOS CONTEXTOS ECOLÓGICO Y EVOLUTIVO EN LA DOMINANCIA TERRITORIAL EN COLIBRÍES

TESIS

QUE PARA OBTENER EL GRADO DE DOCTOR EN CIENCIAS

BIOLÓGICAS Y DE LA SALUD

PRESENTA

Ubaldo Márquez Luna

COMITÉ TUTORAL

Dr. Pablo Corcuera Martínez del Río (Codirector) P Concera

Dr. Carlos Alberto Lara Rodríguez (Codirector)

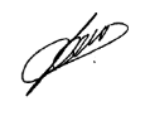

Dr. Pedro Luis Valverde Padilla (Asesor)

Ciudad de México, Agosto 2020 
El presente trabajo fue realizado en el laboratorio de Ecología Animal del Departamento de Biología de la Universidad Autónoma Metropolitana bajo la dirección del Dr. Pablo Corcuera Martínez del Río y en el laboratorio de Ecología de la Conducta del Centro de Investigación en Ciencias Biologicas de la Universidad Autónoma de Tlaxcala bajo la dirección del Dr. Carlos Lara Rodríguez. El asesoramiento del presente trabajo estuvo a cargo del Dr. Pedro Luis Valverde Padilla.

El autor agradece al Consejo Nacional de Ciencia y Tecnología (CONACyT) por la beca otorgada para sus estudios de doctorado, con el número de registro 425674 , que comprendió del periodo del 1/09/2015 al 31/08/2019. El doctorado de Ciencias Biológicas y de la Salud de la Universidad Autónoma Metropolitana pertenece al Padrón de Posgrados de excelencia del CONACyT y además, cuenta con apoyo del mismo Consejo con el convenio PFP-20-93. 
Evaluación del papel de los contextos ecológico $y$

evolutivo en la dominancia

territorial en colibries.
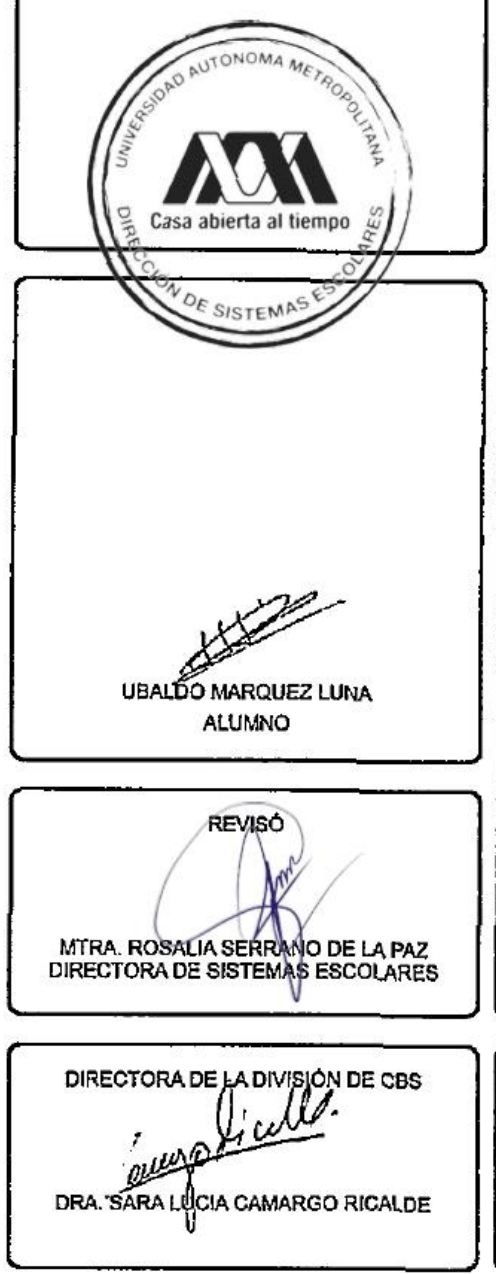

VOCAL

Lus Antomo Sánster G. DR. LUIS ANTONIO SANCHEZ GONZALEZ
Con base en la Legislación de la Universidad Auconoma Metropolitana, en la Ciuciad de Méxlco se presentaron a las 16:00 horas del dia 26 del mes de agosto del ano 2020 POR VIA REMOTA ELECTRONICA, los suscritos miembros del jurado designado por la Comision del posgrado:

DR. PABLO CORCUERA MARTINEZ DEL RIO

DR. PEDRO LUIS VALVERDE PADILLA

QR. LUIS ANTONIO SANCHEZ GONZALEZ

DRR. FLOR DEL CARNEN RODRIGUEZ GOMEZ

DR. CARLOS ALBERTO LARA RODRIGUEZ

Bajo la Presidencia del primero $y$ con carácter de Secretario el último, se reunieron a la presentacjón de la Disertación pública cuya denominación aparece al margen, para la obtención del grado de:

DOCTOR EN CIENCIAS BIOLOGICAS Y DE LA SALUD

OE: UBAIDO MARQUEZ ZUNA

$y$ de acuerdo con el articulo 78 fracción IV del Reglamento de Estudios Superiores de la universidad Autónoma Metropolitana, los miembros del jurado resolvieron:

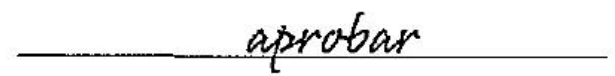

Acto continuo, el presidente del juraco comunicó al interesado el resultado de la evaluación $y$, en caso aprobatorio, le fue tomada la protesta.
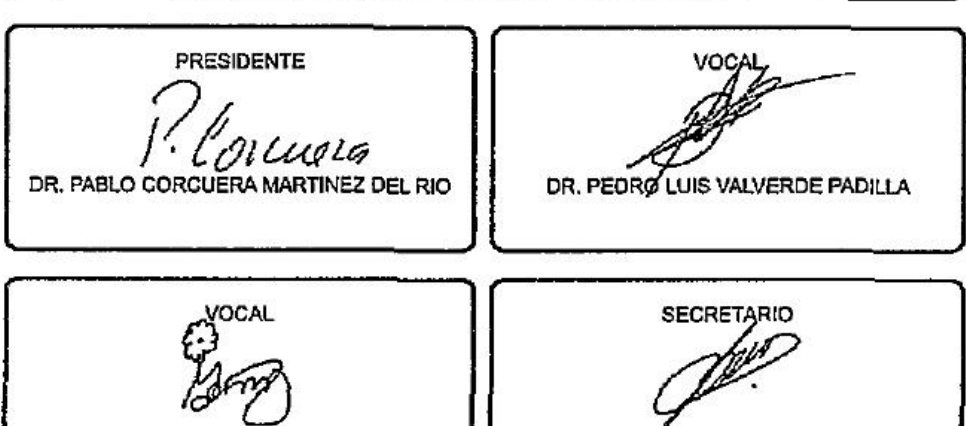

DRA. FLOR DEL CARMEN RODRIGUE: GOMEZ

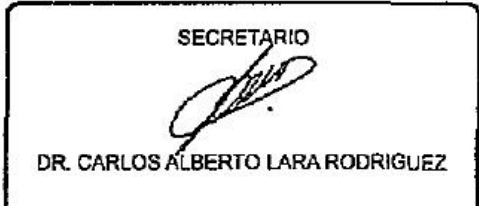

El presente documento cuenta con la firma -autógrafa, escaneada o digital, según corresponda- del funcionario universitario competente, que certifica que las firmas que aparecen en esta acta - Temporal, digital o dictamen-son auténticas y las mismas que usan los c.c. profesores mencionados en ella 


\section{AGRADECIMIENTOS INSTITUCIONALES}

Al programa de Posgrado en Ciencias Biológicas y de la Salud de la Universidad Autónoma Metropolitana por brindarme la oportunidad de continuar mi formación académica

Al Consejo Nacional de Ciencia y Tecnología (CONACyT) por otorgarme la beca con el número de registro 425674. Sin este apoyo institucional, me hubiera sido imposible continuar con mis estudios de Posgrado.

A las autoridades de la Estación Científica La Malinche, perteneciente a la Universidad Autónoma de Tlaxcala (UAT) y a la Universidad Nacional Autónoma de México (UNAM) por el alojamiento durante el desarrollo del trabajo de campo del capítulo II de esta tesis. A las autoridades del Santuario de Bosque de Niebla, perteneciente al Instituto de Ecología, A. C. por el apoyo para la realización del trabajo de campo del capítulo III de esta tesis. 


\section{AGRADECIMIENTOS PERSONALES}

Al Doctor Carlos Lara, Doctor Pablo Corcuera y Doctor Pedro Luis Valverde muchas gracias por siempre apoyar y guiar mis ideas. Fue muy enriquecedor trabajar bajo su tutela. Siempre les estaré agradecido por haber confiado en mí al haber aceptado formar parte de mi comité y con esto darme la oportunidad de fortalecer mi desarrollo profesional.

Al Doctor Luis Antonio Sánchez González, Doctora Flor Rodríguez-Gómez, Doctora Herlinda Bonilla Jaime y al Doctor Cuauhtémoc Chávez Tovar por el trabajo y tiempo que dedicaron a la revisión de este trabajo. Sus comentarios y sugerencias mejoraron significativamente la presente tesis.

A Andrea por la increíble ilustración que transmite a la perfección la esencia del trabajo contenido en esta tesis.

A mis compañeros y amigos del Laboratorio de Ecología Animal (Norma, Verónica, Marco, Ever, Carmen, Yani), de la REPSA (Pablo, Marce, Memo, Andrea, Néstor, Lore, Fernanda, Kali, Adrián, Jess, Tere), de Tótotl (Gustavo, Tatiana) y a Remi, Jorge, Aarón, Jon, Oscar, y Benjamín, muchas gracias por su apoyo, consejo y amistad.

A Isabel por estar juntos en las buenas y en las malas, tu compañía y apoyo han sido fundamentales en este proceso.

A mi mamá, mi hermana y mi hermano por apoyar mis objetivos y por seguir adelante a pesar de las adversidades, siempre han estado conmigo cuando más los he necesitado. A mi papá por estar presente en todos los pasos que damos, tu esencia y enseñanzas siguen guiando nuestro camino. Estoy eternamente agradecido por todo lo que aprendí de ti. Muchas gracias por seguirnos cuidando. 


\section{ÍNDICE GENERAL}

Abreviaturas...............................................................................

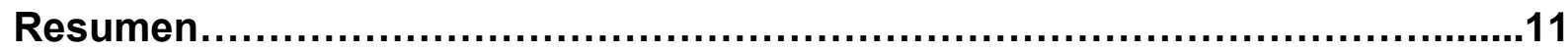

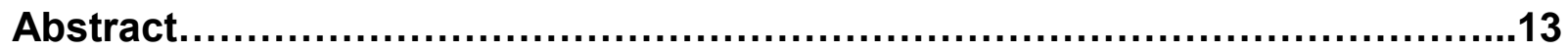

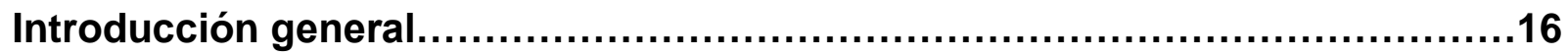

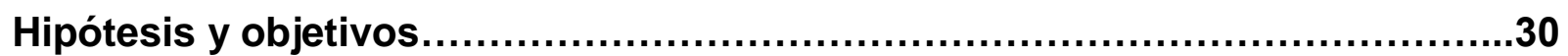

Capítulo I Efecto del tamaño corporal y distancia evolutiva en las interacciones agonísticas de colibríes (Trochilidae) ......................................... 33

Capítulo II Factors affecting the dominance hierarchy dynamics in a

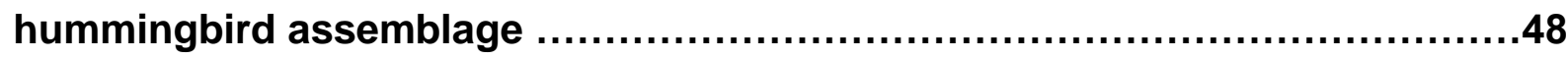

Capítulo III Diferencias en rasgos morfológicos y su influencia en el rango que ocupan las especies de colibríes dentro de una jerarquía de dominancia.

Discusión general.

Literatura citada. 88 


\section{ÍNDICE DE TABLAS Y FIGURAS}

llustración. Momento previo a una contienda entre Eugenes fulgens y Saucerottia cyanocephala por el acceso a flores de Palicourea padifolia.

Introducción general

Tabla 1. Lista de especies de colibríes presentes en México .22

Figura 1. Mapa de la riqueza de especies de colibríes en México...................26

Figura 2. Mapa de la riqueza de clados de colibríes en México .27

Figura 3. Mapa de distribución de las especies de colibríes endémicas de México

Capítulo I. Efecto del tamaño corporal y distancia evolutiva en las interacciones agonísticas de colibríes (Trochilidae)

Tabla 1. Peso corporal de la especie de colibrí ganadora y perdedora de cada contienda, país donde se registró la contienda y secuencia del gen mitocondrial NADH deshidrogenesa subunidad 2.

Figura 1. Frecuencia de contiendas ganadas y perdidas por los clados de colibríes

Figura 2. Distancia genética entre colibríes de América, Norteamérica, Centroamérica y Sudamérica.

Capítulo II. Factors affecting the dominance hierarchy dynamics in a hummingbird assemblage

Tabla 1. Características biológicas de las especies de plantas ornitófilas más abundantes en el PNLM.

Tabla 2. Masa corporal y clado al que pertenecen las especies de colibríes estudiadas.

Tabla 3. Distancia genética entre las especies de colibríes del PNLM............52

Figura 1. Dinámica de la jerarquía dominancia en el PNLM......................52

Figura 2. Frecuencia de encuentros intraespecíficos e interespecíficos ganados por los colibríes dueños de los territorios .53 
Figura 3. Frecuencia de encuentros interespecíficos en relación a la energía producida por el territorio en torno al cual se desarrollaron las contiendas

Figura 4. Encuentros ganados por colibríes más grandes (barras blancas) y más pequeños (barras negras) en relación a su contendiente.

Figura 5. Diferencias en la carga de la envergadura y la longitud de las alas entre las especies de colibríes

Capítulo III. Diferencias en rasgos morfológicos y su influencia en el rango que ocupan las especies de colibríes dentro de una jerarquía de dominancia

Tabla 1. Masa corporal, longitud del pico y rango de dominancia de las especies de colibríes en el SBN

Tabla 2. Distancia genética y contiendas totales entre las especies de colibríes en el SBN.

Figura 1. Relación entre el componente principal (masa corporal y longitud del pico) y el rango de dominancia que ocuparon las especies de colibríes dentro de la jerarquía de domincia.

Figura 2. Contiendas ganadas por el competidor más grande "1" y más pequeño " 0 " como función de la diferencia entre (A) la masa corporal, (B) la longitud del pico y (C) la distancia genética entre colibríes contendientes. .71

Figura 3. Contiendas ganadas por el competidor de mayor rango "1" y por el de menor rango " 0 " como función del número de flores de $P$. padifolia en el territorio. 


\section{ABREVIATURAS}

$A=$ Especie amenazada.

$\mathrm{B}=$ Brasil.

Bleu = Basilinna leucotis

$\mathrm{C}=$ Colombia

Ccan $=$ Chlorestes candida .

$\mathrm{CE}=$ Especie cuasiendémica, su distribución se extiende ligeramente fuera de México (menos de $35000 \mathrm{~km}^{2}$ ).

CONABIO = Comisión Nacional para el Conocimiento y Uso de la Biodiversidad.

Ctha $=$ Colibri thalassinus

DS = Marcador de David

$E=$ Ecuador .

Eful = Eugenes fulgens.

EN = Especie endémica, se distribuye exclusivamente en México.

$\mathrm{GLM}=$ modelo lineal generalizado.

INECOL, A. C. = Instituto de Ecología, Asociación Civil.

Lcle $=$ Lampornis clemenciae .

$M=$ México.

MI = Especie presente en México durante el invierno (septiembre - abril).

MV = Especie presente en México durante la temporada de reproducción de verano (marzo septiembre).

$\mathrm{P}=$ Panamá. 
$P=$ Especie en peligro de extinción.

Pcur = Pampa curvipennis.

PNLM = Parque Nacional La Malinche.

$\operatorname{Pr}=$ Especie sujeta a protección especial.

$\mathrm{R}=$ Costa Rica.

$\mathrm{R}=$ Especie residente en México durante todo el año.

Sber = Saucerottia beryllina .

SBN = Santuario de Bosque de Niebla.

SCIELO = Scientific Electronic Library Online.

Scya = Saucerottia cyanocephala .

$\mathrm{SE}=$ Especie semiendémica, su población total se distribuye en México durante alguna temporada del año.

SMN = Servicio Meteorológico Nacional.

SORA = Searchable Ornithological Research Archive.

Spla = Selasphorus platycercus.

$\mathrm{U}=$ Estados Unidos.

VIF = Valor de inflación de la varianza 


\section{RESUMEN}

Las redes de interacción biótica tienen un efecto importante en la distribución espacial y la estructuración de las comunidades así como en la riqueza de especies a escala local. Algunas especies participantes, como las aves nectarívoras han sido utilizadas como modelo para el estudio de un gran número de interacciones biológicas: desde los mutualismos con las plantas de las que se alimentan, hasta la competencia inter e intraespecífica que se genera por el acceso al néctar floral. Los colibríes son aves nectarívoras endémicas del continente americano, se conocen 338 especies en el continente, 58 de las cuales se distribuyen en México, de las cuales 14 son endémicas del territorio nacional. Estas aves se caracterizan por su alta tasa metabólica, su talla pequeña y su tipo de vuelo. Estas características limitan su almacenamiento de energía por largos periodos de tiempo y a su vez generan que su requerimiento calórico sea elevado y constante. Debido a esto, los colibríes usan distintas estrategias de forrajeo. La dependencia del néctar obliga a los colibríes a asegurar su alimento moviéndose temporalmente entre parches de hábitat y compitiendo por este recurso. Otra de las principales estrategias de forrajeo es el establecimiento y defensa de territorios de forrajeo.

Históricamente se ha reportado una correlación positiva entre un mayor tamaño corporal y una defensa territorial más efectiva, en la que las especies de colibríes de mayor tamaño tienden a dominar a las especies más pequeñas, relegándolas del acceso a los mejores recursos energéticos. No obstante, existen especies pequeñas de colibríes que pueden ganar contiendas agresivas contra especies más grandes. Sin embargo, el contexto en el cual dichas contiendas ocurre ha sido poco estudiado.

El objetivo del presente estudio fue evaluar la influencia de los contextos ecológico y evolutivo en el resultado de las contiendas agonísticas entre colibríes. En el primer capítulo de este trabajo se exploró 1) la frecuencia con la que las especies grandes de colibríes ganan a las pequeñas cuando compiten por el acceso a los recursos, 2) la influencia del tamaño corporal, la identidad del clado y la distancia genética en el resultado de contiendas territoriales de 74 especies de colibríes de siete países de América. El segundo capítulo se enfocó en evaluar si la masa 
corporal y la distancia genética entre contendientes así como los cambios fenológicos de los tres principales recursos florales (Salvia elegans, Bouvardia ternifolia y Penstemon roseus) influyen sobre la jerarquía de dominancia de los colibríes durante un ciclo anual en un bosque templado del centro de México (Parque Nacional La Malinche, Tlaxcala). En el tercer capítulo exploramos si la probabilidad de ganar una contienda agonística es influenciada por la diferencia en la masa corporal, la longitud del pico y la distancia genética entre las especies de un ensamble de colibríes en un Bosque de Niebla (Santuario de Bosque de Niebla, Veracruz) durante la floración de Palicourea padifolia.

Los principales resultados de este trabajo confirmaron que los colibríes establecen jerarquías de dominancia interespecíficas cuando compiten por el acceso a recursos alimenticios (Capítulos II y III). El orden que las especies ocupan dentro de las jerarquías de dominancia es dinámico y es influenciado por los ciclos fenológicos anuales de los recursos disponibles en el ambiente y por la identidad de los colibríes que compiten por su acceso (Capítulo II). Las diferencias entre los rasgos morfológicos de los colibríes contendientes (masa corporal y longitud del pico) representan ventajas competitivas y pueden influir en el resultado de las contiendas, y por lo tanto en el orden que las especies ocupan dentro de la jerarquía de dominancia (Capítulo III). Sin embargo, la dominancia de los colibríes más grandes sobre contendientes más pequeños no es absoluta (Capítulo I). En relación a los nueve clados de colibríes, las especies pertenecientes al clado de las Esmeraldas participan con más frecuencia en contiendas agonísticas por el acceso a recursos alimenticios (Capítulo I). La distancia genética entre las especies de colibríes que conforman un ensamble específico puede ser un factor importante en la resolución de las contiendas, ya que de manera indirecta puede reflejar procesos de divergencia morfológica y conductual entre dos especies contendientes. Sin embargo, la importancia de este factor y su relación con la resolución de contiendas dependerá de la composición de especies del ensamble de estudio (Capítulo II y III).

Palabras clave: Trochilidae, interacciones biológicas, contiendas agonísticas, jerarquía de dominancia, territorialidad, competencia. 


\section{ABSTRACT}

The biological interaction networks have an important effect on the structure and spatial distribution of the species in a community, as well as on the species richness at a local scale. Some of the involved species in these interactions are the nectarivorous birds. These birds have been used as a study model for several biological interactions: such as the mutualistic relationship between hummingbirds and the plants they feed on, or the intraspecific and interspecific competition for floral nectar access. The hummingbirds are nectarivorous birds endemic to the American continent, 338 species are known on the continent, 58 of which are distributed in Mexico, of wich 14 are endemic to the national territory. These birds have a high metabolic rate, small size and a characteristic type of flight. These traits limit their energy storage capacity for long time periods and thus generate a constant and high caloric food intake. Because of this, the hummingbirds use different foraging strategies. Dependence on nectar forces hummingbirds to secure their food moving between patches of habitat and to compete for this resource. Other of the foraging strategies is the establishment and defense of foraging territories.

Historically, a positive correlation between a lager body size and a more effective territorial defense has been found, in which the largest hummingbird species tend to dominate the smaller species and to relegate them from the access to the best energy resources. However, there are small species of hummingbirds that can win aggressive contests against larger species. This scenario has been little studied.

The objective of this study was to evaluate the influence of the ecological and evolutionary contexts on the result of agonistic contests between hummingbirds. The first chapter of this paper explored 1) the frequency with which larger hummingbird species win over small ones when they compete for access to resources, 2) the influence of body mass, the clade identity and the genetic distance on the outcome of territorial contests of 74 hummingbird species from seven countries of America. The second chapter focused on whether the body mass and the genetic distance between contenders as well as the phenological changes of the three main floral resources (Salvia elegans, Bouvardia ternifolia y Penstemon roseus) influence the dominance hierarchy of hummingbirds during an annual cycle in a temperate forest in central 
Mexico (La Malinche National Park, Tlaxcala). In the third chapter we explore whether the probability of winning an agonistic contest is influenced by the difference in body mass, the length of the exposed culmen and the genetic distance between the species of an assemblage of hummingbirds in a Cloud Forest (Cloud Forest Sanctuary, Veracruz) during the flowering period of Palicourea padifolia.

The main results of this work confirmed that hummingbirds establish interspecific dominance hierarchies when they compete for access to food resources (Chapters II and III). The order that the species occupy within the dominance hierarchy is dynamic and is influenced by the annual phenological cycles of the resources available, and by the identity of the competing hummingbirds (Chapter II). The differences between the morphological traits of the contending hummingbirds (body mass and beak length) represent competitive advantages and can influence the outcome of the contests, and therefore the order that the species occupy within the dominance hierarchy (Chapter III). However, the dominance of the larger hummingbirds over smaller contenders is not absolute (Chapter I). In relation to the nine hummingbird clades, the species belonging to the Emerald clade participate more frequently in agonistic contests (Chapter I). The genetic distance between the hummingbird species that make up a specific assemblage may be an important factor in the resolution of the contests, since it may indirectly reflect processes of morphological and behavioral divergence between two contending species. However, the importance of this factor and its relationship with the resolution of the contests will depend on the species composition (Chaper II and III).

Keywords: Trochilidae, biological interactions, agonist contests, dominance hierarchy, territoriality, competition. 


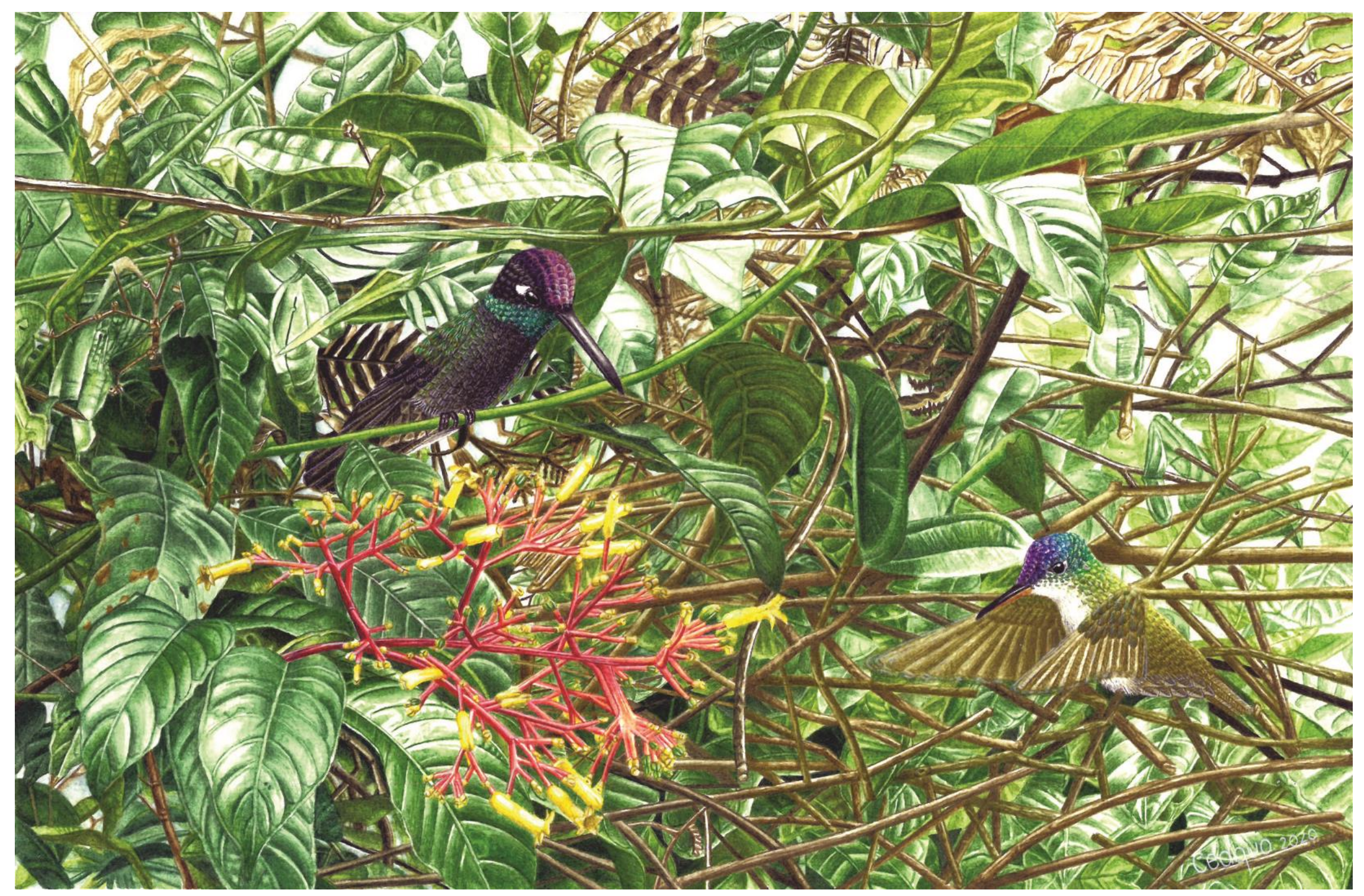




\section{INTRODUCCIÓN GENERAL}

Las especies se encuentran inmersas en redes complejas de interacciones ecológicas (Cazelles et al. 2016). Las interacciones entre organismos juegan un papel fundamental para entender los sistemas biológicos (Schemske et al. 2009).

Estas interacciones pueden ser positivas (mutualismo, $+/+$ ), negativas (competencia, $-(-)$ o una combinación entre efectos positivos, negativos o neutrales entre ambos interactuantes, por ejemplo en la depredación, herbivoría o parasitismo $(+/-)$, o en el amensalismo (-/0) y comensalismo (+/0; Stachowicz 2001, Araújo y Rozenfeld 2014). Los efectos generados por las interacciones bióticas suelen ser directos, es decir, resultan de la interacción física entre dos individuos. Sin embargo, el resultado de estas interacciones directas puede generar cambios en la abundancia de recursos 0 en alguna variable que afecte a otras especies. Estos efectos se denominan indirectos, por ejemplo un depredador puede disminuir la abundancia de su presa, de este modo otras especies que también consuman esa presa verán disminuidos sus recursos (Wootton 1994).

Se ha hipotetizado que las redes de interacción tienen un efecto importante en la distribución espacial y la estructuración de las comunidades (Araújo y Rozenfeld 2014), así como en la riqueza de especies a escala local (Paine 1976). Ejemplo de lo anterior es la depredación, la cual puede incrementar la riqueza específica de un área. Esto ocurre cuando un depredador tiene preferencia por una presa competitivamente superior, ya que evita que una sola especie monopolice los recursos disponibles. Lo anterior permite el incremento de la abundancia de competidores inferiores y facilita la coexistencia de diferentes especies dentro de una comunidad a través de la repartición de recursos e incluso de amenazas generadas por depredadores (Paine 1976; Shurin y Allen 2001).

Los factores abióticos como el clima, la humedad o la altitud juegan un papel importante en los procesos de estructuración de las comunidades terrestres a una escala regional mientras que las interacciones bióticas tendrán un mayor peso a escala local (Whittaker et al. 2001). Sin embargo, hay evidencia que señala que las interacciones bióticas pueden influir patrones a mayor escala e incluso tener efectos 
sobre la distribución de las especies (Gotelli et al. 2010; Araújo y Rozenfeld 2014). Adicionalmente, la integración y el análisis de las relaciones filogenéticas puede generar información robusta acerca de cómo las interacciones bióticas y los factores ambientales históricos y actuales han determinado la composición de especies en escalas locales y regionales (Graham et al. 2009).

Las aves son uno de los grupos de vertebrados mejor estudiados debido a su atractivo estético y a que son relativamente conspicuas, lo cual las hace fáciles de observar. Estas ventajas han permitido conocer a fondo características morfológicas, fisiológicas y conductuales del grupo, al igual que aspectos como la estructuración de sus comunidades o las redes de interacción en las que participan (Abrahamczyck y Kessler 2014). En este sentido, las aves nectarívoras y las relaciones que establecen con su principal recurso alimentico (i.e., néctar floral) han sido utilizadas como modelo para el estudio de un gran número de interacciones biológicas, desde los mutualismos con las plantas de las que se alimentan, hasta la competencia inter e intraespecífica (Cotton 2007).

Los colibríes, son aves nectarívoras endémicas del continente americano, se caracterizan por su talla pequeña y por su alta tasa metabólica, lo que limita el almacenamiento de energía por largos periodos de tiempo. Estas características hacen que su requerimiento calórico sea elevado y constante (Stiles 1995, Altshuler et al. 2004). La dependencia del néctar obliga a los colibríes a utilizar distintas estrategias para asegurar su alimento. Por ejemplo, moviéndose temporalmente entre parches de hábitat y compitiendo por el acceso a este recurso (Montgomerie y Gass 1981).

Los colibríes se pueden dividir en dos grandes grupos dependiendo de sus estrategias de forrajeo: los que usan rutas de alimentación (colibríes ruteros) y los que establecen y defienden parches florales (colibríes territoriales). Los colibríes ruteros (trapliners) establecen un plan de vuelo y forrajean haciendo visitas secuenciales y repetidas a diferentes parches de alimentación (Ohashi y Thomson 2009). Por el contrario, los colibríes territoriales defienden un área bien delimitada para obtener acceso exclusivo al néctar. Sin embargo, un mismo individuo puede 
modificar la estrategia de forrajeo (i.e., territorial a rutero y viceversa) que utiliza dependiendo de la abundancia floral, la calidad del néctar y la composición de especies de colibríes que compitan por el acceso a dichos recursos (Feinsinger y Colwell 1978, Dearborn 1998). Por ejemplo, se ha documentado que el establecimiento y defensa de un territorio de forrajeo está relacionado al costobeneficio del colibrí dueño del territorio. Es decir, el costo de la defensa territorial (i.e., energía invertida en las contiendas para expulsar intrusos del territorio) no deberá exceder el beneficio (i.e., energía obtenida del néctar de las flores defendidas) de monopolizar los recursos florales (Kodric-Brown y Brown 1978; Márquez-Luna et al. 2015). Adicionalmente, la estrategia de forrajeo puede ser influenciada por la categoría de edad y el sexo de los colibríes. Se ha reportado que las hembras y los juveniles también pueden establecer territorios de forrajeo (Wolf 1969; Márquez-Luna et al. 2017), aunque regularmente optan por el uso de otras estrategias de forrajeo como el robo de néctar o el uso de recursos no defendidos. En contiendas agonísticas intraespecíficas, los machos tienden a dominar a las hembras y a establecer territorios de forrajeo de mayor calidad, es decir, más pequeños y con mayor densidad de flores que las hembras (Kodric-Brown y Brown 1978; Carpenter et al. 1993).

Históricamente se ha reportado una correlación positiva entre el tamaño corporal y una defensa territorial exitosa. Por lo que las especies de colibríes de mayor tamaño tienden a dominar a las especies más pequeñas, relegándolas del acceso a los mejores recursos energéticos (Hainsworth y Wolf 1972, Dearborn 1998, Araújo-Silva y Bessa 2010 y Justino et al. 2012). La hipótesis más aceptada para explicar dicho patrón es que los colibríes de mayor tamaño tienden a monopolizar parches florales para aumentar la eficiencia de obtención de energía durante el forrajeo (Dearborn 1998).

La dominancia se define como la posición social o rango de un individuo relativo a uno o más competidores contra los cuales el individuo tiende a ganar contiendas agonísticas (Ewald 1985). Una jerarquía de dominancia será el conjunto de posiciones o rangos que ocupen los individuos dentro de un grupo o las especies 
dentro de un ensamble (Chase y Seitz 2011). El rango de cada especie se puede determinar cuantitativamente evaluando la frecuencia de los resultados de las contiendas que gana y pierde contra otras especies cuando compiten por el acceso a algún recurso (Francis et al. 2018). Las especies con rangos altos serán más dominantes que aquellas con rangos bajos dentro de la jerarquía de dominancia, el rango más alto en una jerarquía será el 1 y el menor será igual al número de especies en el ensamble (Chase y Seitz 2011). Existen diferentes métodos cuantitativos para determinar el rango que ocupan las especies de un ensamble dentro de una jerarquía de dominancia. En aves se han utilizado los métodos conocidos como el marcador de David (David 1987; López-Segoviano et al. 2017) y la aleatorización de la puntuación Elo (Elo 1978; Sánchez-Tojar et al. 2017; Francis et al. 2018) para determinar jerarquías de dominancia interespecíficas.

El estudio cuantitativo de las relaciones de dominancia interespecíficas a través del establecimiento de una jerarquía es fundamental en colibríes pues se ha documentado que existen especies pequeñas que pueden ganar contiendas agresivas contra especies más grandes (Pimm et al. 1985). Sin embargo, el contexto en el cual dichas contiendas ocurre ha sido poco estudiado. Martin y Ghalambor (2014) reportan que un ave de menor talla tiene más probabilidades de ganar un encuentro agresivo contra otra especie de mayor tamaño cuando existe una mayor distancia evolutiva entre ambas especies interactuantes. Los autores sugieren que a lo largo del tiempo evolutivo las especies pequeñas pueden desarrollar características que les permitan superar las desventajas competitivas asociadas a un menor tamaño corporal (e.g., mayor desarrollo muscular, incremento en la aceleración y maniobrabilidad durante el vuelo, mayor producción de testosterona, estradiol o deshidroepiandrosterona). Es decir, las ventajas de un mayor tamaño corporal declinan conforme se incrementa la distancia evolutiva entre las dos especies participantes en un encuentro agonístico.

Bajo este contexto la incorporación de las perspectivas filogenéticas podría ayudar a explicar las relaciones de dominancia entre especies de colibríes en comunidades específicas. En este sentido McGuire et al. (2014) postulan una 
hipótesis filogenética basada en datos de 284 de las 338 especies de colibríes distribuidas en todo el continente americano. Esta hipótesis sugiere que el origen de los colibríes ocurrió en Eurasia y que invadieron Sudamérica a través del estrecho de Bering hace $\approx 40-22$ millones de años. El grupo se diversificó en Sudamérica y posteriormente recolonizaron Norteamérica y el Caribe. Se reconocen los siguientes 9 clados de colibríes: Topacios, Ermitaños, Mangos, Brillantes, Coquetas, Patagona gigas, Gemas de Montaña, Abejas y Esmeraldas (Bleiweiss et al. 1997; McGuire et al. 2014). Estos clados surgieron diferencialmente en el tiempo y se diversificaron en diferentes regiones del continente, siete de los nueve clados de colibríes se diversificaron en Sudamérica (i.e., Ermitaños, Topacios, Mangos, Brillantes, Coquetas, Patagona y Esmeraldas), mientras que el ancestro común de las Abejas y las Gemas de Montaña recolonizó Norteamérica ( $\approx 12$ millones de años) donde posteriormente ambos clados se diversificaron. Estos procesos de diversificación estuvieron promovidos por el surgimiento de barreras geográficas y el subsecuente origen de nuevos nichos ecológicos (e.g., la Cordillera de los Andes o el Itsmo de Panamá; McGuire et al. 2014). La historia de diversificación del grupo en el continente genera diferentes patrones en la composición de especies, ya que en algunas localidades habrá mayor presencia de especies poco emparentadas (filogenéticamente distantes), mientras que en otras los ensambles estarán conformados por especies filogenéticamente más cercanas (Graham et al. 2009). Un ejemplo de lo anterior son los ensambles del Norte de Norteamérica, ya que están conformados casi exclusivamente por colibríes del clado de las Abejas.

En México se distribuyen 58 especies de colibríes (Tabla 1), 14 son endémicas del territorio nacional (Berlanga et al. 2015). Del total nacional 17 especies se encuentran bajo alguna categoría de riesgo con base en la NOM-059SEMARNAT (2010). En México los colibríes aprovechan en una gran variedad de hábitats, desde los áridos en el norte hasta los tropicales del sureste del país. Además de lo anterior, en muchas localidades de México la composición de especies de colibríes es variable temporalmente, ya que algunas especies realizan movimientos migratorios latitudinales y altitudinales. Estos movimientos migratorios están asociados a los ciclos fenológicos (i.e., disponibilidad y abundancia) de las 
plantas de las que se alimentan (Feinsinger et al. 1985; Araujo y Sazima 2003; Cotton 2007). Los cambios temporales en la composición de especies tienen efectos sobre las preferencias de forrajeo de los colibríes y sobre el éxito reproductivo de las plantas de las que se alimentan (Magrach et al. 2020). Se ha reportado que la dinámica temporal en la composición de especies de colibríes puede tener efectos sobre las relaciones de dominancia interespecíficas al incrementar la competencia por el acceso a los recursos (Rodríguez-Flores y Arizmendi 2016). 


\begin{tabular}{|c|c|c|c|c|c|}
\hline Nombre científico & Nombre común & Residencia & Endemismo & NOM-ECOL-059 & Clado \\
\hline Florisuga mellivora & Colibrí Capucha Azul & $\mathrm{R}$ & & & Topacio \\
\hline Phaethornis longirostris & Colibrí Ermitaño Pico Largo & $\mathrm{R}$ & & & Ermitaño \\
\hline Phaethornis mexicanus & Colibrí Ermitaño Mexicano & $\mathrm{R}$ & EN & & Ermitaño \\
\hline Phaethornis striigularis & Colibrí Ermitaño Enano & $\mathrm{R}$ & & $\operatorname{Pr}$ & Ermitaño \\
\hline Colibri thalassinus & Colibrí Orejas Violetas & $\mathrm{R}$ & & & Mango \\
\hline Heliothryx barroti & Colibrí Hada Enmascarada & $\mathrm{R}$ & & A & Mango \\
\hline Anthracothorax prevostii & Colibrí Garganta Negra & $\mathrm{R}, \mathrm{MV}, \mathrm{Ml}$ & & & Mango \\
\hline Lophornis brachylophus & Coqueta de Atoyac & $\mathrm{R}$ & EN & $P$ & Coqueta \\
\hline Lophornis helenae & Coqueta Cresta Negra & $\mathrm{R}$ & & $A$ & Coqueta \\
\hline Eugenes fulgens & Colibrí Magnífico & $\mathrm{R}$ & & & Gema de Montaña \\
\hline Heliomaster longirostris & Colibrí Picudo Coroniazul & $\mathrm{R}$ & & $\operatorname{Pr}$ & Gema de Montaña \\
\hline Heliomaster constantii & Colibrí Picudo Occidental & $\mathrm{R}$ & & & Gema de Montaña \\
\hline Lampornis viridipallens & Colibrí Garganta Verde & $\mathrm{R}$ & & $\operatorname{Pr}$ & Gema de Montaña \\
\hline Lampornis amethystinus & Colibrí Garganta Amatista & $\mathrm{R}$ & & & Gema de Montaña \\
\hline Lampornis clemenciae & Colibrí Garganta Azul & $\mathrm{R}$ & SE & & Gema de Montaña \\
\hline Lamprolaima rhami & Colibrí Multicolor & $\mathrm{R}$ & & $A$ & Gema de Montaña \\
\hline Tilmatura dupontii & Colibrí Cola Pinta & $\mathrm{R}$ & & A & Abeja \\
\hline Doricha enicura & Colibrí Tijereta Guatemalteco & $\mathrm{R}$ & & A & Abeja \\
\hline
\end{tabular}




\begin{tabular}{|c|c|c|c|c|c|}
\hline Nombre científico & Nombre común & Residencia & Endemismo & NOM-ECOL-059 & Clado \\
\hline Doricha eliza & Colibrí Tijereta Mexicano & $\mathrm{R}$ & EN & $\mathrm{P}$ & Abeja \\
\hline Calothorax lucifer & Colibrí Lucifer & $\mathrm{MV}, \mathrm{MI}, \mathrm{R}$ & SE & & Abeja \\
\hline Calothorax pulcher & Colibrí Mixteco & $\mathrm{R}$ & EN & & Abeja \\
\hline Archilochus colubris & Colibrí Garganta Rubí & Ml & & & Abeja \\
\hline Archilochus alexandri & Colibrí Barba Negra & $\mathrm{MV}, \mathrm{MI}$ & SE & & Abeja \\
\hline Calypte anna & Colibrí Cabeza Roja & MI, R & & & Abeja \\
\hline Calypte costae & Colibrí Cabeza Violeta & $\mathrm{R}, \mathrm{Ml}$ & & & Abeja \\
\hline Selasphorus heloisa & Zumbador Mexicano & $\mathrm{R}$ & EN & & Abeja \\
\hline Selasphorus ellioti & Zumbador Guatemalteco & $\mathrm{R}$ & & $A$ & Abeja \\
\hline Selasphorus platycercus & Zumbador Cola Ancha & $\mathrm{R}, \mathrm{MI}, \mathrm{MV}$ & SE & & Abeja \\
\hline Selasphorus rufus & Zumbador Canelo & Ml & & & Abeja \\
\hline Selasphorus sasin & Zumbador de Allen & MI, MV & SE & & Abeja \\
\hline Selasphorus calliope & Zumbador Garganta Rayada & MI, MV & SE & & Abeja \\
\hline Phaeoptila sordida & Colibrí Opaco & $\mathrm{R}$ & EN & & Esmeralda \\
\hline Cynanthus auriceps & Esmeralda Occidental & $\mathrm{R}$ & EN & & Esmeralda \\
\hline Cynanthus forficatus & Esmeralda de Isla Cozumel & $\mathrm{R}$ & EN & & Esmeralda \\
\hline Cynanthus canivetii & Esmeralda Oriental & $\mathrm{R}$ & & & Esmeralda \\
\hline Cynanthus latirostris & Colibrí Pico Ancho & $\mathrm{R}$ & SE & & Esmeralda \\
\hline Basilinna leucotis & Zafiro Orejas Blancas & $\mathrm{R}$ & & & Esmeralda \\
\hline
\end{tabular}




\begin{tabular}{|c|c|c|c|c|c|}
\hline Nombre científico & Nombre común & Residencia & Endemismo & NOM-ECOL-059 & Clado \\
\hline Basilinna xantusii & Zafiro Bajacaliforniano & $\mathrm{R}$ & EN & & Esmeralda \\
\hline Abeillia abeillei & Colibrí Pico Corto & $\mathrm{R}$ & & $\operatorname{Pr}$ & Esmeralda \\
\hline Phaeochroa cuvierii & Colibrí Pecho Escamoso & $\mathrm{R}$ & & & Esmeralda \\
\hline Pampa curvipennis & Fandanguero Mexicano & $\mathrm{R}$ & & & Esmeralda \\
\hline Pampa excellens & Fandanguero Tuxtleño & $\mathrm{R}$ & EN & $\operatorname{Pr}$ & Esmeralda \\
\hline Pampa rufa & Fandanguero Canelo & $\mathrm{R}$ & CE & $\operatorname{Pr}$ & Esmeralda \\
\hline Campylopterus hemileucurus & Fandanguero Morado & $\mathrm{R}$ & & & Esmeralda \\
\hline Eupherusa ridgwayi & Colibrí Cola Rayada & $\mathrm{R}$ & EN & A & Esmeralda \\
\hline Eupherusa eximia & Colibrí Miahuatleco & $\mathrm{R}$ & & & Esmeralda \\
\hline Eupherusa cyanophrys & Colibrí Guerrerense & $\mathrm{R}$ & EN & $\mathrm{P}$ & Esmeralda \\
\hline Eupherusa poliocerca & Ninfa Mexicana & $\mathrm{R}$ & EN & A & Esmeralda \\
\hline Leucolia violiceps & Colibrí Corona Violeta & $\mathrm{R}$ & SE & & Esmeralda \\
\hline Leucolia viridifrons & Colibrí Frente Verde & $\mathrm{R}$ & EN & A & Esmeralda \\
\hline Saucerottia cyanocephala & Colibrí Corona Azul & $\mathrm{R}$ & & & Esmeralda \\
\hline Saucerottia beryllina & Colibrí Berilo & $\mathrm{R}$ & & & Esmeralda \\
\hline Saucerottia cyanura & Colibrí Cola Azul & $\mathrm{R}$ & & & Esmeralda \\
\hline Amazilia tzacatl & Colibrí Cola Canela & $\mathrm{R}$ & & & Esmeralda \\
\hline Amazilia yucatanensis & Colibrí Vientre Canelo & $\mathrm{R}$ & CE & & Esmeralda \\
\hline Amazilia rutila & Colibrí Canelo & $\mathrm{R}$ & & & Esmeralda \\
\hline
\end{tabular}


Tabla 1. Lista de especies de colibríes presentes en México.

\begin{tabular}{|c|c|c|c|}
\hline Nombre científico & Nombre común & Residencia Endemismo NOM-ECOL-059 & Clado \\
\hline Chlorestes candida & Colibrí Cándido & $\mathrm{R}, \mathrm{MI}$ & Esmeralda \\
\hline Chlorestes eliciae & Zafiro Garganta Azul & $\mathrm{R}$ & Esmeralda \\
\hline
\end{tabular}

Residencia: $\mathrm{R}$ = Presente en México durante todo el año, $\mathrm{Ml}=$ Presente en México durante el invierno (septiembre abril), MV = Presente en México durante la temporada de reproducción de verano (marzo - septiembre). Endemismo: EN = Especie endémica, se distribuye exclusivamente dentro de México, SE = Especie semiendémica, su población total se distribuye en México durante alguna temporada del año, $C E$ = Especie cuasiendémica, su distribución se extiende ligeramente fuera de México (menos de $35.000 \mathrm{~km}^{2}$ ). NOM-ECOL-059: $\mathrm{Pr}=$ Especie sujeta a protección especial, $\mathrm{A}=$ Especie amenazada, $\mathrm{P}=$ Especie en peligro de extinción. Los nombres comunes, categorías de residencia y endemismo fueron tomados de Berlanga et al. (2015), la categoría de riesgo fue tomada de la NOM-059-SEMARNAT (2010) y el clado de pertenencia de cada especie fu tomado de McGuire et al. (2014). Los nombres científicos están actualizados a los cambios propuestos por Chesser et al. (2020). 
El número de especies en el país aumenta de Norte a Sur (Figura 1). La mayor riqueza de especies de colibríes se concentra en las zonas montañosas y áreas tropicales de México (Figura 1).

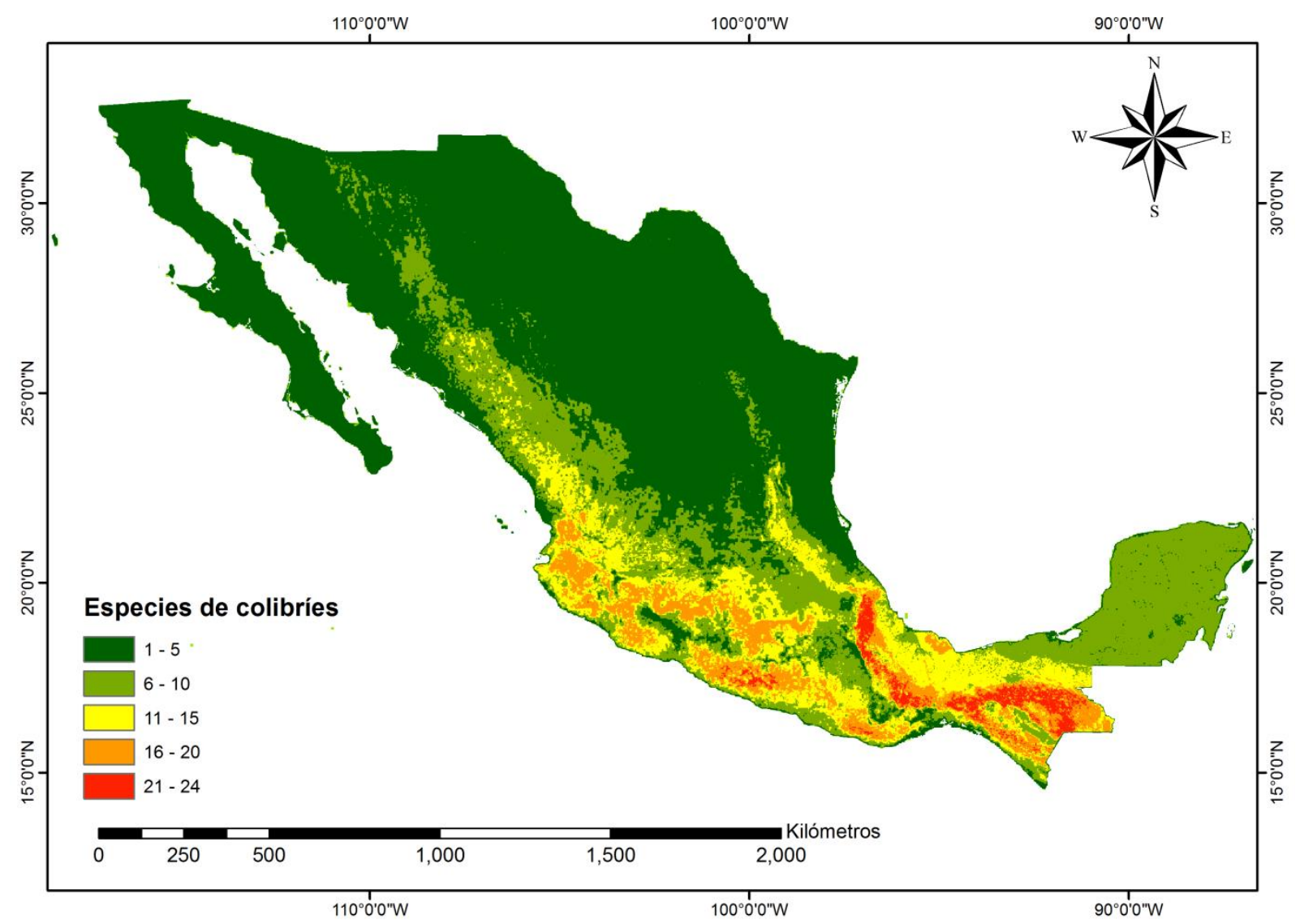

Figura 1. Riqueza de especies de colibríes en México. El mapa se realizó utilizando los datos de distribución potencial de Navarro y Peterson (2007) para las 58 especies de colibríes que ocurren en México.

Con base en McGuire y colaboradores (2014), en México se distribuyen especies de colibríes que pertenecen a siete clados (i.e., Topacios, Ermitaños, Mangos, Coquetas, Gemas de Montaña, Abejas y Esmeraldas). La mayor riqueza de clados en México se encuentra en el sureste del país (Figura 2). 


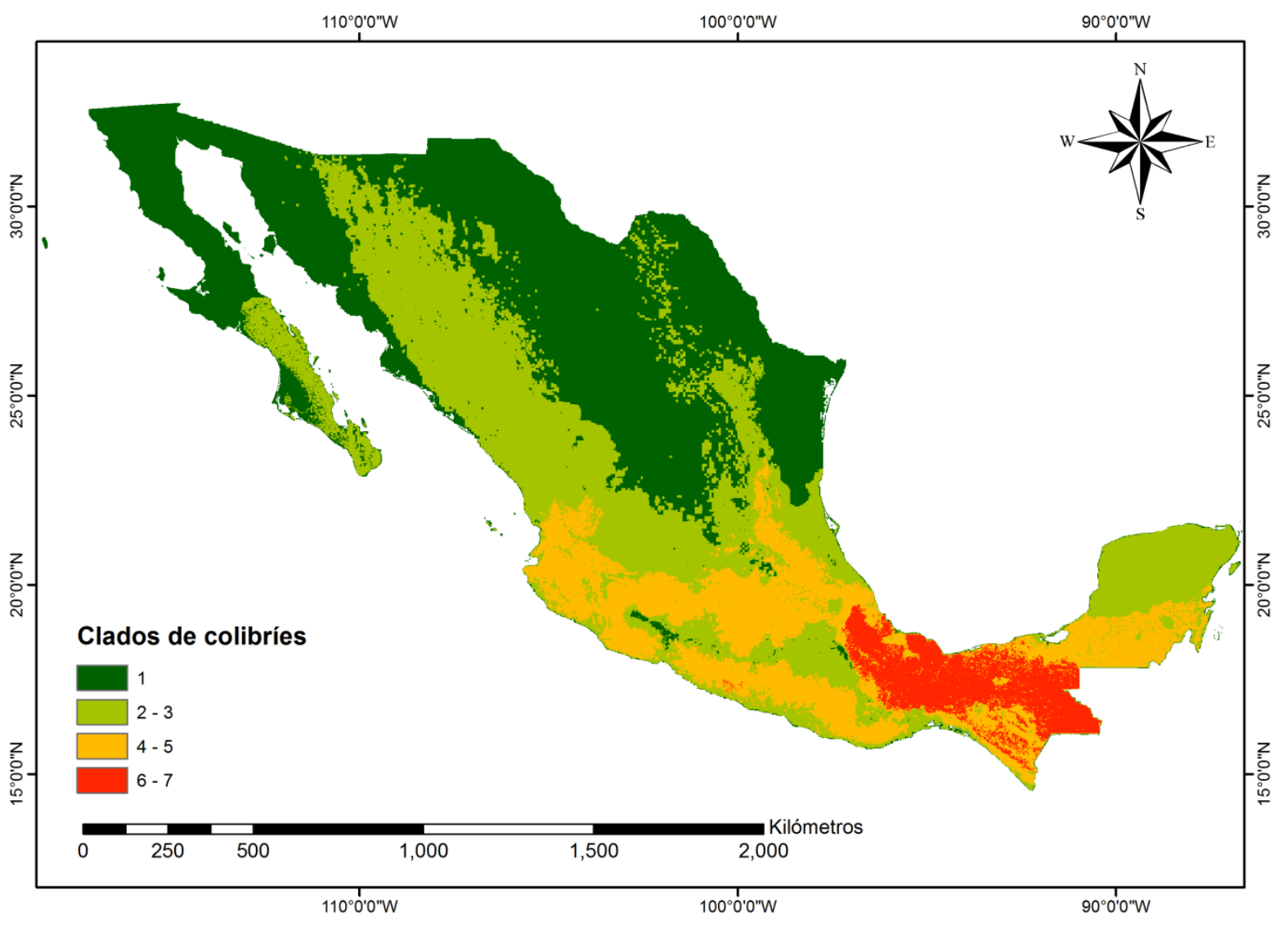

Figura 2. Riqueza de clados de colibríes en México. El mapa se realizó utilizando los datos de distribución potencial de Navarro y Peterson (2007) para las 58 especies de colibríes que ocurren en México.

Catorce especies de colibríes son endémicas de México, es decir, se distribuyen exclusivamente dentro del territorio mexicano (Berlanga et al. 2015). El área que concentra el mayor número de especies endémicas es la zona serrana de Guerrero (Figura 3). 


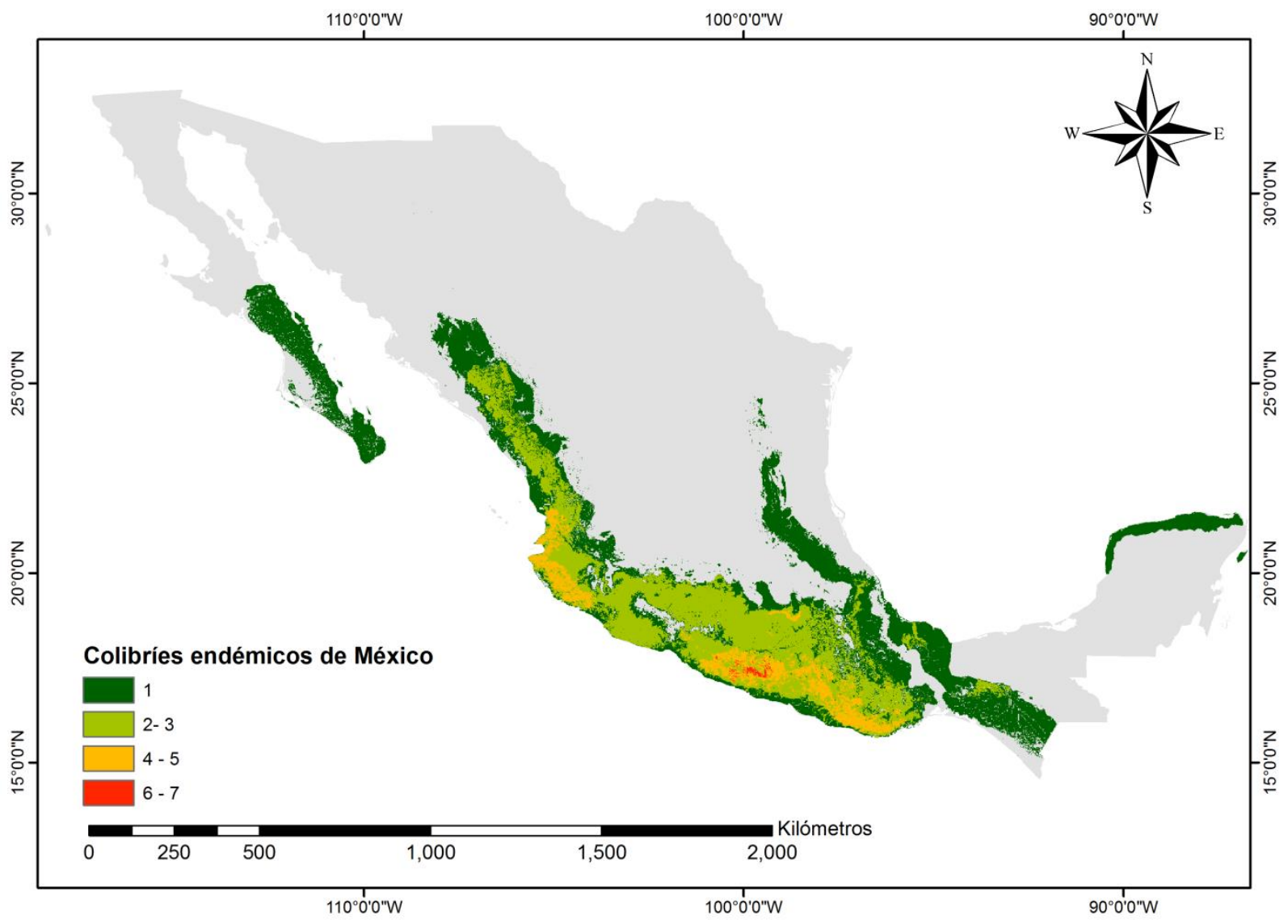

Figura 3. Especies de colibríes endémicas de México. El mapa se realizó utilizando los datos de distribución potencial de Navarro y Peterson (2007) para las 14 especies de colibríes endémicas de México.

El estudio de los factores involucrados en el resultado de las contiendas agonísticas por el acceso a recursos entre diferentes especies de colibríes podría contribuir a la comprensión de la dinámica de dominancia al interior de los ensambles y su respuesta a los cambios temporales en la composición de especies de colibríes y abundancia y disponibilidad de recursos. Históricamente la dominancia en colibríes se ha asociado casi de forma exclusiva a un mayor tamaño corporal. Sin embargo, la influencia de otros rasgos morfológicos ha sido poco estudiada, así como de factores ambientales e incluso las relaciones evolutivas entre las especies que compiten por el acceso al néctar. Por lo cual, en el presente trabajo evaluamos si el contexto ecológico y evolutivo tiene una influencia en el resultado de las contiendas agonísticas interespecíficas en colibríes. Para responder esta pregunta de 
investigación nos planteamos los siguientes objetivos: 1) realizar un análisis de los datos publicados en la literatura científica para determinar la frecuencia con la cual las especies de colibríes ganan contiendas agonísticas cuando se enfrentan a contendientes más grandes y pequeños, 2) determinar si la abundancia floral y recursos disponibles, además de como la especie, masa corporal y distancia genética entre contendientes influyen el rango que ocupan las especies dentro de la jerarquía de dominancia de un ensamble de colibríes durante un ciclo anual, y 3) evaluar si la diferencia en la masa corporal, la longitud del culmen expuesto y la distancia genética entre contendientes así como el número de flores en los territorios influyen la probabilidad de que los colibríes de mayor masa corporal ganen contiendas agonísticas contra especies más pequeñas.

En el capítulo I de este trabajo se exploró 1) la frecuencia con la que las especies grandes de colibríes ganan a las pequeñas cuando compiten por el acceso a los recursos, 2) la influencia del tamaño corporal, la identidad del clado y la distancia genética en el resultado de contiendas territoriales de 74 especies de colibríes de siete países de América. El segundo capítulo se enfocó en evaluar si la masa corporal y la distancia genética entre contendientes, así como los cambios fenológicos de los tres principales recursos florales (Salvia elegans, Bouvardia ternifolia y Penstemon roseus) influyen sobre la jerarquía de dominancia de los colibríes durante un ciclo anual en un bosque templado del centro de México (Parque Nacional La Malinche, Tlaxcala). En el capítulo III exploramos si la probabilidad de ganar una contienda agonística es influenciada por la diferencia en la masa corporal, la longitud del culmen expuesto y la distancia genética entre las especies de un ensamble de colibríes en un Bosque de Niebla (Santuario del Bosque de Niebla, Veracruz) durante la floración de Palicourea padifolia. 


\section{HIPÓTESIS Y OBJETIVOS}

Capítulo I. Efecto del tamaño corporal y distancia evolutiva en las interacciones agonísticas de colibríes (Trochilidae).

Hipótesis 1: Debido a que históricamente se ha reportado una correlación positiva entre un mayor tamaño corporal y una defensa territorial más efectiva, se espera que las especies de colibríes de mayor tamaño dominen a las especies más pequeñas en contiendas por el acceso a recursos.

Hipótesis 2: Con base en la hipótesis postulada por Martin y Ghalambor (2014), se espera que las especies de colibríes más pequeñas ganen más frecuentemente contiendas contra competidores de mayor tamaño corporal cuando la distancia genética entre ambos contendientes sea mayor. Asimismo, debido a que los clados de colibríes se diversificaron en diferentes regiones de América se espera que estos patrones cambien en Norte, Centro y Sudamérica.

Objetivos:

Determinar la frecuencia con la que especies de colibríes de mayor tamaño ganan encuentros agonísticos contra especies más pequeñas y vice versa.

Evaluar la influencia del tamaño corporal y el clado de pertenencia de los colibríes en la frecuencia de encuentros ganados y perdidos.

Estimar la distancia genética entre especies contendientes y evaluar su influencia en la frecuencia de contiendas ganadas por colibríes más grandes y pequeños que su competidor.

Determinar si existe un patrón y si este cambia o se mantiene en Norte, Centro y Sudamérica. 
Capítulo II. Factors affecting the dominance hierarchy dynamics in a hummingbird assemblage.

Hipótesis: La composición de especies de colibríes en el Parque Nacional La Malinche, Tlaxcala, experimenta cambios temporales a lo largo de un ciclo anual, debido a esto, se espera que el rango que las especies de colibríes ocupan dentro de la jerarquía de dominancia sea dinámico. Se espera que la variación en el rango de las especies de colibríes dentro de la jerarquía de dominancia esté asociada a la identidad de los recursos florales disponibles, la energía dentro de los territorios y la composición de especies de colibríes competidores. Dado que la masa corporal puede determinar la resolución de las contiendas, se espera que especies de colibríes más grandes releguen del acceso a los mejores recursos a las especies más pequeñas. Sin embargo, se espera que las especies pequeñas de colibríes ganen más frecuentemente contiendas cuando compitan contra especies de colibríes más grandes y distantemente emparentadas.

Objetivos:

Determinar el rango que ocupan las especies de colibríes dentro de la jerarquía de dominancia en el Parque Nacional La Malinche durante un ciclo anual.

Evaluar la influencia de las especies florales y la energía (Kj/flor) en los territorios, así como la identidad del colibrí dueño del territorio en la frecuencia de contiendas intraespecíficas e interespecíficas.

Estimar la distancia genética entre especies contendientes y evaluar su influencia en la frecuencia de contiendas ganadas por colibríes más grandes y pequeños que su competidor. 
Capítulo III. Diferencias en rasgos morfológicos y su influencia en el rango que ocupan las especies de colibríes dentro de una jerarquía de dominancia.

Hipótesis: Los rasgos morfológicos de las especies de colibríes pueden representar ventajas competitivas durante las contiendas por el acceso a recursos. La diferencia entre la masa corporal y la longitud del pico, así como la distancia genética entre contendientes podrían tener influencia sobre el resultado de las contiendas. Se espera que especies de colibríes con mayor masa corporal y longitud del pico ocupen rangos más altos dentro de la jerarquía de dominancia. Así mismo, se espera que las especies con mayor masa corporal y mayor longitud del pico ganen más frecuentemente las contiendas. El rango que las especies de colibríes ocupan dentro de la jerarquía de dominancia determinará sus probabilidades de ganar contiendas contra otras especies. Se espera que especies de colibríes con un rango alto dentro de la jerarquía de dominancia ganen las contiendas contra especies que ocupan rangos inferiores.

Objetivos:

Determinar la jerarquía de dominancia del ensamble de colibríes en el Santuario de Bosque de Niebla, Xalapa durante el periodo de floración Palicourea padifolia.

Evaluar la relación entre rasgos morfológicos (masa corporal y la longitud del pico) y el rango que las especies de colibríes ocupan dentro de la jerarquía de dominancia.

Evaluar la influencia de las diferencias en masa corporal, longitud del pico y distancia genética entre contendientes sobre la probabilidad de que los contendientes de mayor masa corporal ganen las contiendas.

Evaluar la influencia de las diferencias en masa corporal, longitud del pico y distancia genética entre contendientes sobre la probabilidad de que los contendientes con un mayor rango jerárquico ganen contiendas contra colibríes con menor rango. 


\section{Capítulo I}

Efecto del tamaño corporal y distancia evolutiva en las interacciones agonísticas de colibríes

(Trochilidae)

Publicado en Revista Mexicana de Biodiversidad (2018) 89 (1):149-162. 


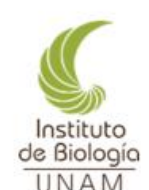

Revista Mexicana de Biodiversidad 89 (2018): 149-162

Ecología

\title{
Efecto del tamaño corporal y distancia evolutiva en las interacciones agonísticas de colibríes (Trochilidae)
}

\section{Effect of body size and evolutionary distance in the agonistic interactions of hummingbirds (Trochilidae)}

\author{
Ubaldo Márquez-Luna ${ }^{\mathrm{a}, *}$, Carlos Lara ${ }^{\mathrm{b}}$, Pablo Corcuera ${ }^{\mathrm{c}}$ y Pedro Luis Valverde ${ }^{\mathrm{c}}$
}

\author{
a Doctorado en Ciencias Biológicas y de la Salud, Universidad Autónoma Metropolitana-Iztapalapa, Av. San Rafael Atlixco Nủm. 186, Col. \\ Vicentina, Delegación Iztapalapa, 09340 Ciudad de México, México \\ ${ }^{b}$ Centro de Investigación en Ciencia Biológicas, Universidad Autónoma de Tlaxcala, Km 10.5 Autopista Tlaxcala-San Martín Texmelucan, 90120 \\ San Felipe Ixtacuixtla, Tlaxcala, México \\ ' Departamento de Biología, Universidad Autónoma Metropolitana, Av. San Rafael Atlixco Núm. 186, Col. Vicentina, Delegación Iztapalapa, \\ 09340 Ciudad de México, México
}

*Autor para correspondencia: marquezubaldo@gmail.com (U. Márquez-Luna)

Recibido: 08 agosto 2016; aceptado: 26 julio 2017

Resumen

Es frecuente que los colibríes de mayor tamaño dominen a especies más pequeñas en contiendas por recursos. Recientemente se ha postulado que en las aves, esta ventaja declina conforme aumenta la distancia evolutiva entre 2 especies interactuantes. En el presente estudio usamos a los colibríes como modelo para evaluar: 1) la frecuencia de encuentros agonisticos ganados por especies de mayor y menor tamaño corporal, 2) si el tamaño corporal respecto al del competidor y el clado de pertenencia de los colibries tienen un efecto sobre la frecuencia de encuentros ganados, y 3) si existen diferencias entre la distancia genética de los colibríes que ganaron enfrentamientos contra contendientes más pequeños. Nuestro estudio incluyó interacciones de 74 especies de colibríes distribuidas en 7 países de América. Encontramos que las especies de mayor tamaño dominaron el $74 \%$ de los encuentros. Los colibríes del clado Esmeralda dominaron el $45 \%$ de las contiendas analizadas y todos los clados de colibríes ganaron más contiendas cuando enfrentaron a un contendiente más pequeño. Finalmente, no se encontraron diferencias significativas entre la distancia genética de los colibries que ganaron contiendas contra competidores más pequeños. Los resultados resaltan la importancia de incorporar perspectivas evolutivas en el estudio de comunidades.

Palabras clave: Dominancia; Jerarquía; Competencia; Clados de colibríes; América

Abstract

Larger hummingbirds often dominate smaller species in contest for resources. It has recently been postulated that in birds, this advantage declines as the evolutionary distance between two interacting species increases. In the present study we used hummingbirds as a model to evaluate: I) the frequency of agonistic interactions won by larger and smaller hummingbirds, 2) if the body size relative to the competitor and the clade belonging to the hummingbirds have an effect on the frequency of won encounters, and 3) if there are differences between the genetic distance of hummingbirds that won encounters against smaller contenders. Our study included interactions of 74 species of hummingbirds distributed in seven countries of America. We found that the largest species dominated $74 \%$ of the

ISSN versión impresa: 1870-3453; versión electrónica: 2007-8706; Universidad Nacional Autónoma de México, Instituto de Biología. Open Access bajo la licencia CC BY-NC-ND (4.0) https://doi.org/10.22201/ib.20078706e.2018.1.1876 
encounters. Hummingbirds of the Emerald clade dominated $45 \%$ of the total contests analyzed, and all clades of hummingbirds won more encounters when they faced a smaller contender. Finally, no significant differences were found between the genetic distances of the hummingbirds that won contests against smaller competitors. The results highlight the importance of incorporating evolutionary perspectives in the study of communities.

Keywords: Dominance; Hierarchy; Competition; Clades of hummingbirds; America

\section{Introducción}

Los colibríes han sido utilizados frecuentemente como modelos para el estudio de las interacciones mutualistas que establecen con las plantas de las que se alimentan, y de las interacciones competitivas inter e intraespecíficas generadas por el acceso al néctar (Cotton, 2007). Aunque aún se desconocen aspectos básicos de la biología de muchas especies de colibríes y de los procesos que estructuran sus comunidades, recientemente se ha sugerido el posible papel de las relaciones evolutivas (e.g., coevolución entre plantas y polinizadores), alterando o limitando las interacciones biológicas, así como la distribución de las especies (Abrahamczyk y Kessler, 2014; Vizentin-Bugoni et al., 2014).

El desarrollo y mejoramiento de hipótesis filogenéticas robustas ha permitido que las relaciones evolutivas se incorporen al estudio de la ecología de comunidades (Johnson y Stinchcombe, 2007; Webb et al., 2002). En este sentido, McGuire et al. (2014) desarrollaron una hipótesis filogenética basada en datos de 284 de las 338 especies de colibríes. Dicha hipótesis ubica el origen de los colibríes en Eurasia ( $\approx 40$ millones de años) y que su llegada al continente americano ocurrió a través de Norteamérica, región de la cual se dispersaron hacía el sur. Posteriormente, en Sudamérica el grupo se diversificó tras los cambios geográficos que ocurrieron en la región (e.g., el surgimiento de la Cordillera de los Andes). Siete de los nueve clados de colibríes se diversificaron en Sudamérica (i.e., Ermitaños, Topacios, Mangos, Brillantes, Coquetas, Patagona y Esmeraldas), mientras que el ancestro común de las Abejas y las Gemas de Montaña recolonizó Norteamérica $(\approx 12$ millones de años) donde posteriormente ambos clados se diversificarían. Esta hipótesis sugiere que los 9 clados aparecieron diferencialmente en el tiempo (i.e., Ermitaños y Topacios $\approx 22$ millones de años, Mangos $\approx 18$ millones de años, Brillantes y Coquetas $\approx 15$ millones de años, Patagona gigas $\approx 14$ millones de años, Esmeraldas $\approx 12$ millones de años, Gemas de montaña $\approx 10$ millones de años y Abejas $\approx 5$ millones de años) (McGuire et al., 2014). Pese a estas diferencias, las comunidades de colibríes usualmente están integradas por especies que tienen cierto grado de parentesco o incluso pertenecen al mismo clado. Este patrón da como resultado que las especies que integran a cada comunidad tiendan a ser ecológicamente parecidas y que compartan características morfológicas tales como, tamaño corporal o el largo del pico. Esta similitud intensifica la competencia inter e intraespecífica por el acceso a los recursos florales (Freshwater et al., 2014).

Se ha encontrado que las especies de colibríes de mayor tamaño corporal tienden a dominar a las especies más pequeñas, limitándoles el acceso a los mejores recursos (Dearborn, 1998). Dicho patrón también ocurre a nivel intraespecífico (Carpenter et al., 1993). Sin embargo, existen reportes en donde las especies pequeñas de colibríes pueden ganar contiendas agresivas contra especies más grandes (Justino et al., 2012). En este sentido, Martin y Ghalambor (2014) postulan que una especie de ave de menor talla tiene más probabilidades de ganar un encuentro agresivo contra otra especie de mayor tamaño cuando la distancia evolutiva aumenta entre ellas. Esta hipótesis fue puesta a prueba utilizando como modelo las interacciones agonísticas originadas por el acceso a recursos en 3 grupos de aves: buitres, colibríes y pájaros hormigueros. Los autores sugieren que a lo largo del tiempo evolutivo, las especies pequeñas pueden acumular características que les permitan superar las desventajas competitivas asociadas a un menor tamaño corporal, por ejemplo, un incremento en la aceleración y maniobrabilidad que les permite ser más eficientes energéticamente al defender sus territorios de forrajeo en comparación a especies más grandes, mientras que las especies de mayor tamaño pudieron desarrollar otras características que comprometen su habilidad de competir agresivamente, por ejemplo la especialización hacía recursos particulares (e.g., los colibríes ermitaños del género Phaethornis y las plantas que visitan del género Heliconia). Es decir, las ventajas de un mayor tamaño corporal declinan conforme aumenta la distancia evolutiva entre las 2 especies participantes en un encuentro agonístico. Sin embargo, en el caso de los colibríes la diferencia entre el peso corporal del colibrí ganador y perdedor puede ser muy pequeña para determinar claramente a la especie con mayor o menor masa corporal de la interacción. Esto es particularmente importante en aquellas especies que realizan movimientos migratorios latitudinales, ya que su masa corporal puede cambiar significativamente en un solo día (Carpenter et al., 1983). Lo anterior sugiere que otros factores como la historia filogenética y de diversificación del grupo, o 
las características conductuales asociadas a la forma de explotar los recursos de las especies contendientes, pueden estar involucrados en determinar el resultado final de una interacción agonística.

El presente estudio fue diseñado para evaluar el efecto del tamaño corporal y la distancia genética entre colibríes en el resultado de las contiendas agonísticas generadas por el acceso a los recursos. Para lograr esto evaluamos: 1) la frecuencia con la que especies de colibríes de menor tamaño ganan encuentros agonísticos contra especies más grandes, 2) si la frecuencia de encuentros ganados y perdidos es influenciada por el tamaño corporal y el clado de pertenencia de los colibríes contendientes y 3 ) si la distancia genética entre contendientes es significativamente diferente entre las contiendas ganadas por colibríes más grandes y pequeños que su competidor y si debido a la historia de diversificación de los clados de colibríes en América, este patrón cambia en Norte, Centro y Sudamérica. Para explorar esta hipótesis, se generó una base de datos derivada de una compilación bibliográfica exhaustiva.

\section{Materiales y métodos}

Los datos utilizados en este estudio se obtuvieron a partir de una búsqueda de trabajos publicados en revistas científicas que reportaron la jerarquía de dominancia en una comunidad de colibríes o explícitamente indicaron las especies de colibríes que estuvieron involucradas en contiendas agonísticas por el acceso a los recursos. Los artículos se obtuvieron de forma electrónica a través de una búsqueda intensiva en bases de datos públicas como Scientific Electronic Library Online (SciELO), Searchable Ornithological Research Archive (SORA) y Google Scholar. Las búsquedas se realizaron utilizando las siguientes palabras claves y sus combinaciones en español e inglés: territorialidad colibríes, jerarquía colibríes, dominancia colibríes, comunidad colibríes y ensamble colibríes. Los artículos utilizados en este trabajo debían cumplir con los siguientes criterios: 1) mencionar de forma explícita la jerarquía de dominancia de los colibríes de una localidad, 2) la especie del colibrí ganador del encuentro agonístico y la especie desplazada o expulsada (solo se incluyeron interacciones agonísticas interespecíficas), y 3 ) que las contiendas agonísticas ocurrieran por el acceso a un recurso alimenticio (incluyendo aquellos estudios donde se utilizaron bebederos) por el cual competían al momento de la observación. Se incluyeron artículos que cuantificaron las interacciones entre las especies (i.e., número de encuentros agonísticos) y aquellos que mencionaron las interacciones agonísticas de forma anecdótica o cualitativa. Treinta y dos artículos entre 1969 y 2016 cumplieron con dichos criterios. Cada interacción entre 2 especies diferentes de colibríes en una localidad específica se consideró como un caso de estudio. Se obtuvieron 160 pares de interacciones o casos de estudio (tabla 1) que incluyeron a 74 especies de colibríes de 7 países de América, los cuales fueron agrupados en Norteamérica (EUA y México), Centroamérica (Costa Rica y Panamá) y Sudamérica (Ecuador, Brasil y Colombia).

En cada caso de estudio, se determinó si la especie ganadora de cada interacción agonística fue de mayor o menor masa corporal (g) que su competidor. Para lo anterior, se consideró que el peso corporal promedio y los errores estándar que reportaron los autores de cada artículo no se empalmaran. Esto permitió asegurar que la asimetría entre ambas especies fuera la suficiente para poder considerar a una especie más grande que otra (tabla 1). En caso de que el artículo no mencionara la masa corporal de las especies interactuantes, se utilizaron los rangos de peso propuestos por Schuchmann (1999). En estos casos se consideró una diferencia de al menos un gramo entre el peso máximo registrado para ambas especies como diferencia suficiente.

Para los análisis, a cada especie se le asignó el clado de pertenencia de acuerdo a McGuire et al. (2014). En la búsqueda se encontraron interacciones que involucraron a especies pertenecientes a los 9 clados de colibríes: Ermitaños, Topacios, Mangos, Brillantes, Coquetas, Esmeraldas, Gemas de Montaña, Abejas y al compuesto por Patagona gigas; este último conformado únicamente por la especie de colibrí de mayor tamaño corporal (i.e., colibrí gigante; 20-22 cm y 18.5-20.2 g; Schuchmann, 1999). La distancia genética entre cada par de colibríes contendientes se calculó utilizando secuencias genéticas mitocondriales del gen NADH deshidrogenasa subunidad 2, (sensu Martin y Ghalambor, 2014) disponibles en Genbank (tabla 1). Las secuencias fueron alineadas mediante el algoritmo de alineamiento ClustalW (Thompson et al., 1994) y posteriormente se calculó la distancia genética entre cada par de especies mediante el modelo de Tamura-Nei (Tamura y Nei, 1993), el cual corrige las sustituciones múltiples en un sitio considerando las diferencias en la tasa de sustitución nucleotídica entre secuencias de DNA. Estas fueron obtenidas en MEGA versión 7.0 (Kumar et al., 2016).

Evaluamos las diferencias entre la frecuencia de encuentros agonísticos ganados y perdidos por colibríes a través de 2 modelos lineales generalizados (GLM) con distribución Poisson y función de enlace log (Nelder y Wedderburn, 1972). Para el primer modelo utilizamos como variable de respuesta la frecuencia de encuentros ganados por los colibríes y como variables predictoras se incluyeron la identidad del clado del colibrí ganador con 
Tabla 1

Resumen de la información contenida en este estudio. Se indica el pais (i.e., Estados Unidos $=\mathrm{U}, \mathrm{México}=\mathrm{M}$, Panamá $=\mathrm{P}$, Costa Rica $=\mathrm{R}$, Colombia $=\mathrm{C}, \mathrm{Ecuador}=\mathrm{E}$ y Brasil = B), la especie del colibri ganador y perdedor de cada contienda, la distancia genética entre contendientes, la secuencia del gen mitocondrial NADH deshidrogenasa subunidad 2 de Genbank y el peso promedio en caso de haberlo indicado el autor, el rango de peso de acuerdo a Schuchmann (1999) o Contreras-Martínez (2014) para aquellos pesos marcados con *. El número está asociado a las siguientes referencias: 1) Antunes, 2003;2) Araujo-Silva y Bessa, 2010;3) Arizmendi y Ornelas, 1990;4) Ayala, 1986; 5) Boyden, 1978; 6) Chaves, 1997; 7) Colwell, 1973;8) Copenhaver y Ewald, 1980;9) Cotton, 1998; 10) Dearbon, 1998; 11) Ewald y Bransfield, 1987; 12) Fraga, 1989; 13) Justino et al., 2012; 14) Kuban et al., 1983;15) Kuban y Neill, 1980;16) Lara, 2006; 17) Lara et al., 2009; 18) Lara et al., 2011; 19) Lyon, 1976; 20) Ornelas et al., 2002; 21) Persegona et al., 2009; 22) Pimm et al., 1985; 23) Powers y Mckee, 1994; 24) Primack y Howe, 1975; 25) Ramirez-Burbano et al., 2007; 26 Rodriguez-Flores y Arizmendi, 2016; 27) Salamanca-Reyes, 2011;28) Taylor, 2005;29) Toloza-Moreno et al., 2014;30) Wolf, 1969;31) Wolf et al., 1976;32) Woods y Ramsay, 2001 .

\begin{tabular}{|c|c|c|c|c|c|c|c|c|}
\hline Especie ganadora & Peso (gramos) & Secuencia & Especie perdedora & Peso (gramos) & Secuencia & $\begin{array}{l}\text { Distancia } \\
\text { genética }\end{array}$ & Pais & Referencia \\
\hline Aglaectis cupripennis & $7.6-8.1$ & KM389474.1 & Lesbia victoriae & $5.1-5.3$ & AY830499.1 & 0.157 & E & 32 \\
\hline Aglaectis cupripennis & $7.6-8.1$ & KM389474.1 & Oreotrochilus estella & 8.8 & AY830507.1 & 0.177 & E & 32 \\
\hline Aglaectis cupripennis & $7.6-8.1$ & KM389474.1 & Eriocnemis mosquera & $5.2-5.8$ & EU042550.1 & 0.172 & E & 32 \\
\hline Aglaectis cupripennis & $7.6-8.1$ & KM389474.1 & Patagona gigas & $18.5-20.2$ & AY830510.1 & 0.203 & E & 32 \\
\hline Aglaectis cupripennis & $7.6-8.1$ & KM389474.1 & Pterophanes cyanopterus & $9.6-11.2$ & AY830520.2 & 0.18 & E & 32 \\
\hline Aglaectis cupripennis & $7.6-8.1$ & KM389474.1 & Chalcostigma herrani & 6.4 & EU042536.1 & 0.163 & E & 32 \\
\hline Amazilia beryllina & $4.6+0.513 n=30$ & KJ602161.1 & Amazilia violiceps & $6.2 \mathrm{n}=1$ & KJ602176.1 & 0.099 & $\mathrm{M}$ & 26 \\
\hline Amazilia beryllina & $4.6+0.513 n=30$ & KJ602161.1 & Atthis heloisa & $2.293+0.24 n=14$ & KJ602190.1 & 0.177 & $\mathrm{M}$ & 26 \\
\hline Amazilia beryllina & $4.6+0.513 n=30$ & KJ602161.1 & Eugenes fulgens & $7.233+0.764 n=3$ & AY830481.1 & 0.194 & M & 26 \\
\hline Amazilia beryllina & $4.6+0.513 n=30$ & KJ602161.1 & Hylocharis leucotis & $3.595+0.303 \mathrm{n}=40$ & KJ602252.1 & 0.165 & $\mathrm{M}$ & 26 \\
\hline Amazilia beryllina & $4.6+0.513 n=30$ & KJ602161.1 & Lampornis amethystinus & $6.170+0.675 n=27$ & KJ602255.1 & 0.196 & M & 26 \\
\hline Amazilia beryllina & $4.6+0.513 n=30$ & KJ602161.1 & Selasphorus calliope & $2.482+0.197 \mathrm{n}=136^{*}$ & EU042593.1 & 0.188 & $\mathrm{M}$ & 26 \\
\hline Amazilia beryllina & $4.6+0.513 n=30$ & KJ602161.1 & Selasphorus platycercus & $3.029+0.355 n=7$ & AY830522.1 & 0.179 & $\mathrm{M}$ & 26 \\
\hline Amazilia beryllina & $4.6+0.513 n=30$ & KJ602161.1 & Selasphorus rufus & $3.128+0.171 \mathrm{n}=29$ & EU042590.1 & 0.183 & $\mathrm{M}$ & 26 \\
\hline Amazilia beryllina & $4.6+0.513 n=30$ & KJ602161.1 & Tilmatura dupontii & $2.250+0.086 \mathrm{n}=5^{*}$ & KJ602351.1 & 0.192 & M & 26 \\
\hline Amazilia fimbriata & $4.89+0.1 \mathrm{n}=76$ & EU042520.1 & Eupetomena macroura & $8-9.7$ & GU167228.1 & 0.152 & B & 13 \\
\hline Amazilia fimbriata & $4.89+0.1 \mathrm{n}=76$ & EU042520.1 & Colibri serrirostris & $5.6-6.8$ & GU167222.1 & 0.231 & B & 13 \\
\hline Amazilia fimbriata & $4.89+0.1 \mathrm{n}=76$ & EU042520.1 & Phaethornis pretrei & $4.5-7$ & GU167247.1 & 0.241 & B & 13 \\
\hline Amazilia fimbriata & $4.89+0.1 \mathrm{n}=76$ & EU042520.1 & Chlorostilbon aureoventris & $3-3.8$ & KJ602211.1 & 0.201 & B & 13 \\
\hline Amazilia fimbriata & $4.89+0.1 \mathrm{n}=76$ & EU042520.1 & Calliphlox amethystina & $2.3-2.5$ & GU167211.1 & 0.184 & B & 13 \\
\hline Amazilia fimbriata & $4.89+0.1 \mathrm{n}=76$ & EU042520.1 & Chrysuronia oenone & $4.30+0.1 \mathrm{n}=12$ & AY830472.1 & 0.104 & $\mathrm{C}$ & 9 \\
\hline Amazilia fimbriata & $4.89+0.1 \mathrm{n}=76$ & EU042520.1 & Chlorostilbon mellisugus & $2.60 \mathrm{n}=1$ & AY830471.1 & 0.191 & $\mathrm{C}$ & 9 \\
\hline Amazilia lactea & $4.3+0.35$ & GU167203.1 & Aphantochroa cirrhochloris & $7.1-9$ & EU042528.1 & 0.16 & B & 1 \\
\hline Amazilia lactea & $4.3+0.35$ & GU167203.1 & Chlorostilbon aureoventris & $3.2+0.29$ & KJ602211.1 & 0.2 & B & 1 \\
\hline Amazilia lactea & $4.3+0.35$ & GU167203.1 & Calliphlox amethystina & $2.3-2.5$ & GU167211.1 & 0.186 & B & 1 \\
\hline Amazilia lactea & $4.3+0.35$ & GU167203.1 & Leucochloris albicollis & $6.6+0.20$ & KJ602266.1 & 0.11 & B & 1 \\
\hline Amazilia lactea & $4.3+0.35$ & GU167203.1 & Hylocharis cyanus & $2.8-3.5$ & EU04256.1 & 0.12 & B & 1 \\
\hline Amazilia rutila & $4.3+0.1$ & EU042522.1 & Heliomaster constantii & $7.5+09$ & KJ602250.1 & 0.168 & $\mathrm{M}$ & 3 \\
\hline Amazilia rutila & $4.3+0.1$ & EU042522.1 & Cynanthus latirostris & $2.9+0.3$ & KJ602233.1 & 0.179 & M & 3 \\
\hline Amazilia rutila & $4.3+0.1$ & EU042522.1 & Chlorostilbon auriceps & $2.1+0.3$ & $\mathrm{x}$ & $\mathrm{X}$ & M & 3 \\
\hline
\end{tabular}


Tabla 1

Continuación.

\begin{tabular}{|c|c|c|c|c|c|c|c|c|}
\hline Especie ganadora & Peso (gramos) & Secuencia & Especie perdedora & Peso (gramos) & Secuencia & $\begin{array}{l}\text { Distancia } \\
\text { genética }\end{array}$ & Pais & Referencia \\
\hline Amazilia tzacatl & $4.4-5.5$ & EU983390.1 & Microchera albocoronata & 2.5 & EU042571.1 & 0.16 & $\mathrm{R}$ & 10 \\
\hline Amazilia tzacatl & $4.4-5.5$ & EU983390.1 & Klais guitmeti & 2.9 & AY830495.1 & 0.175 & $\mathrm{R}$ & 24 \\
\hline Amazilia violiceps & 5 & KJ602176.1 & Calothorax pulcher & $2.6-3.1$ & KU375421.1 & 0.115 & $\mathrm{M}$ & 20 \\
\hline Anthracothorax nigricollis & $5.5-7.5$ & EU042527.1 & Thalurania furcata & $3.6-6$ & KJ602346.1 & 0.238 & B & 2 \\
\hline Anthracothorax nigricollis & $5.5-7.5$ & EU042527.1 & Leucochloris albicollis & $5.1-8$ & KJ602266.1 & 0.248 & B & 21 \\
\hline Anthracothorax nigricollis & $5.5-7.5$ & EU042527.1 & Amazilia versicolor & $3.1-4$ & EU042525.1 & 0.239 & B & 21 \\
\hline Aphantochroa cirrhochloris & 7.1-9 & EU042528.1 & Amazilia lactea & $4.3+0.35$ & GU167203.1 & 0.16 & B & 1 \\
\hline Aphantochroa cirrhochloris & $7.1-9$ & EU042528.1 & Amazilia versicolor & $3.9+0.29$ & EU042525.1 & 0.141 & B & 1 \\
\hline Aphantochroa cirrhochloris & $7.1-9$ & EU042528.1 & Calliphlox amethystina & $2.3-2.5$ & GU167211.1 & 0.176 & B & 1 \\
\hline Aphantochroa cirrhochloris & $7.1-9$ & EU042528.1 & Colibri serrirostris & $6.7+0.34$ & GU167222.1 & 0.243 & B & 1 \\
\hline Aphantochroa cirrhochloris & $7.1-9$ & EU042528.1 & Leucochloris albicollis & $6.6+0.20$ & KJ602266.1 & 0.148 & B & 1 \\
\hline Archilochus alexandri & $2.7-4.3$ & EU042529.1 & Calothorax lucifer & $2.9-3.5$ & KP136391.1 & 0.078 & $\mathrm{U}$ & 15 \\
\hline Atthis heloisa & $2.293+0.24 n=14$ & KJ602190.1 & Hylocharis leucotis & $3.595+0.303 \mathrm{n}=40$ & KJ602252.1 & 0.164 & $\mathrm{M}$ & 26 \\
\hline Atthis heloisa & $2.293+0.24 n=14$ & KJ602190.1 & Selaphorus rufus & $3.128+0.171 \mathrm{n}=29$ & EU042590.1 & 0.041 & M & 26 \\
\hline Boissonneaua flavescens & $8-8.6$ & EU042530.1 & Eriocnemis mirabilis & $3.8+0.2$ & $\mathrm{X}$ & $\mathrm{X}$ & $\mathrm{C}$ & 25 \\
\hline Calypte anna & $3.3-5.8$ & EU042532.1 & Selasphorus sasin & $2.5-3.8$ & KJ602332.1 & 0.068 & $\mathrm{U}$ & 8 \\
\hline Calypte anna & $3.3-5.8$ & EU042532.1 & Archilochus alexandri & $2.7-4.3$ & EU042529.1 & 0.105 & $\mathrm{U}$ & 11 \\
\hline Campylopterus largipennis & $8.48+0.2 n=12$ & AY830467.1 & Amazilia fimbrata & $4.89+0.1 \mathrm{n}=76$ & EU042520.1 & 0.173 & $\mathrm{C}$ & 9 \\
\hline Campylopterus largipennis & $8.48+0.2 \mathrm{n}=12$ & AY830467.1 & Chrysuronia oenone & $4.30+0.1 \mathrm{n}=12$ & AY830472.1 & 0.173 & $\mathrm{C}$ & 9 \\
\hline Campylopterus largipennis & $8.48+0.2 n=12$ & AY830467.1 & Chlorostilbon mellisugus & $2.60 n=1$ & AY830471.1 & 0.172 & $\mathrm{C}$ & 9 \\
\hline Chalcostigma herrani & 6.4 & EU042536.1 & Lesbia victorae & $5.1-5.3$ & AY830499.1 & 0.103 & E & 32 \\
\hline Chalybura buffonii & $6-7.3$ & EU042537.1 & Chlorostilbon canivetii & $2.1-2.8$ & KJ602212.1 & 0.166 & $P$ & 5 \\
\hline Chalybura buffonii & $6-7.3$ & EU042537.1 & Phaethornis superciliosus & $4.1-6$ & JQ445678.1 & 0.204 & $P$ & 12 \\
\hline Chrysuronia oenone & $4.30+0.1 \mathrm{n}=12$ & AY830472.1 & Chlorostilbon mellisugus & $2.60 \mathrm{n}=1$ & AY830471.1 & 0.178 & $\mathrm{C}$ & 9 \\
\hline Colibri coruscans & $6.9+1.36 n=27$ & AY830476.1 & Eriocnemis vestita & $4.7+.58 \mathrm{n}=137$ & EU042551.1 & 0.243 & $\mathrm{C}$ & 29 \\
\hline Colibri coruscans & $6.9+1.36 \mathrm{n}=27$ & AY830476.1 & Metallura tyrianthina & $3.4+0.52 \mathrm{n}=85$ & AY830502.1 & 0.223 & $\mathrm{C}$ & 29 \\
\hline Colibri serrirostris & $5.6-6.8$ & GU167222.1 & Eupetomena macroura & $8-9.7$ & GU167228.1 & 0.232 & B & 13 \\
\hline Colibri serrirostris & $5.6-6.8$ & GU167222.1 & Amazilia fimbriata & $4.89+0.1 \mathrm{n}=76$ & EU042520.1 & 0.23 & B & 13 \\
\hline Colibri serrirostris & $5.6-6.8$ & GU167222.1 & Leucochloris albicollis & 5 & KJ602266.1 & 0.24 & B & 21 \\
\hline Colibri serrirostris & $5.6-6.8$ & GU167222.1 & Florisuga fusca & 9 & GU167229.1 & 0.21 & B & 21 \\
\hline Colibri thalassinus & $5.11+0.07$ & EU042544.1 & Eugenes fulgens & $7-7.5$ & AY830481.1 & 0.223 & $\mathrm{M}$ & 16 \\
\hline Colibri thalassinus & $5.11+0.07$ & EU042544.1 & Archilochus colubris & $3.03+0.02$ & KJ602257.1 & 0.203 & M & 17 \\
\hline Colibri thalassinus & $5.11+0.07$ & EU042544.1 & Selasphorus rufus & $3.17+0.03$ & EU042529.1 & 0.219 & $\mathrm{M}$ & 17 \\
\hline Colibri thalassinus & $5.11+0.07$ & EU042544.1 & Selasphorus sasin & $3.09+0.04$ & KJ602257.1 & 0.22 & $\mathrm{M}$ & 17 \\
\hline Colibri thalassinus & $5.11+0.07$ & EU042544.1 & Selasphorus platycercus & $3.16+0.02$ & KJ602255.1 & 0.225 & $\mathrm{M}$ & 17 \\
\hline Colibri thalassinus & $5.7+0.10 \mathrm{n}=15$ & EU042544.1 & Selasphorus flammula & $2.6+0.07 n=8$ & EU042589.1 & 0.232 & $\mathrm{R}$ & 31 \\
\hline Colibri thalassinus & $5.7+0.10 \mathrm{n}=15$ & EU042544.1 & Eugenes fulgens & $9.8+0.20 \mathrm{n}=11$ & AY830481.1 & 0.223 & $\mathrm{R}$ & 31 \\
\hline Colibri thalassinus & $4.850+0.751 \mathrm{n}=4$ & EU042544.1 & Atthis heloisa & $2.293+0.24 n=14$ & KJ602190.1 & 0.232 & M & 26 \\
\hline
\end{tabular}


Tabla 1

\begin{tabular}{|c|c|c|c|c|c|c|c|c|}
\hline Especie ganadora & Peso (gramos) & Secuencia & Especie perdedora & Peso (gramos) & Secuencia & $\begin{array}{l}\text { Distancia } \\
\text { genética }\end{array}$ & Pais & Referencia \\
\hline Colibri thalassinus & $4.850+0.751 \mathrm{n}=4$ & EU042544.1 & Eugenes fulgens & $7.233+0.764 n=3$ & AY830481.1 & 0.226 & $\mathrm{M}$ & 26 \\
\hline Colibri thalassinus & $4.850+0.751 \mathrm{n}=4$ & EU042544.1 & Hylocharis leucotis & $3.595+0.303 n=40$ & KJ602252.1 & 0.209 & $\mathrm{M}$ & 26 \\
\hline Colibri thalassinus & $4.850+0.751 \mathrm{n}=4$ & EU042544.1 & Lampornis amethystinus & $6.170+0.675 \mathrm{n}=27$ & KJ602255.1 & 0.225 & $\mathrm{M}$ & 26 \\
\hline Colibri thalassinus & $4.850+0.751 \mathrm{n}=4$ & EU042544.1 & Selasphorus calliope & $2.482+0.197 \mathrm{n}=136^{*}$ & EU042593.1 & 0.221 & $\mathrm{M}$ & 26 \\
\hline Colibri thalassinus & $4.850+0.751 \mathrm{n}=4$ & EU042544.1 & Selasphorus platycercus & $3.029+0.355 \mathrm{n}=7$ & AY830522.1 & 0.228 & $\mathrm{M}$ & 26 \\
\hline Colibri thalassinus & $4.850+0.751 \mathrm{n}=4$ & EU042544.1 & Selasphorus rufus & $3.128+0.171 \mathrm{n}=29$ & EU042590.1 & 0.221 & $\mathrm{M}$ & 26 \\
\hline Colibri thalassinus & 5.7 & EU042544.1 & Eugenes fulgens & $7-7.5$ & AY830481.1 & 0.224 & $\mathrm{R}$ & 7 \\
\hline Cynanthus latirostris & $2.9+0.3$ & KJ602233.1 & Chlorostilbon auriceps & $2.1+0.3$ & $\mathrm{X}$ & $\mathrm{X}$ & $\mathrm{M}$ & 3 \\
\hline Eriocnemis mirabilis & $3.8+0.2$ & $\mathrm{X}$ & Coeligena torquata & 7.3 & FJ960712.1 & $\mathrm{x}$ & $\mathrm{C}$ & 25 \\
\hline Eriocnemis vestita & $4.7+.58 \mathrm{n}=136$ & EU042551.1 & Metallura tyrianthina & $3.4+0.52 \mathrm{n}=85$ & AY830502.1 & 0.168 & $\mathrm{C}$ & 29 \\
\hline Eriocnemis vestita & $4.7+.58 n=137$ & EU042551.1 & Chaetocercus mulsant & 4 & AY830456.1 & 0.18 & $\mathrm{C}$ & 29 \\
\hline Eugenes fulgens & $7.03+0.04$ & AY830481.1 & Colibri thalassinus & $5.11+0.07$ & EU042544.1 & 0.226 & $\mathrm{M}$ & 18 \\
\hline Eugenes fulgens & $9.8+0.20 n=11$ & AY830481.1 & Panterpe insignis & $6.2+0.08 n=33$ & AY830509.1 & 0.149 & $\mathrm{R}$ & 31 \\
\hline Eugenes fulgens & $9.8+0.20 \mathrm{n}=11$ & AY830481.1 & Colibri thalassinus & $5.7+0.10 \mathrm{n}=15$ & EU042544.1 & 0.226 & $\mathrm{R}$ & 31 \\
\hline Eugenes fulgens & $9.8+0.20 n=11$ & AY830481.1 & Selasphorus flammula & $2.6+0.07 n=8$ & EU042589.1 & 0.166 & $\mathrm{R}$ & 31 \\
\hline Eugenes fulgens & $7.7+0.4 \mathrm{n}=24$ & AY830481.1 & Hylocharis leucotis & $3.6+0.3 \mathrm{n}=11$ & KJ602252.1 & 0.176 & M & 19 \\
\hline Eugenes fulgens & $7.233+0.764 n=3$ & AY830481.1 & Amazylia beryllina & $4.6+0.513 n=30$ & KJ602161.1 & 0.194 & $\mathrm{M}$ & 26 \\
\hline Eugenes fulgens & $7.233+0.764 n=3$ & AY830481.1 & Hylocharis leucotis & $3.595+0.303 n=40$ & KJ602252.1 & 0.176 & $\mathrm{M}$ & 26 \\
\hline Eugenes fulgens & $7.233+0.764 n=3$ & AY830481.1 & Selasphorus platycercus & $3.029+0.355 n=7$ & AY830522.1 & 0.164 & M & 26 \\
\hline Eupetomena macroura & $8-9.7$ & GU167228.1 & Colibri serrirostris & $5.6-6.8$ & GU167222.1 & 0.233 & B & 13 \\
\hline Eupetomena macroura & $8-9.7$ & GU167228.1 & Phaethornis pretrei & $4.5-7$ & GU167247.1 & 0.205 & B & 13 \\
\hline Eupetomena macroura & $8-9.7$ & GU167228.1 & Amazilia fimbriata & $4.89+0.1 \mathrm{n}=76$ & EU042520.1 & 0.152 & B & 13 \\
\hline Eupetomena macroura & $8-9.7$ & GU167228.1 & Calliphlox amethystina & $2.3-2.5$ & GU167211.1 & 0.158 & B & 13 \\
\hline Eupetomena macroura & $9.2+0.33$ & GU167228.1 & Amazilia lactea & $4.3+0.35$ & GU167203.1 & 0.153 & B & 1 \\
\hline Eupetomena macroura & $9.2+0.33$ & GU167228.1 & Chlorostilbon aureoventris & $3.2+0.29$ & KJ602211.1 & 0.17 & B & 1 \\
\hline Florisuga fusca & $8.7+0.29$ & GU167229.1 & Eupetomena macroura & $9.2+0.33$ & GU167228.1 & 0.228 & B & 1 \\
\hline Florisuga fusca & $8.7+0.29$ & GU167229.1 & Amazilia lactea & $4.3+0.35$ & GU167203.1 & 0.231 & B & 1 \\
\hline Florisuga fusca & $8.7+0.29$ & GU167229.1 & Calliphlox amethystina & $2.3-2.5$ & GU167211.1 & 0.21 & B & 1 \\
\hline Florisuga fusca & $8.7+0.29$ & GU167229.1 & Colibri serrirostris & $6.7+0.34$ & GU167222.1 & 0.212 & B & 1 \\
\hline Florisuga fusca & $8.7+0.29$ & GU167229.1 & Heliomaster squamosus & $7.3+1.32$ & KJ602251.1 & 0.225 & B & 1 \\
\hline Florisuga fusca & 9 & GU167229.1 & Leucochloris albicollis & $5.1-8$ & KJ602266.1 & 0.235 & B & 21 \\
\hline Florisuga fusca & 9 & GU167229.1 & Anthracothorax nigricollis & $5.5-7.5$ & EU042527.1 & 0.225 & B & 21 \\
\hline Florisuga fusca & 9 & GU167229.1 & Amazilia versicolor & $3.1-4$ & EU042525.1 & 0.222 & B & 21 \\
\hline Glaucis hirsuta & $6.33+0.1 \mathrm{n}=186$ & AY830486.1 & Chrysuronia oenone & $4.30+0.1 \mathrm{n}=12$ & AY830472.1 & 0.213 & $\mathrm{C}$ & 9 \\
\hline Helidoxa jacula & $7-9.5$ & AY830491.1 & Phaethornis guy & $4-8.1$ & AY830511.1 & 0.229 & $\mathrm{R}$ & 28 \\
\hline Heliomaster constantii & $7.5+09$ & KJ602250.1 & Amazilia rutila & $4.3+0.1$ & EU042522.1 & 0.168 & M & 3 \\
\hline Heliomaster constantii & $7.5+09$ & KJ602250.1 & Cynanthus latirostris & $2.9+0.3$ & KJ602233.1 & 0.157 & $\mathrm{M}$ & 3 \\
\hline Hylocharis leucotis & $3.6+0.3 n=11$ & KJ602252.1 & Atthis heloisa & $2-2.7$ & KJ602190.1 & 0.164 & $\mathrm{M}$ & 18 \\
\hline
\end{tabular}


Tabla 1

Continuación.

\begin{tabular}{|c|c|c|c|c|c|c|c|c|}
\hline Especie ganadora & Peso (gramos) & Secuencia & Especie perdedora & Peso (gramos) & Secuencia & $\begin{array}{l}\text { Distancia } \\
\text { genética }\end{array}$ & Pais & Referencia \\
\hline Hylocharis leucotis & $3.6+0.3 \mathrm{n}=11$ & KJ602252.1 & Archilochus colubris & $3.03+0.02$ & EU042544.1 & 0.147 & M & 17 \\
\hline Hylocharis leucotis & $3.6+0.3 n=11$ & KJ602252.1 & Selasphorus rufus & $3.17+0.03$ & KJ602252.1 & 0.165 & M & 17 \\
\hline Hylocharis leucotis & $3.6+0.3 n=11$ & KJ602252.1 & Selasphorus sasin & $3.09+0.04$ & EU042590.1 & 0.164 & M & 17 \\
\hline Hylocharis leucotis & $3.6+0.3 n=11$ & KJ602252.1 & Selasphorus platycercus & $3.16+0.02$ & AY830522.1 & 0.163 & M & 17 \\
\hline Hylocharis leucotis & $3.595+0.303 n=40$ & KJ602252.1 & Amazilia beryllina & $4.6+0.513 n=30$ & KJ602161.1 & 0.165 & $\mathrm{M}$ & 26 \\
\hline Hylocharis leucotis & $3.595+0.303 n=40$ & KJ602252.1 & Atthis heloisa & $2.293+0.24 n=14$ & KJ602190.1 & 0.164 & $\mathrm{M}$ & 26 \\
\hline Hylocharis leucotis & $3.595+0.303 n=40$ & KJ602252.1 & Colibri thalassinus & $4.850+0.751 \mathrm{n}=4$ & EU042544.1 & 0.209 & $\mathrm{M}$ & 26 \\
\hline Hylocharis leucotis & $3.595+0.303 n=40$ & KJ602252.1 & Eugenes fulgens & $7.233+0.764 n=3$ & AY830481.1 & 0.176 & M & 26 \\
\hline Hylocharis leucotis & $3.595+0.303 n=40$ & KJ602252.1 & Lampornis amethystinus & $6.170+0.675 \mathrm{n}=27$ & KJ602255.1 & 0.173 & M & 26 \\
\hline Hylocharis leucotis & $3.595+0.303 \mathrm{n}=40$ & KJ602252.1 & Selasphorus calliope & $2.482+0.197 \mathrm{n}=136^{*}$ & EU042593.1 & 0.157 & M & 26 \\
\hline Hylocharis leucotis & $3.595+0.303 n=40$ & KJ602252.1 & Tilmatura dupontii & $2.250+0.086 \mathrm{n}=5^{*}$ & KJ602351.1 & 0.173 & M & 26 \\
\hline Lampornis amethystinus & $6.170+0.675 n=27$ & KJ602255.1 & Amazilia beryllina & $4.6+0.513 n=30$ & KJ602161.1 & 0.196 & $\mathrm{M}$ & 26 \\
\hline Lampornis amethystinus & $6.170+0.675 n=27$ & KJ602255.1 & Atthis heloisa & $2.293+0.24 n=14$ & KJ602190.1 & 0.155 & $\mathrm{M}$ & 26 \\
\hline Lampornis amethystinus & $6.170+0.675 n=27$ & KJ602255.1 & Hylocharis leucotis & $3.595+0.303 n=40$ & KJ602252.1 & 0.173 & M & 26 \\
\hline Lampornis amethystinus & $6.170+0.675 n=27$ & KJ602255.1 & Selasphorus platycercus & $3.029+0.355 \mathrm{n}=7$ & AY830522.1 & 0.151 & M & 26 \\
\hline Lampornis amethystinus & $6.170+0.675 n=27$ & KJ602255.1 & Tilmatura dupontii & $2.250+0.086 \mathrm{n}=5^{*}$ & KJ602351.1 & 0.162 & $\mathrm{M}$ & 26 \\
\hline Lampornis clemenciae & $8.4+0.4 \mathrm{n}=62$ & KJ602257.1 & Archilochus alexandri & $2.7-4.3$ & EU042529.1 & 0.162 & $\mathrm{U}$ & 23 \\
\hline Lampornis clemenciae & $8.4+0.4 \mathrm{n}=62$ & KJ602257.1 & Eugenes fulgens & $7.0-7.5$ & AY830481.1 & 0.167 & $\mathrm{U}$ & 22 \\
\hline Lampornis clemenciae & $8.4+0.4 n=62$ & KJ602257.1 & Lampornis amethystinus & $6.8+0.8 n=5$ & KJ602255.1 & 0.111 & $\mathrm{M}$ & 19 \\
\hline Lampornis clemenciae & $8.4+0.4 \mathrm{n}=62$ & KJ602257.1 & Colibri thalassinus & $6.3+0.2 \mathrm{n}=11$ & EU042544.1 & 0.243 & M & 19 \\
\hline Lampornis clemenciae & $8.4+0.4 n=62$ & KJ602257.1 & Hylocharis leucotis & $3.6+0.3 \mathrm{n}=11$ & KJ602252.1 & 0.185 & M & 19 \\
\hline Lampornis clemenciae & $8.4+0.4 \mathrm{n}=62$ & KJ602257.1 & Selasphorus rufus & $2.9-3.9$ & EU042590.1 & 0.149 & U & 14 \\
\hline Lampornis clemenciae & $8.4+0.4 \mathrm{n}=62$ & KJ602257.1 & Selasphorus platycercus & $2.6-4.1$ & AY830522.1 & 0.151 & $\mathrm{U}$ & 14 \\
\hline Lesbia victoriae & $5.1-5.3$ & AY830499.1 & Aglaeactis cupripennis & $7.6-8.1$ & KM389474.1 & 0.157 & E & 32 \\
\hline Leucochloris albicollis & $5.1-8$ & KJ602266.1 & Florisuga fusca & 9 & GU167229.1 & 0.232 & B & 21 \\
\hline Leucochloris albicollis & $5.1-8$ & KJ602266.1 & Amazilia versicolor & $3.1-4$ & EU042525.1 & 0.107 & B & 21 \\
\hline Leucochloris albicollis & $5.1-8$ & KJ602266.1 & Chlorostilbon aureoventris & 3-3.8 & KJ602211.1 & 0.185 & B & 21 \\
\hline Oxypogon guerinii & $5.7+0.7 \mathrm{n}=16$ & EU042573.1 & Lesbia victoriae & $5.1-5.3$ & AY830499.1 & 0.119 & $\mathrm{C}$ & 27 \\
\hline Oxypogon guerinii & $5.7+0.7 \mathrm{n}=16$ & EU042573.1 & Aglaectis cupripennis & $7.6-8.1$ & KM389474.1 & 0.173 & $\mathrm{C}$ & 27 \\
\hline Panterpe insignis & $6.2+0.4 n=33$ & AY830509.1 & Colibri thalassinus & 5.7 & AU042544.1 & 0.225 & $\mathrm{R}$ & 30 \\
\hline Panterpe insignis & $6.2+0.08 n=33$ & AY830509.1 & Selasphorus flammula & $2.6+0.07 \mathrm{n}=8$ & EU042589.1 & 0.144 & $\mathrm{R}$ & 31 \\
\hline Panterpe insignis & $6.2+0.08 n=33$ & AY830509.1 & Eugenes fulgens & $9.8+0.20 \mathrm{n}=11$ & AY830481.1 & 0.148 & $\mathrm{R}$ & 31 \\
\hline Panterpe insignis & $5.9-6.2$ & AY830509.1 & Eugenes fulgens & $7-7.5$ & AY830481.1 & 0.147 & $\mathrm{R}$ & 7 \\
\hline Patagona gigas & $18.5-20.2$ & AY830510.1 & Aglaectis cupripennis & $7.6-8.1$ & KM389474.1 & 0.203 & E & 32 \\
\hline Phaethornis superciliosus & $4.1-6$ & JQ445678.01 & Phaethornis longuemareus & $1.5-3.8$ & EU042580.1 & 0.131 & $\mathrm{R}$ & 6 \\
\hline Phaethornis superciliosus & $4.1-6$ & JQ445678.01 & Threnetes ruckeri & $5.5-7$ & FJ175727.1 & 0.15 & $\mathrm{R}$ & 6 \\
\hline Pterophanes cyanopterus & $9.6-11.2$ & AY830520.1 & Lesbia victoriae & $5.1-5.3$ & AY830499.1 & 0.174 & $\mathrm{E}$ & 32 \\
\hline Pterophanes cyanopterus & $9.6-11.2$ & AY830520.2 & Aglaectis cupripennis & $7.6-8.1$ & KM389474.1 & 0.18 & $\mathrm{E}$ & 32 \\
\hline
\end{tabular}


Tabla

\begin{tabular}{|c|c|c|c|c|c|c|c|c|}
\hline Especie ganadora & Peso (gramos) & Secuencia & Especie perdedora & Peso (gramos) & Secuencia & $\begin{array}{l}\text { Distancia } \\
\text { genéticas }\end{array}$ & Pais & Referencia \\
\hline Selasphorus calliope & $\begin{array}{l}2.482+0.197 \\
\mathrm{n}-136^{*}\end{array}$ & EU042593.1 & Hylocharis lencotis & $3.595+0.303 n=40$ & KJ 602252.1 & 0.157 & $\mathrm{M}$ & 26 \\
\hline Selasphonus planycercus & $3.029+0.355 n=7$ & AY830522.I & Eugenes fuilgens & $7.233+0.764 n=3$ & AY830481.1 & 0.164 & M & 26 \\
\hline Selasphonis rufics & $3,128+0.171 \mathrm{n}-29$ & EU042590.1 & Amazilia heryllina & $4.6+0.513 \mathrm{n}-30$ & KJ602161.1 & 0.183 & $\mathrm{M}$ & 26 \\
\hline Selasphonus rufurs & $3.128+0.171 n=29$ & EU0 42590.1 & Athis heloisa & $2.293+0.24 n=14$ & KJ602190.1 & 0.041 & M & 26 \\
\hline Selasphenoss rufics & $3.128+0.171 n-29$ & EU042590.1 & Selasphanus calliope & $2.482+0.197 \mathrm{n}-136^{*}$ & EU042593.1 & 0.024 & $\mathrm{M}$ & 26 \\
\hline Thalurania furcata & $3.6-6$ & KJ602346.I & Chorastitban gibsoni & 2.8 & $\mathrm{x}$ & $\mathrm{x}$ & C & 4 \\
\hline Thalurania fiercata & $3.6-6$ & KJ602346.I & Coeligena praneillei & $6.6-7$ & GU167221.1 & 0.172 & c & 4 \\
\hline Thalurania furcata & $3.6-6$ & KJ 6012346,1 & Ocreatas unnderาห⿻าdii & $2.6-3.2$ & AY830504.1 & 0.196 & C & 4 \\
\hline Thalurania fuercata & $3.6-6$ & KJ602346.I & Anthrucothorax nigricollis & $5.5-7.5$ & EU042527.1 & 0.239 & B & 2 \\
\hline Thaturania glancopis & 5 & GU167251.1 & Leweachlaris albicentlis & $5.1 \cdot 8$ & KJ602266.1 & 0.167 & B & 21 \\
\hline Thalurania glaucopis & 5 & GU167251.I & Amazilta versicolar & $3.1-4$ & EU042525.1 & 0.151 & B & 21 \\
\hline Thaturania glatucopis & 5 & GU167251.1 & Florisuga fusca & 9 & GU167229.1 & 0.202 & B & 21 \\
\hline Threnetes rucken & $5.5-7$ & FJ175727.1 & Phaethorwis suppenciliasus & $4.1-6$ & JQ445678.1 & 0.15 & $\mathrm{R}$ & 6 \\
\hline Threnetes ruckeri & $5.5-7$ & FJ175727.1 & Phaetharnis longuemareto & $1.5-3.8$ & EU042580.1 & 0.154 & R & 6 \\
\hline Tilmatura dupontii & $2.250+0.086 \mathrm{n}=5^{*}$ & KJ602351.I & Amazilia beryllina & $4.6+0.513 n=30$ & KJ602161.I & 0.192 & M & 26 \\
\hline Tilmatura dippontiti & $2.250+0.086 \mathrm{t}=5^{\circ}$ & KJ602351.I & Lampornis amethystimus & $6.170+0.675 n=27$ & KJ602255.I & 0.162 & $\mathrm{M}$ & 26 \\
\hline
\end{tabular}


9 niveles (i.e., Ermitaños, Topacios, Mangos, Brillantes, Coquetas, Esmeraldas, Gemas de Montaña, Abejas, y Patagona) y el tamaño corporal del colibrí ganador respecto al de su competidor con 2 niveles (i.e., grande y pequeño). En el segundo modelo incluimos como variable de respuesta la frecuencia de encuentros perdidos por los colibríes y como variables predictoras la identidad del clado del colibrí perdedor con 9 niveles y el tamaño corporal del perdedor respecto al de su competidor con 2 niveles. Finalmente, utilizamos pruebas de KruskalWallis para evaluar si existieron diferencias significativas entre la distancia genética de los colibríes que ganaron enfrentamientos contra contendientes más grandes en cada una de las regiones de América (i.e., Norteamérica, Centroamérica y Sudamérica). Los análisis estadísticos se realizaron en el software R (R Core Team, 2013) y las gráficas se realizaron mediante el paquete ggplot2 (Wickham, 2009).

\section{Resultados}

De los 160 encuentros agonísticos incluidos en este estudio, el $74 \%$ (119 casos de estudio) fueron ganados por el contendiente más grande y el $26 \%$ (41 casos de estudio) restante los ganó una especie más pequeña. En Norteamérica (EUA y México), los colibríes de especies más grandes vencieron en el 74\% (51 casos de estudio) de las contiendas en las que participaron, mientras que el resto $(26 \% ; 18$ casos de estudio) fue ganada por colibríes de especies de menor tamaño corporal. En Centroamérica (Costa Rica y Panamá), el 74\% (14 casos de estudio) de las interacciones agonísticas fue ganada por colibríes de especies grandes y el 26\% (5 casos de estudio) por colibríes de especies pequeñas. Finalmente, en Sudamérica (Ecuador, Brasil y Colombia), el 75\% (54 casos de estudio) de las contiendas fueron dominadas por especies grandes y el $25 \%$ (18 casos de estudio) por colibries de especies pequeñas.

La identidad de los clados tuvo un efecto significativo en la frecuencia de contiendas agonísticas ganadas $\left(x^{2}\right.$ $=176.96$, g.l. $=8, p<0.001)$ y perdidas $\left(x^{2}=145.59\right.$, g.l. $=8, p<0.001)$. Los clados de aquellas especies que dominaron la mayor cantidad de encuentros agonísticos fueron: Esmeraldas, Gemas de Montaña y los Mangos. Los colibríes Esmeraldas dominaron el 45\% $(n=72$ contiendas), las Gemas de Montaña dominaron el 16\% ( $n$ $=26$ contiendas $)$ y los Mangos el $15 \%(n=24$ contiendas $)$ de los casos de estudio incluidos en este estudio. El tamaño corporal de los contendientes tuvo un efecto significativo en el resultado de los enfrentamientos $\left(x^{2}=39.69\right.$, gr.l. $=1, p<0.001$ ), ya que las especies de todos los clados ganaron más encuentros agonísticos cuando fueron la especie más grande de la contienda (fig. 1a) y perdieron mayor cantidad de encuentros al ser el contendiente más pequeño (fig. $1 b$ ).

Para el análisis de las diferencias entre la distancia genética de colibríes de especies grandes y pequeñas que ganaron enfrentamientos agonísticos solo se incluyeron 155 de los 160 casos de estudio. Esto se debió a la falta de secuencias del gen mitocondrial NADH deshidrogenasa subunidad 2 para las siguientes especies: Eriocnemis mirabilis, Chlorostilbon gibsoni y C. auriceps. En estos 155 casos, no se encontraron diferencias significativas entre la distancia genética de los contendientes que participaron en los encuentros ganados por colibríes de especies más grandes y pequeñas $(H=0.204, p=0.651$; fig. 2). Al analizar los casos de estudio por región geográfica tampoco se encontraron diferencias significativas entre la distancia genética de los colibríes que ganaron contiendas contra competidores de especies de tamaños distintos (Norteamérica, $H=0.432, p=0.510$; Centroamérica, $H$ $=0.482, p=0.487$ y Sudamérica, $H=0.141, p=0.706$; fig. 2).

\section{Discusión}

Los resultados obtenidos en este estudio indican que los colibríes de especies de mayor tamaño corporal dominaron a las especies de menor talla cuando disputan el acceso a los recursos alimenticios en la mayoría de los encuentros $(74 \% ; 119$ casos de estudio). Este patrón ha sido previamente reportado en diferentes comunidades de colibríes, sugiriendo que el mayor tamaño corporal de una especie suele estar correlacionado con un comportamiento agresivo (Cotton, 1998; Justino et al., 2012), y asociado al menor costo energético de enfrentarse a un intruso más pequeño (Dearbon, 1998). Sin embargo, los colibríes de especies de menor talla dominaron el $26 \%$ de las interacciones agonísticas (41 casos de estudio). Esta misma tendencia se presentó en Norte, Centro y Sudamérica con un porcentaje de encuentros ganados por contendientes de menor tamaño de $26 \%$ (18 casos de estudio), $26 \%$ ( 5 casos de estudio) y $25 \%$ (18 casos de estudio), respectivamente. Esto implica que la dominancia de los colibries de especies grandes sobre competidores de menor masa corporal no es absoluta.

El hecho de que los colibríes de especies pequeñas ganen encuentros contra colibríes de especies más grandes podría deberse a factores asociados al contexto en el cual ocurre la contienda. Por ejemplo, el colibrí pechizafiro (Amazilia lactea) pesa $4.3 \mathrm{~g}$ en promedio, mientras que el colibrí sombrío (Aphantochroa cirrochloris) alcanza los 7 g. Cuando estas 2 especies compiten por el acceso a las flores de Eucalyptus spp., A. lactea tiende a ganar 


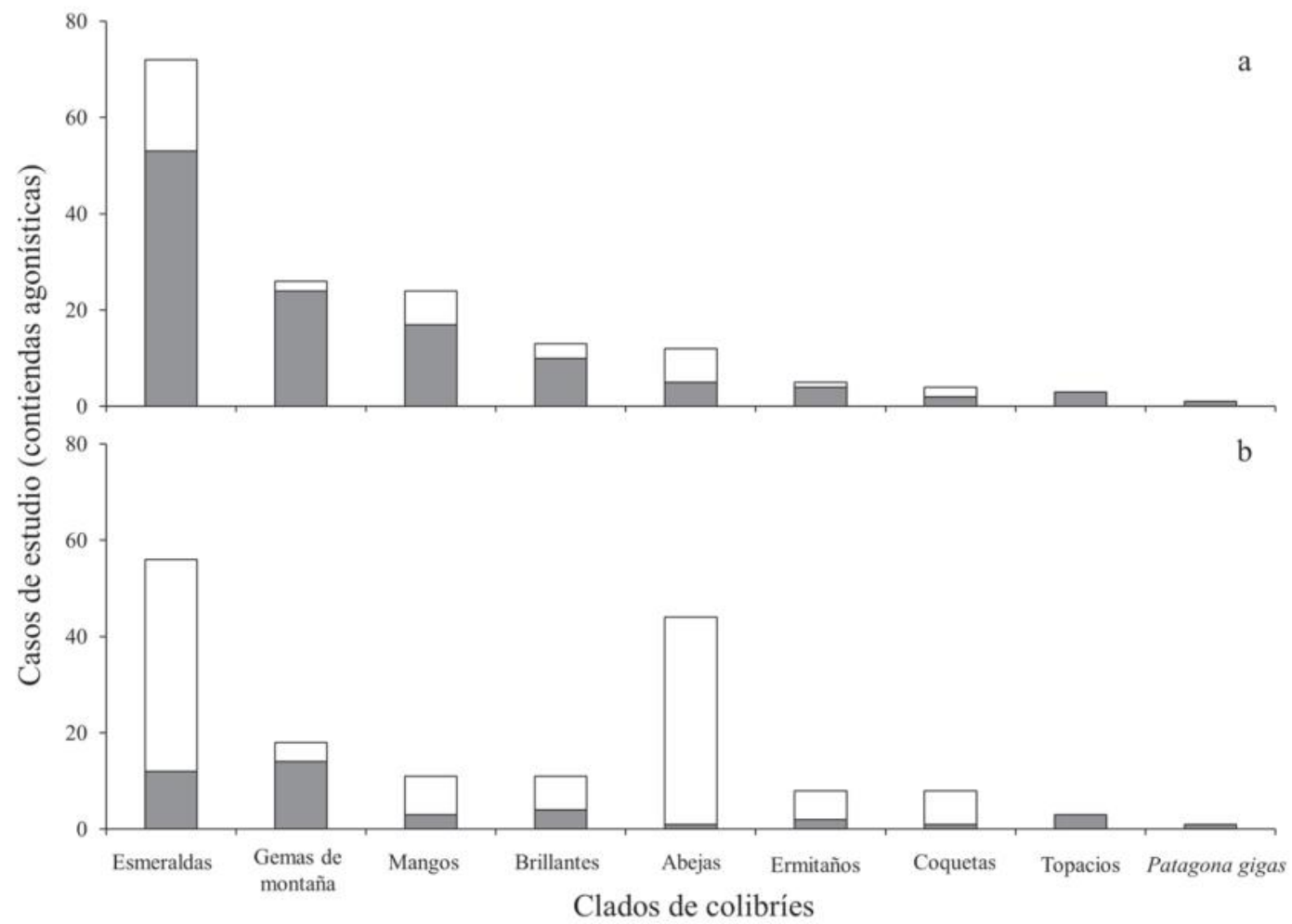

Figura 1. Frecuencia de contiendas ganadas (a) y perdidas (b) por los clados de colibries. El color de las barras representa el tamaño corporal del colibri dentro de la contienda respecto al de su competidor (barras grises = colibríes grandes y barras blancas $=$ colibríes pequeños).

más encuentros agonísticos (56 de 95 encuentros). Sin embargo, en un mismo individuo de Eucalyptus, existe una estratificación en los territorios de ambas especies: Amazilia lactea establece territorios de forrajeo en las flores que se encuentran entre 6 y $15 \mathrm{~m}$ de altura, mientras que $A$. cirrochloris defiende las flores que se encuentran entre $20 \mathrm{y}$ $30 \mathrm{~m}$ en la copa de los árboles (Antunes, 2003). Además de lo anterior, $A$. lactea establece territorios de forrajeo durante toda la época de floración de Eucalyptus, incluso al inicio y final de la misma, cuando la abundancia floral es baja. Por otro lado, A. cirrochloris solo establece territorios de forrajeo durante el pico de abundancia floral de Eucalyptus (Antunes, 2003). Es decir, el comportamiento territorial en $A$. cirrochloris depende de una mayor abundancia de flores de Eucalyptus. En contraste, A. lactea requiere una menor cantidad de recursos para establecer y defender un territorio.
Debe considerarse además que no todas las especies de colibríes establecen territorios de forrajeo o participan en contiendas agonísticas. Lo anterior ha sido descrito con base en los roles primarios que pueden ocupar los colibríes dentro de una comunidad. Al respecto, Feinsinger y Colwell (1978) postulan que los colibries pueden desempeñar diferentes roles dentro de una comunidad para obtener acceso a los recursos disponibles en el ambiente, clasificándolos de acuerdo a sus características morfológicas (tamaño corporal, longitud del pico y patas) como ruteros (i.e., colibríes que establecen una ruta de forrajeo haciendo visitas secuenciales a diferentes puntos de alimentación) de baja calidad y ladrones $(<4 \mathrm{~g}$ y pico corto), generalistas y territoriales (4-5 $\mathrm{g}$ y pico de corto a medio) y ruteros de alta calidad y merodeadores ( $>5 \mathrm{~g} \mathrm{y}$ pico de medio a largo). No obstante, es importante enfatizar que una especie puede cambiar el rol que tiene 


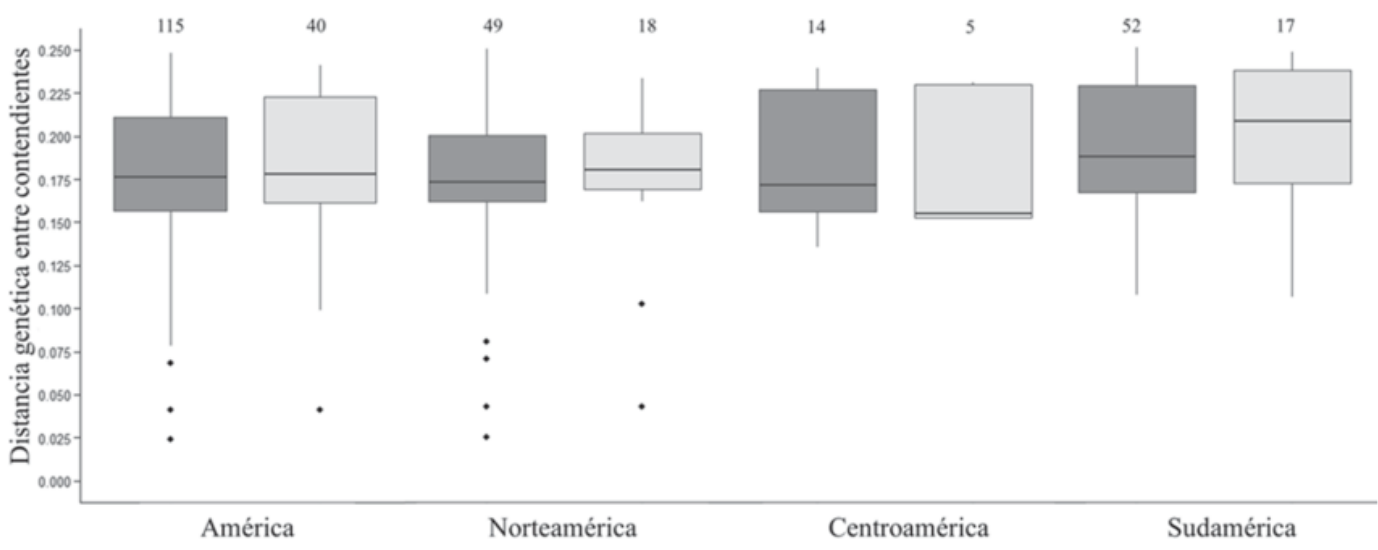

Figura 2. Distancia genética entre colibries de América, Norteamérica, Centroamérica y Sudamérica. El color de las cajas indica el tamaño corporal del colibrí ganador del encuentro respecto a su competidor (cajas gris obscuro = colibríes grandes y cajas gris claro $=$ colibríes pequeños). En la parte superior de cada caja se indica el número de contiendas agonísticas que conforman cada muestra. Las cajas representan el $50 \%$ de los datos divididos por la mediana de cada muestra, las líneas verticales indican los límites de 0.95 y 0.05. Los números sobre las cajas representan el tamaño de cada muestra (casos de estudio). Los puntos representan los outliers de cada distribución.

en una comunidad y con esto la frecuencia y el resultado de las contiendas en las que participa dependiendo de la abundancia, disponibilidad y preferencia por los recursos disponibles en el ambiente, además de la composición de especies de la comunidad de colibríes (Feinsinger y Colwell, 1978). Por ejemplo, el colibrí barbudito del páramo (Oxypogon guerinii) generalmente establece rutas de alimentación; sin embargo, establece territorios de forrajeo en plantas de Espeletia spp. cuando este recurso es abundante. Tanto las rutas como los territorios son defendidos por $O$. guerinii, expulsando a otros colibríes de sus áreas de alimentación. Dentro de los intrusos se encuentran especies más grandes que $O$. guerinii, como Aglaeactis cupripennis, el colibrí cobrizo (SalamancaReyes, 2011). Es importante mencionar que se ha reportado que $O$. guerinii prefiere forrajear en flores de diferentes especies de Espletia, incluso cuando se encuentran marchitas, debido a la presencia de larvas de insectos que también consume (Schuchmann, 1999).

La variedad y plasticidad de los roles que pueden desempeñar las especies de colibríes dentro de una comunidad pueden ser el reflejo de procesos evolutivos, no solo de los colibríes, sino de las plantas que visitan. En conjunto, tales procesos podrían promover una disminución en la competencia interespecífica y aumentar el éxito reproductivo de las plantas (Brown et al., 1981). Un ejemplo de lo anterior son las características morfológicas de las corolas de algunas especies de plantas, las cuales solo pueden ser explotadas por especies de colibríes con cierta longitud y curvatura en el pico (Stiles, 1975; Vizentin-Bugoni et al., 2014).

\section{Dominancia de los clados de colibries}

Los colibríes Esmeraldas, Gemas de Montaña y Mangos fueron los clados que protagonizaron y ganaron más encuentros agonísticos (72, 26 y 24 casos de estudio ganados, respectivamente). Sin embargo, los colibríes Esmeraldas fueron muy superiores al resto de los clados de colibríes, ya que dominaron el $45 \%$ de las interacciones agonísticas incluidas en este estudio (72 casos de estudio). De los 72 casos de estudio en donde participaron, desplazaron a colibríes más pequeños en 53 casos $(74 \%)$ y a colibríes más grandes en 19 casos (26\%). La dominancia de los colibríes Esmeraldas podría explicarse por la diversidad propia del clado ya que agrupa a 28 géneros de colibríes incluyendo a Amazilia, el género con mayor número de especies (30-32 especies) de la familia Trochilidae (McGuire et al., 2009; Ornelas, 1995). En este sentido, se ha reportado que las especies del género Amazilia son capaces de explotar una amplia gama de recursos florales y hábitats. Además de lo anterior, los colibríes de este género son territoriales y muy agresivos, resultando ser competidores superiores y dominantes sobre otras especies de colibríes (Arizmendi y Ornelas, 1990; Ornelas, 1995). El género Amazilia se ajusta a las características del rol de colibrí territorial descrito por 
Feinsinger y Colwell (1978), y la influencia de este género podría explicar la dominancia de los Esmeraldas sobre otros grupos de colibríes. Sin embargo, los Esmeraldas junto con los Abejas son los clados que perdieron mayor cantidad de contiendas cuando se enfrentaron a competidores de mayor tamaño corporal (56 y 44 casos de estudio, respectivamente). Esto puede deberse a que el clado Abejas concentra a los colibríes de menor tamaño corporal $(2-4 \mathrm{~g})$ de la familia Trochilidae. Por ejemplo, Atthis heloisa (colibrí abejorro), la especie más pequeña incluida en este estudio, regularmente forrajea en flores dispersas no defendidas o en la periferia de los territorios de otras especies de colibríes, de donde es desplazado fácilmente por otros colibríes (Lyon, 1976). Si bien, algunas especies de colibríes Abejas suelen ser territoriales, regularmente compiten contra especies de un tamaño corporal similar (e.g., especies del género Selasphorus; Camfield, 2006). En el presente estudio, muchas interacciones entre colibríes Abejas no fueron incluidas, pues podrían generar un grado de incertidumbre en los resultados al no poder determinar claramente a una de las especies como la de mayor tamaño corporal.

Finalmente, los colibríes Esmeralda fueron el clado que perdió la mayor cantidad de encuentros (44 casos de estudio) cuando se enfrentaron a especies de colibríes de mayor tamaño corporal (fig. 1b). Este patrón podría ser explicado por la presencia de los colibríes del género Chlorostilbon (2.1 - $3.8 \mathrm{~g}$ ) en este clado, ya que suelen ser relegados del acceso a los mejores recursos por colibríes de otras especies e incluso por abejas (e.g., Xylocopa spp.; Arizmendi y Ornelas, 1990).

\section{Distancia genética entre contendientes}

La hipótesis propuesta por Martin y Ghalambor (2014) sugiere que especies pequeñas tendrían mayor oportunidad de ganar encuentros agonísticos contra especies más grandes cuando la distancia evolutiva entre las especies interactuantes es mayor. Sin embargo, los resultados del presente estudio indican que no existe una diferencia estadísticamente significativa entre la distancia genética de las especies de colibríes que ganaron contiendas contra competidores de menor tamaño corporal. Este patrón se mantiene en las 3 regiones del continente. No obstante, parece existir una tendencia latitudinal en la cual la distancia genética entre contendientes aumenta de norte a sur del continente. Los valores más altos de distancia genética entre contendientes se registraron en los casos de estudio de Sudamérica y la menor en Norteamérica (fig. 2, outliers). Esta tendencia puede estar relacionada con la historia de diversificación de los colibríes en América. McGuire et al. (2014) postulan que la diversificación en Sudamérica de los primeros 7 clados de colibríes (i.e.,
Ermitaños, Topacios, Mangos, Brillantes, Coquetas, Patagona y Esmeraldas) puede ser atribuida a 2 factores principales, las relaciones que establecieron con las plantas de las que se alimentan, además de la segregación entre especies para el uso de este recurso y el origen de la Cordillera de los Andes, la cual permitió la colonización de nuevas regiones principalmente para las especies de los clados Coquetas y Brillantes. Por otro lado, McGuire et al. (2014) indican que el ancestro común de las Gemas de Montaña y las Abejas recolonizó Norteamérica hace cerca de 12 millones de años, donde posteriormente ambos clados se diversificaron aproximadamente hace 10 y 5 millones de años, respectivamente. No obstante, recientemente LiconaVera y Ornelas (2017) han postulado que la diversificación del clado Abejas ocurrió inicialmente hace cerca de 9.93 millones de años, pero la mayoría de los eventos de divergencia ocurrieron posteriormente (durante el Plioceno y el Pleistoceno Medio tardío). Por ello, la diversificación de los colibríes Abeja en la región pudo estar asociada a la aparición de nuevos hábitats y condiciones climáticas favorables originadas a partir de la formación de los sistemas montañosos en México y Centroamérica (Licona-Vera y Ornelas, 2017). Debido a la historia de diversificación del grupo en el continente, cada comunidad de colibries se ha conformado diferencialmente a lo largo del tiempo con la llegada o diversificación de nuevas especies de colibríes o de recursos. Lo anterior podría reflejarse en la distancia genética entre las especies que conforman un ensamble y por lo tanto, en la frecuencia y resultado de contiendas agonísticas por el acceso a los recursos.

En conclusión, nuestro estudio indica que las especies de colibríes con mayor tamaño corporal generalmente dominan a las especies más pequeñas. Este patrón se mantiene a lo largo de la distribución del grupo y parece ser más evidente en clados como el Esmeraldas. Por otro lado, contrario a lo postulado por Martin y Ghalambor (2014), la distancia genética entre contendientes no resultó significativamente distinta entre colibríes que ganaron enfrentamientos contra competidores de menor masa corporal. Sin embargo, se debe tomar en cuenta que el presente estudio consideró cualitativamente a cada contienda (especie ganadora y especie perdedora) y que, dada la naturaleza de los datos, no se consideró la fuerza de cada interacción (es decir, cuantitativamente). Además de lo anterior, no se tomó en cuenta el contexto ecológico en el cual se desarrollan las contiendas, por lo cual se debe profundizar en el papel que juega la distancia evolutiva, en conjunto con la variabilidad en la disponibilidad y abundancia de los recursos, la calidad energética de los mismos y los cambios en la estructura de las comunidades debidos a la llegada y partida de especies migratorias en localidades particulares. 


\section{Agradecimientos}

Al Consejo Nacional de Ciencia y Tecnología por la beca otorgada a UML para estudios de doctorado (número de becario $=266931$, beca $=425674)$. Este trabajo constituye un requisito para la obtención del grado de UML en el Doctorado de Ciencias Biológicas y de la Salud de la UAM.

\section{Referencias}

Abrahamczyk, S. y Kessler, M. (2014). Morphological and behavioural adaptations to feed on nectar: how feeding ecology determines the diversity and composition of hummingbird assemblages. Journal of Ornithology, 156, 333-347.

Antunes, A. Z. (2003). Partilha de néctar de Eucalyptus spp., territorialidade e hierarquia de dominância em beija-flores (Aves: Trochilidae) no sudeste do Brasil. Ararajuba, 11, 39-44.

Araujo-Silva, L. E. y Bessa, E. (2010). Territorial behaviour and dominance hierarchy of Anthracothorax nigricollis Vieillot 1817 (Aves: Trochilidae) on food resources. Revista Brasileira de Ornitologia, 18, 89-96.

Arizmendi, M. C. y Ornelas, J. F. (1990). Hummingbirds and their floral resources in a tropical dry forest in Mexico. Biotropica, 2, 172-180.

Ayala, R. A. V. (1986). Aspectos de la relación entre Thalurania furcata colombica (Aves Trochilidae) y las flores en que liba, en un bosque subandino. Caldasia, 14, 549-562.

Boyden, T. C. (1978). Territorial defense against hummingbirds and insects by tropical hummingbirds. The Cooper Ornithological Society, 2, 216-221.

Brown, J. H., Kodric-Brown, A., Whitham, T. GR.y Bond, H. W. (1981). Competition between hummingbirds and insects for the nectar of two species of shrubs. The Southwestern Naturalist, 2, 133-145.

Camfield, A. F. (2006). Resource value affects territorial defense by Broad-tailed and Rufous hummingbirds. Journal of Field Ornithology, 77, 120-125.

Carpenter, F. L., Hixon, M. A., Russell, R. W., Paton, D. C. y Temeles, E. J. (1993). Interference asymmetries among age-sex classes of Rufous hummingbirds during migratory stopovers. Behavioral Ecology and Sociobiology, 33, 297304.

Carpenter, F. L., Paton, D. C. y Hixon, M. A. (1983). Weight gain and adjustment of feeding territory size in migrant hummingbirds. Proceedings of the National Academy of Sciences of the United States of America, 80, 7259-7263.

Chaves, C. J. (1997). Coexistencia de varias especies de colibries ermitaños en un parche de Heliconia danielsianna. En F. Bolaños, J. Lobo y D. Briceño (Eds.), Curso de Biologia de Campo (pp. 92-97). San José: Facultad de Ciencias, Escuela de Biologia, Universidad de Costa Rica.

Colwell, R. K. (1973). Competition and coexistence in a simple tropical community. The American Naturalist, 958 , 737-760.

Contreras-Martínez, S. (2014). Dinámica espacio-temporal de colibries (Trochilidae), en bosques de pino-encino postincendio en la Reserva de la Biosfera Sierra de Manantlán, Jalisco, México (Tesis). Guadalajara, Jalisco: Centro Universitario de la Costa del Sur, Universidad de Guadalajara.

Copenhaver, C. y Ewald, P. W. (1980). Cost of territory establishment in hummingbirds. Oecologia, 46, 155-160.

Cotton, P. A. (1998). Temporal partitioning of a floral resource by territorial hummingbirds. Ibis, 140, 647-653.

Cotton, P. A. (2007). Seasonal resource tracking by Amazonian hummingbirds. Ibis, 149, 135-142.

Dearborn, D. C. (1998). Interspecific territoriality by a Rufoustailed hummingbird (Amazilia tzacatl): effects of intruder size and resource value. Biotropica, 30, 306-313.

Ewald, P. W. y Bransfield, R. J. (1987). Territory quality and territorial behavior in two sympatric species of hummingbirds. Behavioral Ecology and Sociobiology, 20, 285-293.

Feinsinger, P. y Colwell, R. K. (1978). Community organization among Neotropical nectar-feeding birds. Amercian Zoologist, $18,779-795$.

Fraga, R. M. (1989). Interactions between nectarivorous birds and the flowers of Aphelandra sinclairiana in Panama. Journal of Tropical Ecology, 5, 19-26.

Freshwater, C., Ghalambor, C. K. y Martin, P. R. (2014). Repeated patterns of trait divergence between closely related dominant and subordinate bird species. Ecology, 95, 2334-2345.

Johnson, M. T. y Stinchcombe, J. R. (2007). An emerging synthesis between community ecology and evolutionary biology. Trends in Ecology and Evolution, 22, 250-257.

Justino, D. G. R., Maruyama, P. K. y Oliveira, P. E. (2012). Floral resource availability and hummingbird territorial behaviour on a Neotropical savanna shrub. Journal of Ornithology, $153,189-197$.

Kuban, J. F., Lawley, J. y Neill, R. L. (1983). The partitioning of flowering century plants by Black-chinned and Lucifer hummingbirds. The Southwestern Naturalist, 28, 143-148.

Kuban, J. F. y Neill, R. L. (1980). Feeding ecology of hummingbirds in the highlands of the Chisos Mountains, Texas. Condor, 82, 180-185.

Kumar, S., Stecher, GR. y Tamura, K. (2016). MEGA7: Molecular evolutionary genetics analysis version 7.0 for bigger datasets. Molecular Biology and Evolution, 33, 1870-1874.

Lara, C. (2006). Temporal dynamics of flower use by hummingbirds in a highland temperate forest in Mexico. Ecoscience, 13, 23-29.

Lara, C., Lumbreras, K. y González, M. (2009). Niche partitioning among hummingbirds foraging on Penstemon roseus (Plantaginaceae) in central Mexico. Ornitologia Neotropical, 20, 73-83.

Lara, C., Martínez-García, V., Ortiz-Pulido, R., Bravo-Cadena, J., Loranca, S. y Córdoba-Aguilar, A. (2011). Temporal-spatial segregation among hummingbirds foraging on honeydew in a temperate forest in Mexico. Current Zoology, 57, 56-62. 
Licona-Vera, Y. y Ornelas, J. F. (2017). The conquering of North America: dated phylogenetic and biogeographic inference of migratory behavior in bee hummingbirds. BMC Evolutionary Biology, 17, 126.

Lyon, D. L. (1976). A montane hummingbird territorial system in Oaxaca, Mexico. The Wilson Bulletin, 88, 280-299.

Martin, P. R. y Ghalambor, C. K. (2014). When David beats Goliath: the adventage of large size in interspecific aggressive contests declines over evolutionary time. Plos One, 9, e108741.

McGuire, J. A., Witt, C. C., Remsen, J. V., Corl, A., Rabosky, D. L., Altshuler, D. L. et al. (2014). Molecular phylogenetics and the diversification of hummingbirds. Current Biology, 24, 910-916.

McGuire, J. A., Witt, C. C., Remsen, J. V., Dudley, R. y Altshuler, D. L. (2009). A higher-level taxonomy for hummingbirds. Journal of Ornithology, 150, 155-165.

Nelder, J. A. y Wedderburn, R. W. M. (1972). Generalized linear models. Journal of the Royal Statistical Society, 135, 370-384.

Ornelas, J. F. (1995). Radiation in the genus Amazilia: a comparative approach to understanding the diversification of hummingbirds (Tesis doctoral). University of Arizona, Arizona, EUA.

Ornelas, J. F., Ordano, M., Hernández, A., López, J. C., Mendoza, L. y Perroni, Y. (2002). Nectar oasis produced by Agave marmorata Roezl. (Agavaceae) lead to spatial and temporal segregation among nectarivores in the Tehuacán Valley, México. Journal of Arid Environments, 52, 37-51.

Persegona, J. E., Corrêa, L. y Roper, J. J. (2009). Interações estacionais entre beija-flores (Trochilidae) em uma região de ecótone no município de Piraquara, Paraná. Estudos de Biologia, 31, 49-58.

Pimm, S. L., Rosenzweig, M. L. y Mitchell, W. (1985). Competition and food selection: field test of a theory. Ecology, 66, 798-807.

Powers, D. R. y McKee, T. (1994). The effect of food availability on time and energy expenditures of territorial and nonterritorial hummingbirds. Condor, 96, 1064-1075.

Primack, R. B. y Howe, H. F. (1975). Interference competition between a hummingbird (Amazilia tzacatl) and skipper butterflies (Hesperiidae). Biotropica, 7, 55-58.

$\mathrm{R}$ Core Team. (2013). R: a language and environment for statistical computing. R Foundation for Statistical Computing, Vienna. Disponible en: http://www.r-project.org/

Ramírez-Burbano, M., Sandoval-Sierra, J. y Gómez-Bernal, L. (2007). Uso de recursos florales por el Zamarrito multicolor Eriocnemis mirabilis (Trochilidae) en el Parque Nacional Natural Munchique, Colombia. Ornitologia Colombiana, 5 , 64-77.

Rodriguez-Flores, C. I. y Arizmendi-Arriaga, M. C. (2016).
The dynamics of hummingbird dominance and foraging strategies during the Winter season in a highland community in Western Mexico. Journal of Zoology, 4, 262-274.

Salamanca-Reyes, J. R. (2011). Ecología del barbudito de páramo (Oxypogon guerinii, Trochilidae) en el páramo de Siscunsí, Boyacá, Colombia. Ornitología Colombiana, 11, 58-75.

Schuchmann, K. L. (1999). Family Trochilidae (Hummingbirds). En J. del Hoyo, A. Elliott, y J. Sargatal (Eds.), Handbook of birds of the World, Volumen 5: Barn-owls to hummingbirds. (pp. 468-535). Barcelona: Lynx Edicions.

Stiles, F. G. R. (1975). Ecology, flowering phenology, and hummingbird pollination of some Costa Rican Heliconia species. Ecology, 56, 285-301.

Tamura, K. y Nei, M. (1993). Estimation of the number of nucleotide substitutions in the control region of mitochondrial DNA in humans and chimpanzees. Molecular Biology and Evolution, 10, 512-526.

Taylor, J. (2005). Do sympatric heliconias attract the same species of hummingbird? Observations on the pollination ecology of Heliconia beckneri and $H$. tortuosa at Cloudbridge Nature Reserve. Brenesia, 15, 151-180.

Thompson, J. D., Higgins, D. G. R. y Gibson, T. (1994). CLUSTAL W: improving the sensitivity of progressive multiple sequence alignment through sequence weighting, position-specific gap penalties and weight matrix choice. Nucleic Acids Research, 22, 4673-4680.

Toloza-Moreno, D. L., León-Camargo, D. A. y Rosero-Lasprilla, L. (2014). El ciclo anual de una comunidad de colibríes (Trochilidae) en bosques altoandinos intactos y paramizados en la Cordillera Oriental de Colombia. Ornitología Colombiana, 14, 28-47.

Vizentin-Bugoni, J., Maruyama, P. K. y Sazima, M. (2014). Processes entangling interactions in communities: forbidden links are more important than abundance in a hummingbirdplant network. Proceedings of the Royal Society of London B: Biological Sciences, 281, 1-8.

Webb, C. O., Ackerly, D. D., McPeek, M. A. y Donoghue, M. J. (2002). Phylogenies and community ecology. Annual Review of Ecology and Systematics, 33, 475-505.

Wickham, H. (2009). ggplot2: elegant graphics for data analysis. Springer, Nueva York, EUA.

Wolf, L. L. (1969). Female territoriality in a tropical hummingbird. The Auk, 86, 490-504.

Wolf, L. L., Stiles, F. G. R. y Hainsworth, F. R. (1976). Ecological organization of a tropical, highland hummingbird community. Journal of Animal Ecology, 45, 349-379.

Woods, S. y Ramsay, P. M. (2001). Variability in nectar supply: implications for high-altitude hummingbirds. En P. M. Ramsay (Ed.), The ecology of volcán Chiles: high-altitude ecosystems on the Ecuador-Colombia border (pp. 209-217). Londres: Pebble \& Shell, Plymouth. 


\section{Capítulo II}

\section{Factors affecting the dominance hierarchy dynamics in a hummingbird assemblage}

Publicado en Current Zoology (2019) 65 (3):261-268. 
Article

\title{
Factors affecting the dominance hierarchy dynamics in a hummingbird assemblage
}

\author{
Ubaldo Márquez-Luna ${ }^{a, *}$, Carlos Lara ${ }^{b}$, Pablo Corcuera ${ }^{c}$, and \\ Pedro Luis Valverde ${ }^{\mathrm{c}}$
}

aDoctorado en Ciencias Biológicas y de la Salud, Universidad Autónoma Metropolitana-Iztapalapa, Ciudad de México, México, '⿳Centro de Investigación en Ciencia Biológicas, Universidad Autónoma de Tlaxcala. Km 10.5 Autopista Tlaxcala-San Martín Texmelucan, San Felipe Ixtacuixtla, Tlaxcala, México, and ${ }^{\mathrm{c} D e p a r t a m e n t o ~ d e}$ Biología, Universidad Autónoma Metropolitana-Iztapalapa, Ciudad de México

*Address correspondence to Ubaldo Márquez-Luna. E-mail: marquezubaldo@gmail.com.

Handling editor: Ximena Nelson

Received on 26 September 2017; accepted on 6 July 2018

\begin{abstract}
Intra and interspecific competition for nectar play an important role in hummingbird communities. Larger sized species usually exclude smaller species from the rich floral resources. However, it has been recently postulated that the competitive advantages of a large body size decline as the evolutionary distance between the contending species increases. In this study, we analyzed dominance hierarchy dynamics in a hummingbird assemblage in central Mexico. By monitoring hummingbird territories established in three plant species through 1 year, we assessed the effects of energy within territories and the territory owners identity in the frequency of inter and intraspecific encounters. We also evaluated if these factors affect the dominance of larger species when they compete against smaller distantly related contenders. Our results show that their frequency of intraspecific encounters was related with the identity of the territory's owner. On the contrary, the frequency of interspecific encounters was related with both the territory and the identity of the territory's owner. We did not find a significant difference between the number of encounters dominated by larger and smaller species and their contenders. However, the increase in genetic distance between contenders was positively associated with a higher frequency of encounters dominated by small hummingbirds. Our results showed that the ecological factors and evolutionary relationships among contenders play important roles in the dominance hierarchy dynamics.
\end{abstract}

Key words: agonistic behavior, competition, hummingbirds, resource quality, territoriality

Dominance hierarchy is defined as the social position of one individual relative to one or more competitors (Ewald 1985). In hummingbirds, competition for the access to floral nectar plays an important role in shaping the species composition of local communities (Wolf et al. 1976; Graham et al. 2009). This close relationship drives many species of hummingbirds to follow flowering plants through altitudinal and latitudinal migrations in order to ensure nectar availability (Montgomerie and Gass 1981). This behavioral response to plant phenology promotes seasonal changes in the species composition of the hummingbird community at a given site (Stiles 1980).
Consequently, these changes can affect the levels of intraspecific and interspecific competition resulting in spatial and temporal patterns or resource sharing (Cotton 1998; Lara et al. 2011).

The hummingbird species can perform different foraging strategies to compete for access to nectar. Feinsinger and Colwell (1978) define 6 foraging roles that hummingbirds could fill in a community: territorialists monopolize access to nectar by establishing and defending foraging territories against other hummingbirds; trapliners (high and low reward) realize sequential visits to different feeding locations (trapline); territory parasites (marauders and filchers) consume the 
nectar of flowers within a foraging territory in absence (filchers) or even in the presence of the territory owner (marauders); and generalists, which either act opportunistically or their role within the community is not clearly defined. These roles are based on the behavioral and morphological traits (e.g., body size and bill length) associated with the hummingbird foraging strategies. These authors emphasize on the ability of hummingbirds to change their role within the community based on the resources available and the identity of the rest of hummingbird species competing for access to resources.

Body size has been shown to explain the dominance hierarchy of hummingbirds in different assemblages (Stiles and Wolf 1970; Dearborn 1998; López-Segoviano et al. 2017). Overall, larger hummingbird species tend to dominate, excluding smaller species from high quality energy resources (Hainsworth and Wolf 1972, Dearborn 1998; Araújo-Silva and Bessa 2010; Justino et al. 2012; Mendiola-Islas et al. 2016). However, in some cases, smaller species also establish and defend foraging territories against larger contenders (Wolf et al. 1976; Chaves 1997; Antunes 2003).

Martin and Ghalambor (2014) provided an explanation for this pattern and suggested that small species may accumulate character istics that allow them to overcome the competitive disadvantages associated with smaller body size in interspecific encounters (e.g., greater muscle development, increased acceleration and maneuverability during flight, and increased production of testosterone) through evolutionary time. Recently, Dakin et al. (2018) provide information on how this pattern might work. They demonstrated that the changes in morphological or physiological traits generate behavioral divergence between species. For example, the maneuverability (i.e., the ability to change the speed and direction of the flight) is an important factor that can determine the success in competitive interactions (Dudley 2002). In this sense, Dakin et al. (2018) demonstrated that the enhanced maneuverability in hummingbirds is directly related to an increase in muscular capacity (measured as the maximum mass of beads that the bird can lift in vertical flight) rather than body mass, and to a lower wing loading (i.e., larger wing area relative to body mass) that also is associated with the use of complex turns as yaw or downward rotations. That is, the morphological traits and maneuver abilities of distantly related species could generate different competitive advantages. Thus, the small species can capitalize such differences to win encounters against larger distantly related contenders. This highlights the importance of phylogenetic relationships between contenders because they could be a determinant factor in the outcome of aggressive encounters.

In addition to harboring resident populations, the highlands of Mexico ( $>1550 \mathrm{~m}$ a.s.l.) are used as stopover or wintering sites by migratory hummingbird species (Russell et al. 1994). Such communities are suitable to study the mechanisms that modify the dominance hier archies. In this article, we analyzed the dominance hierarchy dynamics of a hummingbird assemblage in a temperate montane forest in central Mexico. Our study aimed to specifically address the following two questions: 1) whether the identity of the defended plant species, the energy contained within territories and the identity of the territory owner affected the frequency of interspecific and intraspecific encounters and 2) whether the frequency of encounters won was affected by the body size and the genetic distance of the contending species.

\section{Materials and Methods}

Fieldwork was carried out from October 2015 to October 2016 at the La Malinche National Park (LMNP), Tlaxcala $\left(98^{\circ} 58^{\prime} \mathrm{W}\right.$, $\left.19^{\circ} 14^{\prime} \mathrm{N}\right)$. We used climate data collected at Zitlaltepec weather station $\left(97^{\circ} 54^{\prime} 27^{\prime \prime} \mathrm{W}, 19^{\circ} 11^{\prime} 59^{\prime \prime} \mathrm{N}\right)$ from 1981 to 2010 (SMN 2018). Mean annual temperature over this period was $13.9^{\circ} \mathrm{C}$, and annual precipitation was $788.8 \mathrm{~mm}$. The vegetation in the study area is mainly a mosaic of pine and oak forests and secondary vegetation. The ornithophilous plants have sequential flowering periods that generate a variation of abundance and availability of different flowering plant species throughout the year (Lara et al. 2009). The most abundant ornithophilous plants in LMNP are Penstemon roseus (Plantaginaceae), Salvia elegans (Lamiaceae), and Bouvardia ternifolia (Rubiaceae). The 3 species are perennial herbs that grow in patches (Lara 2006). We focused on the agonistic hummingbirc interactions occurring around floral territories of these plant species over a 1-year period. Additional information about the plant species is given in Table 1. Bouvardia ternifolia (1-1.5 $\mathrm{m}$ high) flowers last 4-5 days and each plant have 2-50 flowers, and 1-15 flowers on average opens per day (Lara and Ornelas 2002). Penstemon roseus (0.4-1.2 $\mathrm{m}$ high) bear 10-20 paniculate inflorescences, each opening 2-4 pendant flowers per day and the flowers last $2-4$ days (Lara and Ornelas 2008). Salvia elegans (0.8-2 m high) display $22-52$ flowers per plant and flowers last an average of 4 days (Espino-Espino et al. 2014).

In this study, we focused in the 5 most abundant hummingbird species in the LMNP: Colibri thalassinus (migratory), Lampornis clemenciae (migratory), Eugenes fulgens (resident), Hylocharis leucotis (resident), and Selasphorus platycercus (altitudinal and latitudinal migratory populations) (Lara et al. 2009). Additional information about the studied hummingbird species is given in Table 2. Other 7 more hummingbird species have been recorded in the study area (Lampornis amethystinus, Amazilia beryllina, Atthis

Table 2. Body size and clade of each hummingbird species studied Hummingbird species Body size (g) Hummingbird clade

Lampornis clemenciae $\quad 8.39 \pm 0.12(n=61) \quad$ Mountain Gems

Eugenes fulgens $\quad 7.65 \pm 0.11(n=49) \quad$ Mountain Gems

Colibrithalassinus $\quad 6.00 \pm 0.06(n=128) \quad$ Mangoes

$\begin{array}{lll}\text { Colibrit thalassinus } & 6.00 \pm 0.06(n=128) & \text { Mangoes } \\ \text { Hylocharis leucotis } & 3.95 \pm 0.06(n=80) & \text { Emeralds }\end{array}$ Selasphorus platycercus $3.74 \pm 0.07(n=61) \quad$ Bees

The body size was estimated of individuals captured in the LMNP from September 2009 to September 2011. The hummingbird clade was defined according to McGuire et al. (2014).

Table 1. Characteristics of the most abundant ornithophilous plant species in the LMPN

\begin{tabular}{lllccc}
\hline Plant species & Flowering season & Plant grow area & Flowers/plant & Nectar volume/flower $(\mu \mathrm{L})$ & Energy/flower $(\mathrm{Kj})$ \\
\hline Salvia elegans & October-April & Forested & $22-52$ & $4.18 \pm 0.34$ & 1.56 \\
Bouvardia ternifolia & May-August & Unforested & $2-50$ & $4.38 \pm 0.2$ & 1.66 \\
Penstemon roseus & July-November & Forested & $10-20$ & $5.74 \pm 0.56$ & 3.18
\end{tabular}

Floral display data were taken from Espino-Espino et al. (2014), Lara and Ornelas $(2002,2008)$, respectively. Mean nectar volume ( \pm SE) and energy produced per flower ( $n=20$ flowers in both cases). 
heloisa, Archilochus colubris, Calothorax lucifer, Selasphorus sasin, and S. rufus) albeit in very low numbers (Lara 2006).

Foraging territories were searched and monitored from 29 October 2015 to 23 October 2016. A floral patch was considered a foraging territory if a hummingbird foraged and perched inside and defended it against intruders (Camfield 2006; Márquez-Luna et al. 2015; Mendiola-Islas et al. 2016). We looked for foraging territories following the hummingbird vocalizations (territorial and feeding calls). The individuals that establish and defend a foraging territory (territory owners) often perform vocalizations to advertise their presence to potential competitors (Goldberg and Ewald 1991). In addition to these cues, we randomly selected floral patches to observe if these were foraging territories.

The number of flowers in each of the monitored territories was counted around the time that each owner was observed. The territory boundaries were defined visually by the foraging and aggressive behavior of the territory owner. In addition, we chose 20 flowers from 20 plants (outside the boundaries of the territories) in the same condition as the plant species inside the territories to measure nectar volume (standing crop) in a nondestructive way by using calibrated micropipettes ( $5 \mu \mathrm{L}$ ) (Corbet 2003). Sugar concentration (percentage sucrose) was measured with a hand-held pocket refractometer (Atago, Master Refractometer $50 \mathrm{H}$, range concentration $0^{\circ}-50^{\circ}$ Brix). Subsequently, the nectar volume and the sugar concentration (Degrees Brix) of each plant species were used to calculate the mean energy per flower (Kilojoules; Bolten et al. 1979). Finally, the number of flowers in each territory was multiplied by the estimated energy per flower (Kj/flower). We assessed the energy within the territories at the moment of the observations with these approximations. The number of flowers could also represent a surrogate measure of the energy within the territories but the number of flowers and the energy within each territory was highly correlated $(r=0.975, n=85, P<0.001)$. For this reason, we only use the estimate of the energy in each territory for the statistical analyzes.

In each of the territories, we recorded the behavior of the territory owner and the intruders, from $07: 00 \mathrm{~h}$ to $13: 00 \mathrm{~h}$, the period of highest hummingbird activity (Lara 2006). The territory owners were identified by their constant vocal behavior and because they often perched in high branches over or near the defended floral patch. We visually followed the owner within its territory to identify its preferred perches. All territory owners only used few perches on their own territories over the observation period. This helped us determine that we were looking at the same individual before and after the agonistic encounters (Márquez-Luna et al. 2015). During each of the field work days we searched for foraging territories in different locations to prevent repeated records of the same territorial individuals. The searching and observation locations were defined depending on the floral abundance and the flowering season.

In each territory, we recorded 1) the identity of the territory owner and the intruders, 2) the frequency of inter and intraspecific agonistic interactions, and 3) the winning species of each agonistic interaction for 90 continuous minutes. A winning species was recognized when it returned to perch or forage in or near the territory after the encounter.

\section{Dominance hierarchy}

Hummingbird dominance hierarchy was established for each of the floral resources we studied. Dominance hierarchy was calculated using David's score (DS; David 1987). DS has been previously used to determinate the dominance hierarchy in a hummingbird assemblage (López-Segoviano et al. 2017). This method considers the proportion of encounters won and lost by each species' pair as well as the total interactions between both contending species (Gammell et al. 2003) through the following equation: $D S=w+w_{2}-l-l_{2}$, where $w$ represents the sum of the encounters won by species $i$ against species $j$ divided by the total of agonistic interactions between $i$ and $j$ (i.e., $\left.P_{i j}\right), w_{2}$ represents the sum of values $w$ (already weighted by the $P_{i j}$ values of the species with which species $i$ interacted), $l$ represents the sum of the encounters won by species $j$ against species $i$ (i.e., $P_{i j}$ ) and $l_{2}$ represents the sum of the values $l$ (already weighted by the $P_{j i}$ values of the species with which the species $j$ interacted). Species with high DS index values have a higher rank in the dominance hierarchy than the species with lower values.

\section{Genetic distance of contenders}

The genetic distance between the contending species was estimated using genetic mitochondrial sequences available from GenBank (Clark et al. 2015). The sequences were aligned using the ClustalW alignment algorithm (Thompson et al. 1994). Once aligned, the genetic distance between the sequences belonging to the contending species was estimated with the Tamura-Nei model (Tamura and Nei 1993) in the MEGA software version 7.0 (Kumar et al. 2016). The genetic distance is expressed as the number of nucleotide substitutions between two DNA sequences (Piñero et al. 2008); that is, a high genetic distance value indicates a greater degree of divergence between two species. Cytochrome $b$ is the most widely used mitochondrial gene to estimate the genetic distance between species. However, since very few cytochrome $b$ sequences are available for hummingbird species, we used the following sequences of the mitochondrial gene nicotinamide dehydrogenase subunit 2 (sensu Martin and Ghalambor 2014): S. platycercus AY830522; L. clemenciae KJ602257; H. leucotis KJ602252; E. fulgens AY830481 and C. thalassinus EU042544.

\section{Statistical analysis}

We used two generalized linear models (GLM) with a quasi-Poisson error distribution due to overdispersion of the data and the log link function to determine the effect of the identity of the territory owner species, the plant species and the energy (log transformed, to prevent outliers influence) within territories (fixed factors) on the number of inter and intraspecific agonistic interactions (response variables). Likewise, we used a GLM with a binomial distribution and the logit link function to determinate the factors associated with the dominance of larger hummingbirds over the small contenders. In this model we codified the encounters as a dummy response variable, using " 1 " for encounters won by the larger hummingbird and " 0 " for those won by the smallest hummingbird. We also included in the model the plant species, the energy (log transformed) within territories and the genetic distance between contenders with three levels: close $(0.15-0.17)$, medium $(0.18-0.21)$ and wide $(0.22$ or more) as fixed factors. These separation categories were based on the frequency distribution of the genetic distance between bird genera for the same family reported by Johns and Avise (1998). We confirmed that the variables did not have collinearity by means of the variance inflation factor ( $<10$ for all variables; Neter et al. 1990). All statistical analyses were performed using the package "base" (R Development Core Team 2017) of the R software version 3.3.3 (R Development Core Team 2017). 
Table 3. Genetic distance between the hummingbird species at the LMNP

\begin{tabular}{lccccc}
\hline Hummingbird species & S. platycercus & L. clemenciae & H. leucotis & E. fulgens & C. thalassinus \\
\hline Selasphorus platycercus & $*$ & & & & \\
Lampornis clemenciae & 0.15 & 0.18 & $*$ & $*$ \\
Hylocharis leucotis & 0.16 & 0.17 & 0.18 & $* .21$ & $*$ \\
Eugenes fulgens & 0.16 & 0.24 & 0.23 & $*$ \\
Colibri thalassinus & 0.23 & *
\end{tabular}

The genetic distance was calculated using the Tamura-Nei model. "Represents the comparison between intraspecific genetic sequences.

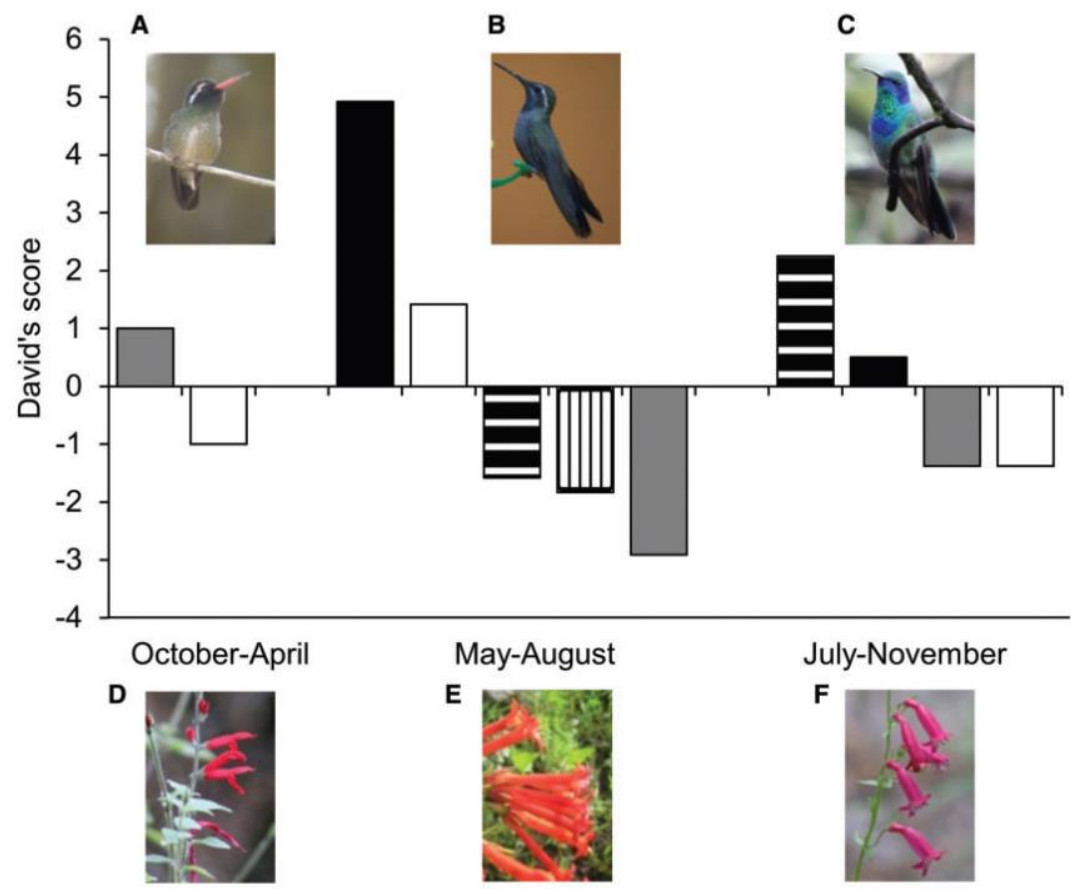

Figure 1. DS for the hummingbird assemblage at LMNP, Mexico, showing the hummingbird species with the higher dominance rank (A) H. leucotis, (B) L. clemenciae and (C) C. thalassinus, through the flowering period of (D) B. ternifolia, (E) S. elegans, and (F) P. roseus. Bars are code-colored as grey (H. leucotis), white (S. platycercus), black (L. clemenciae), horizontal lines (C. thalassinus), and vertical lines (E. fulgens). Photos by Gustavo Hernández-Orta, Carlos Lara, and Ubaldo Márquez.

\section{Results}

We found and monitored a total of 85 hummingbird territories (S. elegans, $n=47$; B. ternifolia, $n=28$ and $P$. roseus, $n=10$ ), that represent 127.5 observation hours. Penstemon roseus had the highest nectar volume and energy produced per flower (Table 1). During our study only E. fulgens did not establish territories, instead acting as a marauder or trapliner in the three flowering seasons throughout the year.

The genetic distance between hummingbird species ranged from 0.15 to 0.24 (Table 3). The widest genetic distance was found between $L$. clemenciae and C. thalassinus $(0.24)$ and the closest between $L$. clemenciae and S. platycercus (0.15).

Different hummingbird species were dominant in each of the three flowering seasons (Figure 1). We recorded 122 agonistic encounters, $75 \%$ of which were intraspecific (92 encounters) and the remainder occurred among hummingbirds of different species (30 encounters; $25 \%$ ). The GLM indicated that the frequency of intraspecific encounters was related with the territory owner species identity $\left(\chi^{2}=9.69, d f=4, P=0.045\right.$; Figure 2 ). However, the plant species identity and the energy contained in a territory had no significant effect on the frequency of intraspecific encounters $\left(\gamma^{2}=\right.$ 5.05, $d f=2, P=0.063$ and $\chi^{2}=0.55, d f=1, P=0.454$, respectively).

The frequency of interspecific encounters was significantly related with the energy within the territories $\left(\chi^{2}=2.57, d f=1\right.$, $P=0.003$; Figure 3$)$ and the territory owner identity $\left(x^{2}=7.32\right.$, $d f=4, P<0.001$; Figure 2$)$. However, the plant species identity had 


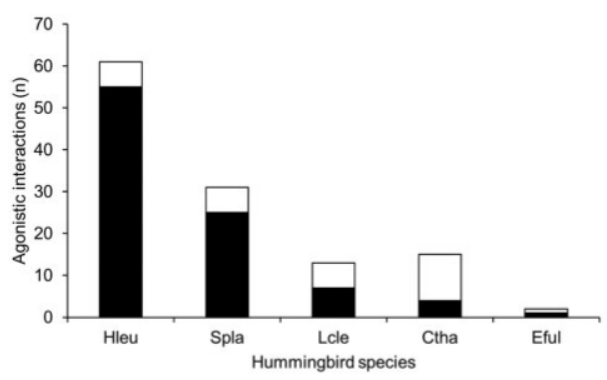

Figure 2. Intraspecific (black bars) and interspecific encounters (white bars won by territory owners. The horizontal axis represents the territory owner's identity: Hleu = Hylocharis leucotis, $\mathrm{Spla}=$ Selasphorus platycercus, Lcle $=$ Lampornis clemenciae, Ctha $=$ Colibri thalassinus, and Eful $=$ Eugenes fulgens.

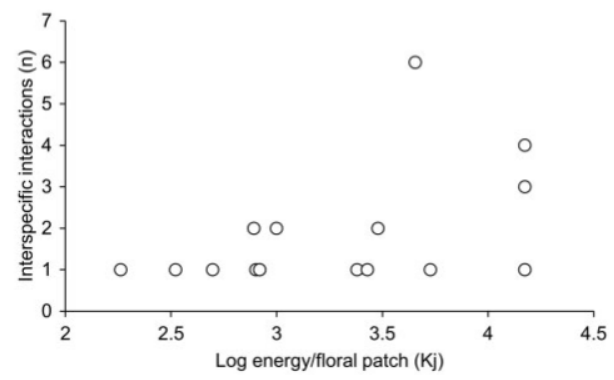

Figure 3. Frequency of encounters between the studied hummingbird species, and the energy contained within their territories.

no significant effect on the frequency of interspecific interactions $\left(\chi^{2}\right.$ $=0.840, d f=2, P=0.252$ ).

Larger hummingbird species dominated $53 \%$ of the interspecific encounters $(n=16)$, while $47 \%(n=14)$ were dominated by species smaller than their contender. There was no significant difference between the number of encounters dominated by larger and smaller species than their competitors $\left(\chi^{2}=30\right.$, g.l. $\left.=29, P=0.41\right)$. The genetic distance was positively associated with a higher frequency of encounters dominated by small hummingbirds $\left(\gamma^{2}=7.31, d f=2\right.$, $P=0.025$; Figure 4). That is, the small hummingbirds dominated more encounters against larger contenders when the genetic distance between contenders was wider (Figure 4). On the contrary, the plant species identity $\left(\chi^{2}=2.78, d f=2, P=0.247\right)$ and the energy within the territory $\left(\gamma^{2}=0.82, d f=1, P=0.362\right)$ did not have a significant effect on the frequency with which large hummingbirds dominated encounters against smaller contenders.

\section{Discussion}

The dominance hierarchy of the hummingbird assemblage in the study site was highly dynamic. The frequency of intraspecific agonistic encounters was associated with identity of the territory owner. Interspecific encounters were related to the energy within the territories and with the identity of the territory owner. There was no

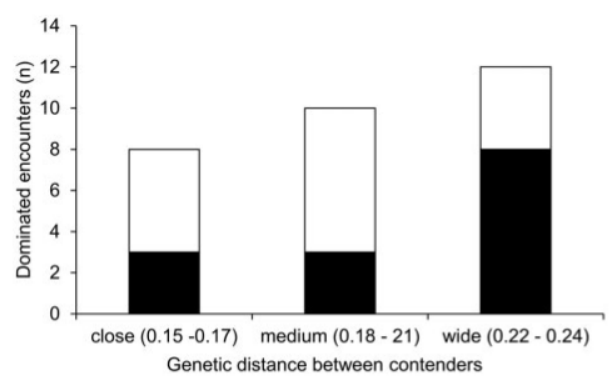

Figure 4. Encounters dominated by larger (white bars) and smaller (black bars) hummingbirds than their contender and the genetic distance between the contenders.

significant difference between the number of encounters dominated by larger and smaller species and their contenders. However, the increase in genetic distance between contenders was positively associated with a higher frequency of encounters dominated by small hummingbirds.

Dominance hierarchy

Dominance hierarchy in the hummingbird assemblage changed during the flowering seasons of the three plant species we studied. The dominant species were H. leucotis, L. clemenciae and C. thalassinus during the sequential flowering periods of S. elegans, B. ternifolia, and $P$. roseus, respectively. Two of these species ( $L$. clemenciae and C. thalassinus) weigh more than $6 \mathrm{~g}$, representing the largest hummingbird species in the assemblage. That is, the higher rank within the dominance hierarchy was associated with large body size species, which coincides with that reported by different authors (Hainsworth and Wolf 1972; Dearborn 1998; Justino et al. 2012). However, these same species were dominated in turn by other hum mingbird species when the available floral resource changed. For example, when $P$. roseus was flowering, the dominant species was $C$. thalassinus and not $L$. clemenciae the species with the highest bod size at that time. These changes in dominance hierarchy could be explained by different factors such as: 1) temporal variability of the hummingbird feeding roles in the assemblage and 2) preference of hummingbird species to defend a specific floral resource.

Temporal variability of hummingbird feeding roles

In our study, $H$. leucotis fits the role of territorialist (sensu Feinsinger and Colwell 1978) in patches of S. elegans. However, its foraging strategy changed from territorial to marauder in the presence of migratory hummingbird species that arrived in the study area at the beginning of the flowering season of B. ternifolia. The change in the hummingbirds foraging role associated to the abundance of competitors has been corroborated experimentally by using feeders and controlling the density and identity of the competitors (Pimm et al. 1985). Even the abundance of competitors could promote a spatial segregation among hummingbird species to maximize energy consumption, and avoid energy and time expenditure in chasing away competitors (Vizentin-Bugoni et al. 2017).

Resource preferences

The hummingbirds preference for exploiting a particular floral re source may be related to traits such as the floral display (number of 
flowers per plant and inflorescence number), the shape and color of the corollas, and the nectar volume and sugar concentration (Meléndez-Ackerman et al. 1997). The floral displays of S. elegans and B. ternifolia are greater than P. roseus. Hummingbirds can visually assess the quality of floral patches by the flower displays; this can drive the foraging preference of both territorial and nonterritorial hummingbirds (Trombulak 1990). In our study, the flowering season of $B$. ternifolia was the only one in which five hummingbird species were present as territorial or territory parasites. Also, in this same flowering season the largest hummingbird in the assemblage ( $L$. clemenciae) had the highest rank in the domin ance hierarchy. Another factor to consider is the structural characteristics of the vegetation in which the plant species grow. For example, in the forested areas the detection of intruders should be more difficult than in open areas, which could drive the intrusion pressure over the territories. Contrarily, territory parasites could prefer the territory owner to detect more easily the intruders in territories of open areas (B. ternifolia), because it would imply that the territory owner spent more time chasing intruders outside the territory boundaries and this period could be used for the filchers to forage in the territory. However, further research is needed to corroborate these hypotheses.

The 3 plant species included in our study share similar morphological traits. They have tubular corollas ranging from 23 to $30 \mathrm{~mm}$ in length. Since the bill length of the hummingbird species was $16-$ $26 \mathrm{~mm}$ (Morales et al. 2012), all the hummingbird species can exploit the floral resources in the study area. Color variation in the corollas was wider, since S. elegans and B. ternifolia have colors ranging from red to reddish salmon, respectively, whereas $P$. roseus has magenta flowers (Pérez et al. 2011). However, it has been reported that hummingbirds learn to associate the color of the corollas with the reward offered by a flower. This association is based on the previous experience of a hummingbird exploiting that same floral resource (Meléndez-Ackerman et al. 1997). Therefore, the preference for a particular floral resource depends on the reward quality and previous experience of hummingbirds and not just on corolla color. Finally, the energy per flower was higher in P. roseus and this could drive the preference of hummingbirds for this floral species.

\section{Agonistic interactions}

The frequency of inter and intraspecific encounters was associated with the territory owner's identity. Most of the recorded agonistic encounters $(75 \%)$ occurred between individuals of the same species. The species with more intraspecific interactions was $H$. leucotis. This hummingbird species was the only one that used advertisement calls as part of their territorial defense in S. elegans floral patches. The advertisement calls might not only deter intruders from stealing resources but also could inform competitors of the presence of a high quality area and encourage their presence (Goldberg and Ewald 1991). This cost-benefit of vocal behavior could explain the higher intraspecific competition between $H$. leucotis individuals. Arguably, agonistic encounters among conspecifics would be frequent because they compete for the same preferred resources (Lyon 1976; Carpenter et al. 1993) and they also share morphological traits that confer to them similar competition abilities (Dearborn 1998). Furthermore, the intraspecific encounters could be motivated by social factors such as the competition and dominance between sexes or age classes (Carpenter et al. 1993), or even may be regulated by their hormone levels (González-Gómez et al. 2014).

In contrast, the occurrence of interspecific interactions was low. Colibri thalassinus was the species that won more interspecific encounters. This hummingbird was dominant during the flowering season of $P$. roseus and expelled larger intruders as $L$. clemenciae. This can be explained through a cost-benefit balance of establishing and defending a foraging territory. The cost of defending $P$. roseus territories could exceed the benefits of exclusive access to nectar from the territory for larger species such as L. clemenciae (KodricBrown and Brown 1978). This reinforces the existence of energy thresholds within which territorial behavior is performed in hummingbirds (Justino et al. 2012; Márquez-Luna et al. 2015). In LMNP, flowering season of $B$. ternifolia and $P$. roseus coincides with the arrival and permanence of migratory hummingbird species, which suggests that in this period the interspecific interactions would have to increase. However, in our study these encounters were scarce (only the $25 \%$ ), suggesting a probable resource segregation which is evidenced in the changes of the species ranks in the dominance hierarchy.

\section{Body size and genetic distance}

There was no a clear dominance of the larger species over the smal contenders, which contrasts with findings in other hummingbird communities (Hainsworth and Wolf 1972; Dearborn 1998; AraújoSilva and Bessa 2010; Justino et al. 2012). However, the frequency of encounters won by smaller species was positively associated with a wider genetic distance between contenders. This pattern could be explained through the differences in the maneuverability, which is associated to the variation in flight-muscle size (Altshuler et al 2010). In hummingbirds, the flight muscles (pectoralissupracoracoideus) amount to $21-30 \%$ of their total weight (Hartman 1961; Greenewalt 1962). However, the muscle capacity is not always related to body mass; for example, C. thalassinus has a greater muscle capacity than larger species (e.g., E. fulgens; Dakin et al. 2018). In this study, C. thalassinus was the species that dominated more competitive interactions versus larger species (e.g., L. clemenciae).

In our study, we did not evaluate the wing loading of the hummingbirds due the lack of data on species' wing area. However, as a surrogate measure, we used span loading (body mass/wing span ${ }^{2}$ which has been used as an estimator of induced power requirements in hovering (Greenewalt 1975). The two hummingbird species with the lowest wing span (Figure 5) were involved in the majority of intraspecific and interspecific encounters $(H$. leucotis and

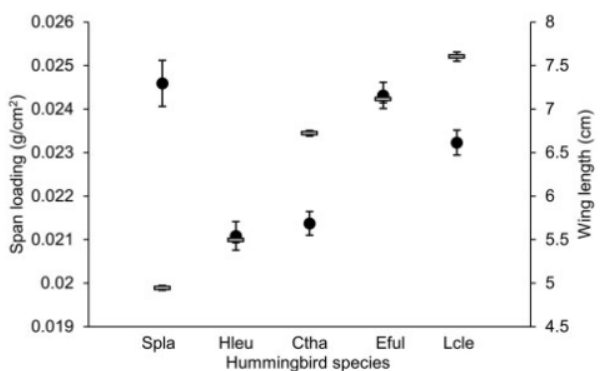

Figure 5. Differences in span loading (black dots) and wing length (white hyphens) between hummingbird species. Vertical lines indicate the standard error and the horizontal axis represents hummingbird species. Species were ordered according to their body mass. Sample sizes are the same as those reported in Table 2 to estimate body size of the hummingbird species. 
C. thalassinus, respectively). These two species also won encounters against larger competitors $(H$. leucotis won encounters against $E$. fulgens and C. thalassinus; C. thalassinus won encounters against $L$. clemenciae). However, S. platycercus, which had the higher span loading (Figure 5), also dominated larger competitors with lower span loading (H. leucotis and C. thalassinus). Dakin et al. (2018) report that smaller species or those with a higher wing loading could use another kind of maneuvers (arcing turns) as a tactical or competitive advantage over competitors. The morphological traits associated with the maneuverability (wing area, muscle capacity, and wing loading) are, on average, conservative within the hummingbird clades, namely closely related species have similar morphologies and maneuvering styles (Skandalis et al. 2017; Dakin et al. 2018). These can explain why some hummingbird clades (e.g., Emeralds) frequently take part in encounters for resources (Márquez-Luna et al. 2018). However, in hummingbirds, the body mass and wing surface may change depending on molting period and food availability (Carpenter et al. 1983; Chai 1997). These changes modify the species maneuverability (Dakin et al. 2018) and, therefore, the competitive skills between species.

The variability in those factors associated to the maneuverability and aggression could promote temporal changes in the dominance hierarchy of hummingbird assemblages. Such temporal dynamic of dominance hierarchy could generate partition of resources, allowing the coexistence of different hummingbird species as a consequence of low levels of interspecific competition (Ornelas et al. 2002). Even at a macroecological scale, resource partitioning and interspecific competition among closely related hummingbirds might also play an important role in structuring interactions in hummingbird-plant networks (Martín González et al. 2015). This highlights the role of the species evolutionary relationships and the possible effects on the way hummingbird species exploit and compete for resource access. Teasing out the varied morphological, physiological, and evolutionary effects on hierarchies is evidently not straightforward, and due to the limited number of encounters observed in this study, we are unable to properly evaluate the role of evolutionary relationships between contender species on the dynamics of dominance hierarchy. This avenue of future research is likely to generate important insights into this field.

\section{Acknowledgments}

We would like to thank Verónica Mendiola, Dalia de la Rosa Perea, and Israel Morales Guzmán for their assistance in the field as well as for their logistical support. Pietro K. Maruyama and 2 anonymous reviewers provided useful comments on previous versions of the manuscript. This work constitutes partial fulfillment of U.M.L's doctorate at the Posgrado en Ciencias Biológicas y de la Salud, Universidad Autónoma Metropolitana.

\section{Funding}

U.M.L. was supported by a doctoral scholarship (425674) from the Consejo Nacional de Ciencia y Tecnología.

\section{References}

Altshuler DL, Dudley R, Heredia SM, McGuire JA, 2010. Allometry of hummingbird lifting performance. J Exp Biol 213:725-734.

Antunes AZ, 2003. Partilha de néctar de Eucalyptus spp., territorialidade e hierarquia de dominância em beija-flores (Aves: trochilidae) no sudeste do Brasil. Ararajuba 11:39-44.
Araújo-Silva LE, Bessa E, 2010. Territorial behaviour and dominance hierarchy of Anthracothorax nigricollis Vieillot 1817 (Aves: trochilidae) on food resources. Revista Brasileira De Ornitologia 18:89-96.

Bolten AB, Feinsinger P, Baker HG, Baker I, 1979. On the calculation of sugar concentration in flower nectar. Oecologia 41:301-304.

Camfield AF, 2006. Resource value affects territorial defense by broad-tailed and rufous hummingbirds. J Field Ornithol 77:120-125.

Carpenter FL, Paton DC, Hixon MA, 1983. Weight gain and adjustment of feeding territory size in migrant hummingbirds. Pro Nat Acad Sci USA 80: 7259-7263.

Carpenter FL, Hixon MA, Russell RW, Paton DC, Temeles EJ, 1993. Interference asymmetries among age-sex classes or Rufous hummingbirds during migratory stopovers. Behav Ecol Sociobiol 33:297-304.

Chai $\mathrm{P}, 1997$. Hummingbird hovering energetics during moult of primary flight feathers. J Exp Biol 200:1527-1536.

Chaves CJ, 1997. Coexistencia de varias especies de colibríes Ermitaños en un parche de Heliconia danielsianna. In: Bolaños F, Lobo y D, Briceño J editors. Curso De Biología De Campo. Costa Rica: Universidad de Costa Rica Facultad de Ciencias Escuela de Biología. 92-97.

Clark K, Karsch-Mizrachi I, Lipman DJ, Ostell J, Sayers EW, 2015. GenBank. Nucleic Acids Res 44:D67-D72.

Corbet SA, 2003. Nectar sugar content: estimating standing crop and secretion rate in the field. Apidologie 34:1-10.

Cotton PA, 1998. Temporal partitioning of a floral resource by territorial hummingbirds. Ibis 140:647-653.

Dakin R, Segre PS, Straw AD, Altshuler DL, 2018. Morphology, muscle capacity, skill and maneuvering ability in hummingbirds. Science 359:653-657. David HA, 1987. Ranking from unbalanced paired-comparison data Biometrika 74:432-436.

Dearborn DC, 1998. Interspecific territoriality by a rufous-tailed hummingbird Amazilia tzacatl: effects of intruder size and resource value. Biotropica 30:306-313.

Dudley R, 2002. Mechanisms and implications of animal flight maneuverability. Integr Comp Biol 42:135-140.

Espino-Espino J, Rosas F, Cuevas-García E, 2014. Variación temporal de visitantes florales en dos especies simpátricas de Salvia con floración simultánea y sindrome de polinización contrastante. Rev Mex Biodivers 85:161-166.

Ewald PW, 1985. Influence of asymmetries in resource quality and age on aggression and dominance in black-chinned hummingbird. Anim Behav 33: 705-719.

Feinsinger P, Colwell RK, 1978. Community organization among Neotropical nectar-feeding birds. American Zoologist 18:779-795.

Gammell MP, Vries HD, Jennings DJ, Carlin CM, Hayden TJ, 2003. David's score: a more appropriate dominance ranking method than Clutton-Brock et al.'s index. Anim Behav 66:601-605.

Goldberg TL, Ewald PW, 1991. Territorial song in the Annás hummingbird, Calypte anna: costs of attraction and benefits of deterrence. Anim Behav 42: 221-226.

González-Gómez PL, Blakeslee WS, Razeto-Barry P, Borthwell RM, Hierbert S et al. 2014. Aggression, body condition, and sesonal changes in sex-steroids in four hummingbird species. J Ornithol 155:1017-1025.

Graham CH, Parra JL, Rahbek C, McGuire JA, 2009. Phylogenetic structure in tropical hummingbird communities. Pro Nat Acad Sci 106: 19673-19678.

Greenewalt CH, 1962. Dimensional relationships for flying animals. Smithson Mis Collect 144:1-46.

Greenewalt $\mathrm{CH}, 1975$. The flight of birds: the significant dimensions, their departure from the requirements for dimensional similarity, and the effect on flight aerodynamics of that departure. Trans Am Phil Soc 65:1-67.

Hartman FA, 1961. Locomotor mechanisms of birds. Smithson Misc Collect 143:1-91.

Hainsworth FR, Wolf LL, 1972. Power for hovering flight in relation to body size in hummingbirds. Am Nat 106:589-596.

Johns GC, Avise JC, 1998. A comparative summary of genetic distances in the vertebrates from the mitochondrial cytochrome $b$ gene. Mol Biol Evol 15: 1481-1490. 
Justino DG, Maruyama PK, Oliveira PE, 2012. Floral resource availability and hummingbird territorial behaviour on a Neotropical savanna shrub. J Ornithol 153:189-197.

Kodric-Brown A, Brown JH, 1978. Influence of economics, interspecific competition, and sexual dimorphism on territoriality of migrant rufous hummingbirds. Ecology 59:285-296.

Kumar S, Stecher G, Tamura K, 2016. MEGA7: molecular evolutionary genetics analysis version 7.0 for bigger datasets. Mol Biol Evol 33:1870-1874.

Lara C, 2006. Temporal dynamics of flower use by hummingbirds in a Highland temperate forest in Mexico. Ecoscience 13:23-29.

Lara C, Lumbreras K, González M, 2009. Niche partitioning among hummingbirds foraging on Penstemon roseus (Plantaginaceae) in Central Mexico. Ornitol Neotrop 20:73-83.

Lara C, Martinez-Garcia V, Ortiz-Pulido R, Bravo-Cadena J, Loranca S et al., 2011. Temporal-spatial segregation among hummingbirds foraging on honeydew in a temperate forest in Mexico. Curr Zool 57:56-62.

Lara C, Ornelas F, 2002. Flower mites and nectar production in six hummingbird-pollinated plants with contrasting flower longevities. Can Bot 80:1216-1229.

Lara C, Ornelas F, 2008. Pollination ecology of Penstemon roseu (Plantaginaceae), an endemic perennial shifted toward hummingbird spe cialization? Plant Sys Evol 271:223-237.

López-Segoviano G, Bribiesca R, Arizmendi MDC, 2017. The role of size and dominance in the feeding behaviour of coexisting hummingbirds. Ibis 160:283-292.

Lyon DL, 1976. A montane hummingbird territorial system in Oaxaca, Mexico. Wilson Bull 88:280-290.

Márquez-Luna U, Lara C, Corcuera P, Valverde PL, 2018. Efecto del tamaño corporal y distancia evolutiva en las interacciones agonísticas de colibríes (Trochilidae). Rev Mex Biodivers 89:149-162.

Márquez-Luna U, Lara C, Ortiz-Pulido R, 2015. La conducta territorial de Zafiro Oreja Blanca Hylocharis leucotis es afectada por la disponibilidad de energía. Ornitol Neotrop 26:13-23.

Martín González AM, Dalsgaard B, Nogués-Bravo D, Graham CH, Schleuning M et al. 2015. The macroecology of phylogenetically structured hummingbird-plant networks. Glob Ecol Biogeogr 24:1212-1224.

Martin PR, Ghalambor CK, 2014. When David beats Goliath: the advantage of large size in interspecific aggressive contests declines over evolutionary time. PLoS One 9: e108741.

McGuire JA, Witt CC, Remsen JV, Corl A Jr, Rabosky DL et al. 2014. Molecular phylogenetics and the diversification of hummingbirds. Curr Biol 24:910-916.

Mendiola-Islas V, Lara C, Corcuera P, Valverde PL, 2016. Residency in white-eared hummingbirds Hylocharis leucotis and its effect in territorial contest resolution. Peer ] 4: e2491.

Meléndez-Ackerman E, Campbell DR, Waser NM, 1997. Hummingbird behavior and mechanisms of selection on flower color in Ipomopsis. Ecology $78: 2532-2541$.

Montgomerie RD, Gass CL, 1981. Energy limitation of hummingbird populaion in tropical and temperate communities. Oecologia 50:162-16.
Morales GI, Lara C, Castillo-Guevara C, 2012. Transporte diferencial de polen por colibries en una planta distílica: no es lo mismo picos cortos que largos. Huitzil 13:74-86.

Neter J, Wasserman W, Kutner MH, 1990. Applied linear statistical models. Regression, analysis of variance, and experimental design. Homewood (IL): Irwin.

Ornelas JF, Ordano M, Hernández A, López JC, Mendoza L et al. 2002. Nectar oasis produced by Agave marmorata Roezl. (Agavaceae) lead to spatial and temporal segregation among nectarivores in the Tehuacán Valley, México. J Arid Environ 52:37-51.

Pérez G, Lara C, Viccon-Pale J, Signoret-Poillon M, 2011. Memory for location and visual cues in white-eared hummingbirds Hylocharis leucotis. Curr Zool 57:468-476.

Pimm SL, Rosenzweig ML, Mitchell W, 1985. Competition and food selection: field tests of a theory. Ecology 66:798-807.

Piñero D, Barahona A, Eguiarte L, Olivares AR, Lizana RS, 2008. La variabilidad genética de las especies: aspectos conceptuales y sus aplicaciones y perspectivas en México. En Capital natural de México, vol. I: Conocimiento actual de la biodiversidad. CONABIO, México. 415-435.

R Development Core Team, 2017. R: A Language and Environment for Statistical Computing. Vienna: R Foundation for Statistical Computing. Russell WR, Carpenter FL, Hixon MA, Paton DC, 1994. The impact of variation in stopover habitat quality on migrant rufous hummingbirds. Conserv Biol 8:483-490.

SMN, 2018. Normales climatológicas por Estado. Servicio Meteorológico Nacional. Retrieved 20 June, 2018, from http://smn.cna.gob.mx/es/.

Skandalis DA, Segre PS, Bahlman JW, Groom DJE, Welch KC Jr et al. 2017. The biomechanical origin of extreme wing allometry in hummingbirds. Nat Comm 8:1047.

Stiles FG, 1980. The annual cycle in a tropical wet forest hummingbird community. Ibis 122:322-343.

Stiles FG, Wolf LL, 1970. Hummingbird territoriality at a tropical flowering tree. Auk 87:467-491.

Tamura K, Nei M, 1993. Estimation of the number of nucleotide substitutions in the control region of mitochondrial DNA in humans and chimpanzees. Mol Biol Evol 10:512-526.

Thompson JD, Higgins DGR, Gibson T, 1994. CLUSTAL W: improving the sensitivity of progressive multiple sequence alignment through sequence weighting, position-specific gap penalties and weight matrix choice. Nucleic Acids Res 22:4673-4680.

Trombulak SC, 1990. Assessment of territory value by a tropical hummingbir Amazilia saucerottei. Biotropica 22:9-15.

Vizentin-Bugoni J, Sonne J, Hodum P, Hagens E, Cordeiro J, 2017. Spatial segregation of the endemic versus non-endemic hummingbird on Robinson Crusoe Island, Chile: the effect of competitor abundance but not resources or habitat. J Ornithol 158:793-798.

Wolf LL, Stiles FG, Hainsworth FR, 1976. Ecological organization of a tropical, highland hummingbird community. J Anim Ecol 45:349-379. 


\section{Capítulo III}

Diferencias en rasgos morfológicos y su influencia en el rango que ocupan las especies de colibríes dentro de una jerarquía de dominancia 


\section{Introducción}

Las interacciones bióticas tienen un papel importante sobre la estructuración de las comunidades ecologías (Araújo y Rozenfeld 2014). En los colibríes (Trochilidae), el papel de la competencia por el acceso a los recursos florales ha sido sugerido como la principal fuerza involucrada en definir la estructura y composición de los ensambles de especies (Wolf et al. 1976, Graham et al. 2009, Lara et al. 2011). Los colibríes han establecido una relación cercana con las plantas de las que extraen el néctar floral debido a que su tamaño corporal, su tipo de vuelo y su acelerada tasa metabólica los obliga a tener acceso a un gran número de flores para cubrir sus demandas energéticas (Montgomerie y Gass 1981, Cotton 2007).

Las especies de colibríes con una mayor masa corporal tienden a dominar a especies más pequeñas relegándolas del acceso a los recursos florales (MárquezLuna et al. 2018; Bribiesca et al. 2019). Es por esto que las especies más grandes suelen ocupar los rangos más altos dentro de las jerarquías de dominancia. No obstante, estas jerarquías de dominancia son dinámicas, es decir, el rango que ocupan las especies dentro de la jerarquía es variable. Estos cambios pueden estar asociados a la variabilidad en la abundancia y disponibilidad de recursos, al cambio estacional en la composición del ensamble de colibríes e incluso a la preferencia de las especies por consumir un recurso específico (Márquez-Luna et al. 2019). Lo anterior implica, que opuesto a lo predicho, no siempre las especies más grandes dominarán la jerarquía. Martin y Ghalambor (2014) postularon una hipótesis alternativa que explica la jerarquización de la dominancia, la cual establece que las especies pequeñas de colibríes tendrán mayor probabilidad de ganar contiendas contra especies más grandes si ambas especies se encuentran distantemente relacionadas filogenéticamente. Dichos autores sugieren que a lo largo del tiempo evolutivo las especies pequeñas pudieron acumular rasgos morfológicos (mayor desarrollo muscular) o fisiológicos (mayor producción de testosterona, estradiol o deshidroepiandrosterona) que les permiten compensar la desventaja competitiva de un menor tamaño corporal. La variabilidad en los rasgos 
morfológicos y fisiológicos puede generar una divergencia conductual entre las especies (Dakin et al. 2018). Esta divergencia puede ser aprovechada por las especies pequeñas de colibríes para ganar contiendas contra competidores más grandes. Lo anterior implica que la distancia genética entre las especies de colibríes podría ser un factor importante en la resolución de contiendas por el acceso a un recurso específico.

Todos los métodos para determinar una jerarquía de dominancia interespecífica se basan en la frecuencia de contiendas ganadas y perdidas por cada especie. El resultado de las contiendas frecuentemente se asocia a diferentes características morfológicas que brindan ventajas competitivas a las especies ganadoras, principalmente una mayor masa corporal. Aunque se ha determinado que la masa corporal es un factor importante en definir el resultado de las contiendas agonísticas, aún no se ha determinado la magnitud de la diferencia entre la masa corporal de dos contendientes para que este factor resulte en una ventaja competitiva.

La diferencia de masa corporal entre la especie de colibrí más grande (Patagona gigas $=20-22 \mathrm{~g}$ ) y la más pequeña (Mellisuga helenae $=1.6-2.6 \mathrm{~g}$ ) puede ser de hasta 19.4 gramos si consideramos el peso máximo reportado para ambas especies por Schuchmann (1999). Si bien, dichas especies no son simpátricas, esta comparación representa la mayor diferencia que puede registrarse entre la masa corporal de dos especies de colibríes. Dentro de los ensambles de colibríes es frecuente encontrar a varias especies pertenecientes a un mismo género (e.g., Saucerottia) compitiendo por el acceso a los recursos. En este sentido, dichas especies presentarán características morfológicas similares ya que estás suelen ser conservativas dentro del mismo clado (Dakin et al. 2018). La diferencia de la masa corporal entre especies de colibríes dentro de un mismo ensamble puede ser de varios gramos (e.g., la masa corporal entre Lampornis clemenciae $=8.39 \pm 0.12$ y Selasphorus platycercus $3.74 \pm 0.07 \mathrm{~g}$ ) o incluso inferior a un gramo (e.g., la masa corporal entre Basilinna leucotis $=3.95 \pm 0.06 \mathrm{~g}$ y Selasphorus platycercus $=3.74 \pm 0.07$ g; Márquez-Luna et al. 2019). Además, se 
ha reportado que algunas especies migratorias de colibríes suelen incrementar su masa corporal en hasta $0.5 \mathrm{~g}$ en un solo día (Carpenter et al. 1983). A pesar de la naturaleza variable y las diferencias, en algunos casos mínimas, entre la masa corporal de algunas especies de colibríes, esta característica se considera determinante en el resultado de las contiendas y por lo tanto en el rango que las especies ocupan dentro de la jerarquía de dominancia. No obstante, además de la masa corporal otros rasgos morfológicos son importantes antes y durante las contiendas agonísticas interespecíficas de colibríes, los cuales serán descritos a continuación.

Las contiendas interespecíficas de colibríes por el acceso a los recursos en general constan de la siguiente secuencia de eventos conductuales: un colibrí monopoliza el acceso a un recurso agregado espacialmente (e.g., un parche floral), este colibrí dueño del territorio percha en alguna rama alta sobre dicho parche floral. Posteriormente, desde la percha, el colibrí dueño puede usar mecanismos de defensa pasiva como vocalizaciones o despliegues visuales de las plumas de la gorguera o vuelos en torno al territorio (Baptista y Schuchmann 1990; Goldberg y Ewald 1991). Estas conductas tienen un carácter de advertencia contra los posibles competidores. En cuanto al otro colibrí (intruso) se acerca a las flores del parche defendido, el colibrí dueño comienza una persecución para expulsar al intruso fuera del territorio. Estas persecuciones suelen ser muy rápidas y tienden a ser ganadas por el colibrí dueño del territorio (Mendiola-Islas et al. 2016), el cual regresa a perchar a la rama de vigilancia o alimentarse del néctar de las flores que defiende. Se ha documentado que durante estas contiendas los colibríes pueden usar sus picos para apuñalar, sujetar e incluso arrancar plumas al intruso (RicoGuevara y Araya-Salas 2015; Rico-Guevara et al. 2019). Bajo este contexto, la longitud del pico de las especies podría ser una ventaja competitiva importante en la resolución de las contiendas y por lo tanto, influir sobre el rango que las especies ocupan dentro de la jerarquía de dominancia, un factor que no ha sido considerado previamente. 
En el presente estudio determinamos la jerarquía de dominancia del ensamble de colibríes en un Bosque de Niebla del centro de Veracruz, México, durante la floración de uno de los principales recursos florales durante primavera y verano en la zona, Palicourea padifolia (Rubiaceae). Además, evaluamos si la masa corporal y la longitud del culmen expuesto de los contendientes, son rasgos asociados al rango que las especies ocupan dentro de la jerarquía de dominancia. Finalmente, evaluamos si la diferencia en la masa corporal, la longitud del culmen expuesto y la distancia genética entre contendientes, así como el número de flores en los territorios influyen la probabilidad de que 1) los colibríes de mayor masa corporal ganen las contiendas agonísticas contra especies más pequeñas; y que 2) los colibríes con mayor rango jerárquico de dominancia ganen las contiendas agonísticas contra colibríes con menor rango.

\section{Métodos}

El trabajo de campo se realizó en el Santuario de Bosque de Niebla del INECOL, A. C. (a partir de aquí SBN), en Xalapa Veracruz (9656'16.20”W, $19^{\circ} 30^{\prime} 47.2^{\prime \prime} \mathrm{N}$ a 1225 m s.n.m.). De acuerdo a los datos colectados por la estación climatológica las Animas (96 $\left.53^{\circ} 06^{\prime \prime} \mathrm{W}, 19^{\circ} 30^{\prime} 00^{\prime \prime} \mathrm{N}\right)$ de 1981 a 2010 (SMN 2019), la temperatura media anual fue de $19.3^{\circ} \mathrm{C}$ y la precipitación media anual $1368.2 \mathrm{~mm}$. El área de estudio conserva un remanente de 30 ha de Bosque de Niebla. Palicourea padifolia (Roem. y Schult.) C. M. Taylor y Lorence (Rubiaceae) es un arbusto de 2 a 7 metros de altura, aunque también puede presentarse como un árbol pequeño de hasta 10 metros. Se distribuye entre los 800 y 2400 m s.n.m. del centro de México hasta Panamá y es un elemento común de los bosques de niebla (Taylor 1989). Las plantas de $P$. padifolia normalmente presentan entre $30-40$ inflorescencias y en cada una abren entre 2 - 4 flores por día durante la temporada de floración la cual se extiende desde mediados de marzo hasta agosto (Contreras y Ornelas 1999; Ornelas et al. 2004a). El pico de abundancia floral se presenta entre mayo y junio (Contreras y Ornelas 1999). Esta especie es distílica, es decir, presenta dos formas florales. La forma floral "pin" o "forma-L" presenta un estigma largo y anteras cortas, mientras la forma "thrum" o "forma-S" 
tiene un estigma corto y anteras largas (Ornelas et al. 2004a). La proporción de ambas formas florales en la localidad de estudio tiene una relación de 1:1 (Ornelas et al. 2004, Hernández-Ramírez 2018). No se reportan diferencias significativas en el número de inflorescencias producidas o el número de flores que abren por día entre ambas formas florales (Contreras y Ornelas 1999; Ornelas et al. 2004a). Aunque se han reportado diferencias en la producción de néctar (mayor en la forma-L) y concentración de azúcar (mayor en la forma-S) entre ambas formas florales (Ornelas et al. 2004a). Sin embargo, ambas formas florales son igualmente visitadas por los colibríes presentes en el área de estudio (Ornelas et al. 2004b). Debido a lo anterior, no consideramos la forma floral de las plantas que conformaron los territorios de forrajeo estudiados. Las flores de $P$. padifolia son tubulares de color amarillo con una longitud promedio de $14.95 \pm 0.26 \mathrm{~mm}(N=20$ flores de 20 plantas distintas) que producen un volumen de néctar de entre 0.59 $0.73 \mu \mathrm{h} \mathrm{h}^{-1}$ con una concentración de azúcar de $15.7-17.5^{\circ}$ BRIX (Ornelas et al. 2004a). Las flores de $P$. padifolia duran un solo día, abren al amanecer y se marchitan al anochecer (Ornelas et al. 2004a). Lo anterior genera un constante cambio en la abundancia y disponibilidad floral para los colibríes. Once especies de colibríes (Colibri thalassinus, Anthracothorax prevostii, Eugenes fulgens, Lampornis amethystinus, Selasphorus heloisa, Pampa curvipennis, Campylopterus hemileucurus, Saucerottia cyanocephala, S. beryllina, Amazilia yucatanensis, Chlorestes candida) y algunos insectos, principalmente Himenópteros y Lepidópteros visitan las flores de P. padifolia (Ornelas et al. 2004a). Se ha reportado que en el área de estudio varias de estas especies de colibríes (e. g., $P$. curvipennis, S. cyanocephala, A. yucatanensis) establecen y defienden territorios de forrajeo en torno a parches de $P$. padifolia (Ornelas et al. 2004a, Jiménez et al. 2012).

El horario de las búsquedas de territorios de forrajeo y registro conductual de los colibríes fue de 8:00 a 13:00 horas. Este periodo se ha reportado como el de mayor actividad en los colibríes (Lara 2006) e incluye el pico de actividad de forrajeo de los colibríes en flores de $P$. padifolia en el área (9:30 - 10:30 horas; Ornelas et al. 2004a). El trabajo de campo se realizó del 15 de junio al 3 de 
septiembre de 2017. Determinamos que un parche floral de $P$. padifolia era un territorio de forrajeo mediante el cumplimiento de los siguientes criterios: el colibrí dueño del territorio (1) perchó dentro o cerca del parche floral observado, (2) forrajeó en las flores del parche floral, y (3) defendió el territorio expulsando a los intrusos mediante persecuciones o vocalizaciones (Camfield 2006, Márquez-Luna et al. 2015, Mendiola-Islas et al. 2016, Márquez-Luna et al. 2019).

Identificamos al colibrí dueño del territorio a través de su conducta vocal, ya que algunas especies territoriales realizan vocalizaciones constantes como parte de la defensa pasiva de su territorio (Goldberg y Ewald 1991). Adicionalmente, los colibríes dueños de territorios utilizaron pocas perchas altas sobre o cerca del parche floral defendido. Desde estas perchas vocalizaron y regresaron a ellas después de una persecución o de forrajear. Durante el periodo de observación identificamos las perchas preferidas del colibrí dueño del territorio y esto nos ayudó a determinar que estábamos observando al mismo individuo antes y después de una persecución (Márquez-Luna et al. 2015, Márquez-Luna et al. 2019).

Identificamos 27 parches florales como territorios de forrajeo. Observamos cada uno de estos territorios de forrajeo en una sola ocasión por 90 minutos continuos. Durante este periodo registramos: 1) la especie del colibrí dueño del territorio y de los colibríes intrusos y 2 ) la especie ganadora de cada interacción agonística interespecífica o contienda. Consideramos una contienda a las persecuciones o enfrentamientos cuerpo a cuerpo entre el colibrí dueño del territorio y los intrusos. Todas las contiendas comenzaron dentro del territorio, pero en muchas ocasiones derivaron en persecuciones para expulsar a los intrusos fuera de los límites del mismo. En estos casos definimos a la especie ganadora de acuerdo a su conducta al finalizar la contienda, ya que el individuo ganador siempre regresó a perchar dentro o cerca del territorio o forrajear dentro del mismo. Al concluir el periodo de observación se contaron las flores de $P$. padifolia para tener una estimación de los recursos disponibles dentro de cada territorio.

\section{Estimación de los rangos en la jerarquía de dominancia}


La jerarquía de dominancia del ensamble de colibríes del SBN se estableció utilizando la modificación al método de puntuación Elo propuesta por SánchezTojar et al. (2017). El método original de puntuación Elo (Elo 1978), establece que el orden en el cual se desarrollaron las contiendas afecta la inferencia de los rangos de dominancia, ya que después de conocer el resultado de cada contienda la puntuación de los contendientes se actualiza (añadiendo puntos al ganador y restándolos al perdedor). La magnitud del cambio en la puntuación de ambos contendientes se establece de acuerdo a la probabilidad de que uno de los dos contendientes gane el encuentro y esta probabilidad cambiará con cada enfrentamiento entre dos contendientes específicos con base a la siguiente ecuación:

$p A=1 /(1+\exp (-0.01($ Elo $A-E l o B)))$

Donde $p A$ es la probabilidad de que gane la especie $A$, mientras que EloA será la puntuación de la especie $A$ antes de la contienda y $E l o B$ será la puntuación de la especie $B$ antes de la contienda. Por ejemplo, dos especies contendientes que jamás se han enfrentado comenzarán con una puntuación de "0", por lo cual tendrán la misma probabilidad de ganar la contienda $(p A=0.5)$.

Después de conocer el resultado de una contienda (e.g., que la especie $A$ ganara dicha contienda) la puntuación de cada especie se actualizará como sigue:

$E l o A^{\prime}=E l o A+(1-p A) k$

$E l o B^{\prime}=E l o B-(1-p A) k$

Donde EloA será la puntuación de la especie $A$ antes de la contienda, EloB será la puntuación de la especie $B$ antes de la contienda, $k$ será la constante que determinará la escala a la cual las puntuaciones cambiarán (en este caso 200, sensu Sánchez-Tojar et al. 2017) y $p A$ será la probabilidad previamente calculada (e. g., 0.5 siguiendo con el ejemplo previamente establecido). La puntuación de ambas especies se actualiza sumando puntos a la especie ganadora y restándolos a la perdedora, en este caso, la puntuación actualizada de la especie ganadora $(A)$ 
después de la contienda sería $E l o A^{\prime}=100$, mientras que la puntuación de la especie perdedora $(B)$ sería $E l o B^{\prime}=-100$.

Sánchez-Tojar et al. (2017) proponen una modificación a este método que consiste en aleatorizar el orden en el cual ocurrieron las contiendas $(n=1000$ aleatorizaciones) permitiendo obtener una puntuación Elo promedio y además intervalos de confianza del 95\% para cada especie. La puntuación Elo de cada especie es equivalente a un rango dentro de la jerarquía de dominancia, puntuaciones Elo altas representarán rangos más altos dentro de la jerarquía de dominancia, mientras que puntuaciones bajas estarán asociadas a rangos inferiores. Las especies con un rango alto (1 o cercano a 1) dentro de la jerarquía serán dominantes sobre aquellas con rangos inferiores (e.g., una especie con rango 2 será dominante sobre una especie con rango 3). El rango más bajo será cercano o igual al número de especies incluidas en la jerarquía de dominancia. En este trabajo, excluimos del análisis a cuatro especies de colibríes que participaron en menos de 10 contiendas (ie., Anthracothorax prevostii, Lampornis amethystinus, Selasphorus heloisa y Amazilia yucatanensis). Lo anterior para garantizar que las especies dentro de la jerarquía usaron las contiendas como principal estrategia para acceder al néctar floral. Este método se ha utilizado para determinar la jerarquía de dominancia interespecífica entre aves paseriformes que compitieron por el acceso a semillas en estaciones de alimentación (Francis et al. 2018). Para calcular la aleatorización de la puntuación Elo usamos el paquete de R aniDom v. 0.1.4 (Farine y Sánchez-Tójar 2017).

\section{Diferencias morfológicas entre contendientes}

Usamos datos de masa corporal y longitud del culmen expuesto (de aquí en adelante longitud del pico) colectados en el SBN durante la temporada de floración de $P$. padifolia de 1999 (Lara datos no publicados). De las especies de colibríes estudiadas solamente 2 presentan dimorfismo sexual (E. fulgens y $S$. cyanocephala). En el caso de dichas especies los datos morfológicos utilizados corresponden a machos. Utilizando estos datos calculamos la diferencia entre la 
masa corporal y la longitud del pico de la especie ganadora y perdedora de cada enfrentamiento registrado.

\section{Distancia genética entre contendientes}

A cada especie de colibrí registrada como visitante de $P$. padifolia le asignamos el clado correspondiente al que pertenecen de acuerdo a McGuire et al. (2014). Estimamos la distancia genética entre las especies que participaron en cada contienda utilizando secuencias genéticas mitocondriales disponibles en Genbank. Las secuencias fueron alineadas mediante el algoritmo de alineamiento ClustalW. Una vez alineadas, estimamos la distancia genética entre las secuencias pertenecientes a las especies de colibríes contendientes utilizando el modelo de Tamura-Nei (Tamura y Nei 1993) mediante el software MEGA versión 7.0 (Kumar et al. 2016). La distancia genética se expresa como el número de sustituciones nucleotídicas entre dos secuencias de ADN (Piñero et al. 2008), es decir, un valor alto de distancia genética indicará un mayor grado de divergencia entre dos especies. Para estimar la distancia genética entre las especies de colibríes utilizamos secuencias del gen mitocondrial NADH subunidad 2 (ND2) debido a que tiene una alta variabilidad a lo largo del tiempo (tasa promedio $=0.0081$ sustituciones/sitio/millón de año; Nabholz et al. 2016). En el presente estudio utilizamos las siguientes secuencias del gen mitocondrial NADH subunidad 2 (ND2), (sensu Martin y Ghalambor 2014): Colibri thalassinus EU042544; Eugenes fulgens AY830481; Pampa curvipennis KC858427; Saucerottia cyanocephala KJ602167; S. beryllina KJ602161 y Chlorestes candida KJ602164. En el caso de que estuviera disponible más de una secuencia genética para cada especie seleccionamos la secuencia con origen geográfico más cercano a la región del estudio.

\section{Análisis estadísticos}

Para determinar si el rango que las especies ocuparon dentro de la jerarquía de dominancia está relacionado con la masa corporal y la longitud del pico, realizamos una regresión sobre el componente principal. Lo anterior, debido a que 
la masa corporal y la longitud del pico están correlacionadas $\left(r^{2}=0.74, F_{1,4}=\right.$ 11.69, $P=0.02$ ). Primero, obtuvimos un componente principal conformado por la masa corporal y la longitud del pico de las especies mediante un análisis de componentes principales (Eigenvalor del componente $=1.85939$; porcentaje de varianza explicada $=92.97$; Factor loading, masa corporal $=0.9642$ ) .

Posteriormente, realizamos una regresión lineal donde utilizamos dicho componente principal como variable explicativa del rango que las especies de colibríes ocuparon en la jerarquía de dominancia. Por otro lado, realizamos dos modelos lineales generalizados con distribución de error binomial y función de enlace probit. En el primer modelo evaluamos si la probabilidad de que el colibrí de mayor masa corporal gane las contiendas está influenciada por las diferencias en la masa corporal, longitud del pico y distancia genética entre contendientes así como por el número de flores dentro de cada territorio. En este modelo la variable de respuesta fue el resultado de cada contienda, donde los enfrentamientos ganados por el contendiente más grande fueron categorizados como "1", mientras que los enfrentamientos ganados por contendientes más pequeños fueron categorizados como "0". En el segundo modelo evaluamos si la probabilidad de que el contendiente de mayor rango de dominancia gane las contiendas está influenciada por las diferencias en la masa corporal, longitud del pico y distancia genética entre contendientes, así como por el número de flores dentro de cada territorio. En este modelo la variable de respuesta fue el resultado de cada contienda, donde si el enfrentamiento fue ganado por el contendiente de mayor rango la contienda se categorizó como "1", mientras que si la contienda fue ganada por el contendiente de menor rango fue categorizada como "0". Todos los análisis estadísticos fueron realizados en R v.3.5.3 (R Core Team 2019). Para realizar las gráficas usamos el paquete ggplot2 v. 3.1.0 (Wickham 2016).

\section{Resultados}

A lo largo del estudio evaluamos 27 territorios de forrajeo ( 40.5 horas de observación) en los cuales registramos a diez especies de colibríes forrajeando en flores de P. padifolia (Colibri thalassinus, Anthracothorax prevostii, Eugenes 
fulgens, Lampornis amethystinus, Selasphorus heloisa, Pampa curvipennis, Saucerottia cyanocephala, Saucerottia beyllina, Amazilia yucatanensis y Chlorestes candida). De las especies registradas la más abundante fue $S$. cyanocephala. Campylopterus hemileucurus ha sido reportado como un visitante floral de $P$. padifolia (Ornelas et al. 2004b), sin embargo, en el presente estudio no registramos la presencia de esta especie. Registramos 149 interacciones agonísticas, de las cuales 66\% (99 contiendas) fueron interespecíficas y $44 \%$ intraespecíficas (50 contiendas). Excluimos de los análisis las contiendas intraespecíficas y a las especies que no cumplieron con un mínimo de participación en 10 contiendas. Debido a lo anterior, el total de datos utilizados en los análisis fue de 82 contiendas interespecíficas. Las especies analizadas junto con sus características morfológicas y el número de contiendas ganadas y perdidas por cada especie se muestran en la Tabla 1. Eugenes fulgens ocupó el rango más alto dentro de la jerarquía de dominancia, mientras que, la especie menos dominante fue $C$. candida (Tabla 1).

Tabla 1. Masa corporal, longitud del pico y rango de dominancia de las especies de colibríes en el SBN. El rango de dominancia de cada especie y sus intervalos de confianza fueron calculados mediante el método de aleatorización de la puntuación Elo (Sánchez-Tójar et al. 2017). Se indica la masa corporal y la longitud del pico promedio y su error estándar. El tamaño de muestra para los datos morfológicos es de 15 individuos para cada especie. $\mathrm{G}=$ ganadas, $\mathrm{P}=$ perdidas; IC = intervalos de confianza.

\begin{tabular}{lccccccc}
\hline & Masa & Longitud & Rango de & & \multicolumn{2}{c}{ Contiendas } \\
\cline { 5 - 8 } Especie & corporal & $\begin{array}{c}\text { del pico } \\
(\mathrm{g})\end{array}$ & $\begin{array}{c}\text { Rm }) \\
\text { dominancia }\end{array}$ & & & G $95 \%$ & $\mathrm{P}$ \\
\hline \hline Eugenes fulgens & $6.9 \pm 0.04$ & $29.4 \pm 0.03$ & 1.73 & 1 a 4 & 24 & 10 \\
Pampa curvipennis & $9.5 \pm 0.03$ & $27.2 \pm 0.02$ & 1.87 & 1 a 4 & 31 & 12 \\
Colibri thalassinus & $5.1 \pm 0.03$ & $21.04 \pm 0.1$ & 2.91 & 1 a 4 & 9 & 6 \\
Saucerottia beryllina & $4.08 \pm 0.06$ & $19.48 \pm 0.03$ & 3.73 & 2 a 5 & 8 & 6 \\
Saucerottia cyanocephala & $4.6 \pm 0.05$ & $19.6 \pm 0.02$ & 4.90 & 3 a 6 & 9 & 38 \\
Chlorestes candida & $3.7 \pm 0.03$ & $17.3 \pm 0.02$ & 5.86 & 5 a 6 & 1 & 10 \\
\hline \hline
\end{tabular}


El rango de la distancia genética entre las especies de colibríes estudiadas fue de 0.037 a 0.193 (Tabla 2). La mayor distancia genética entre especies contendientes (0.193) ocurrió entre dos pares de especies $(C$. thalassinus y $P$. curvipennis; $C$. thalassinus y $S$. beryllina). En ambos casos se trata de la relación entre un Mango y una Esmeralda. Por otro lado, la distancia genética más cercana (0.037) ocurrió entre dos especies de género Saucerottia (S. beryllina y $S$. cyanocephala) perteneciente al clado de las Esmeraldas. Las contiendas entre $E$. fulgens y $P$. curvipennis fueron las más frecuentes con 18 contiendas totales entre ambas especies.

Tabla 2. Distancia genética y contiendas totales entre las especies de colibríes del SBN. Los valores por debajo de la diagonal representan la distancia genética estimada a través del modelo de Tamura-Nei. Por encima de la diagonal se muestra el total de contiendas entre las especies. Eful = Eugenes fulgens, Pcur = Pampa curvipennis, Ctha = Colibri thalassinus, Sber = Saucerottia beryllina, Scya $=$ Saucerottia cyanocephala, y Ccan = Chlorestes candida.

\begin{tabular}{lcccccc}
\hline \hline Clado & Mango & Gema & \multicolumn{4}{c}{ Esmeraldas } \\
\hline Especies & Ctha & Eful & Pcur & Scya & Sber & Ccan \\
\hline \hline Ctha & $*$ & 4 & 3 & 8 & 0 & 0 \\
Eful & 0.184 & $*$ & 18 & 9 & 2 & 1 \\
Pcur & 0.193 & 0.164 & $*$ & 15 & 3 & 4 \\
Scya & 0.190 & 0.191 & 0.174 & $*$ & 9 & 6 \\
Sber & 0.193 & 0.182 & 0.169 & 0.037 & $*$ & 0 \\
Ccan & 0.180 & 0.151 & 0.171 & 0.134 & 0.124 & $*$ \\
\hline \hline
\end{tabular}

Un mayor rango dentro de la jerarquía de dominancia estuvo asociado significativamente a especies de colibríes con una mayor longitud del pico y una mayor masa corporal $\left(r^{2}=0.7825, F_{1,4}=14.39, P=0.0192\right.$, Figura 1). 


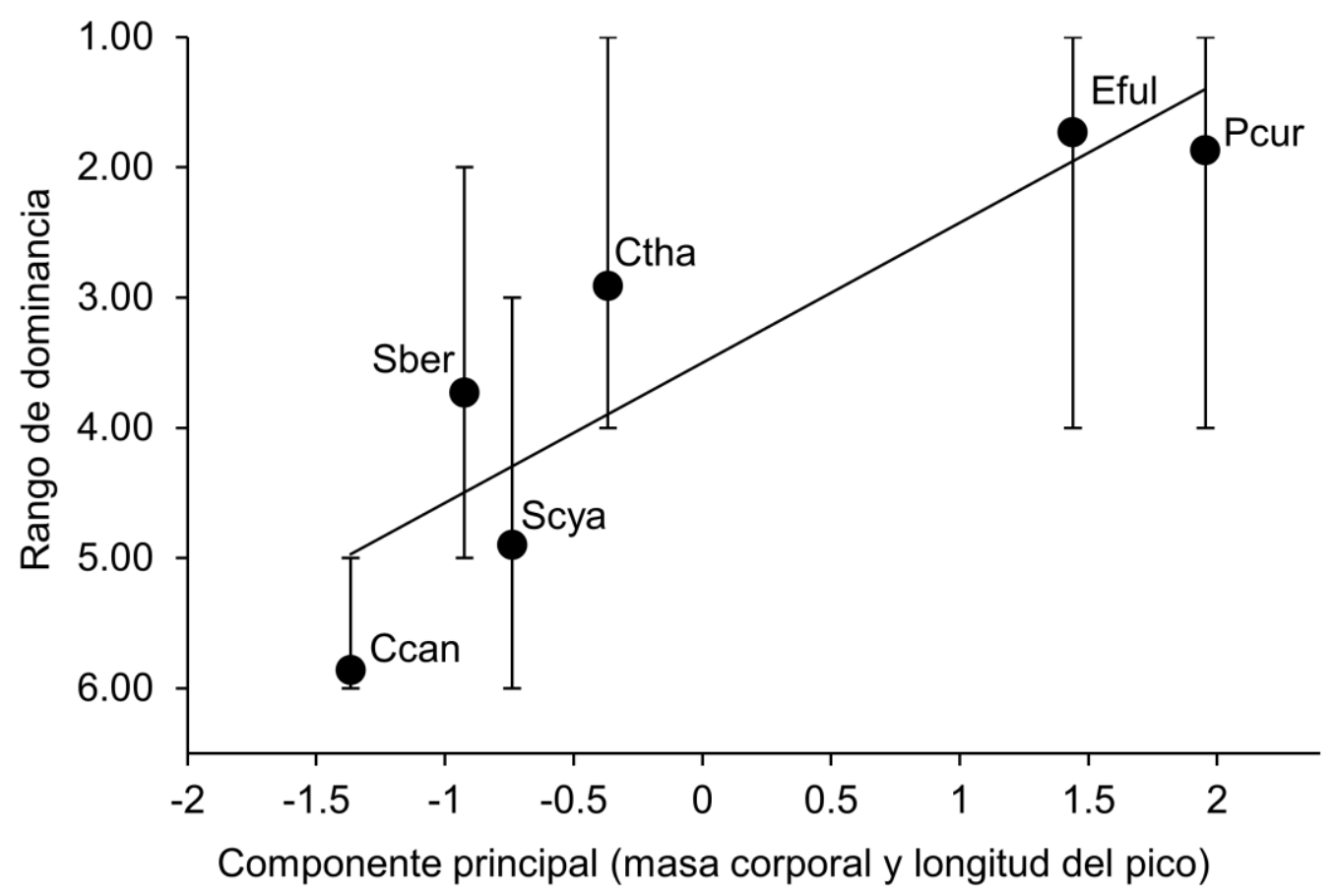

Figura 1. Relación entre el componente principal (la masa corporal y longitud del pico) y el rango de dominancia que ocuparon las especies de colibríes dentro de la jerarquía de dominancia. Los círculos negros representan el rango de cada especie dentro de la jerarquía de dominancia y las líneas verticales los intervalos de confianza del 95\%. El eje " $x$ " (rango de dominancia) fue invertido para mostrar el incremento de la dominancia a lo largo del eje "y" (componente principal). Ctha $=$ Colibri thalassinus, Eful $=$ Eugenes fulgens, Pcur $=$ Pampa curvipennis, Scya $=$ Saucerottia cyanocephala, Sber $=$ Saucerottia beryllina y Ccan $=$ Chlorestes candida.

La probabilidad de que el contendiente más grande ganara las contiendas estuvo asociada significativamente a las diferencias de masa corporal $\left(X^{2}=6.93\right.$, $\mathrm{gl}=1, P=0.008$; Figura $2 \mathrm{~A})$, longitud del pico $\left(X^{2}=9.91, \mathrm{gl}=1, P=0.001\right.$; Figura 2B) y distancia genética entre contendientes $\left(X^{2}=6.43, \mathrm{gl}=1, P=0.011\right.$; Figura 2C). Por otro lado, el número de flores no estuvo asociado a la dominancia de los contendientes grandes sobre los pequeños $\left(X^{2}=1.35, \mathrm{gl}=1, P=0.24\right)$. 


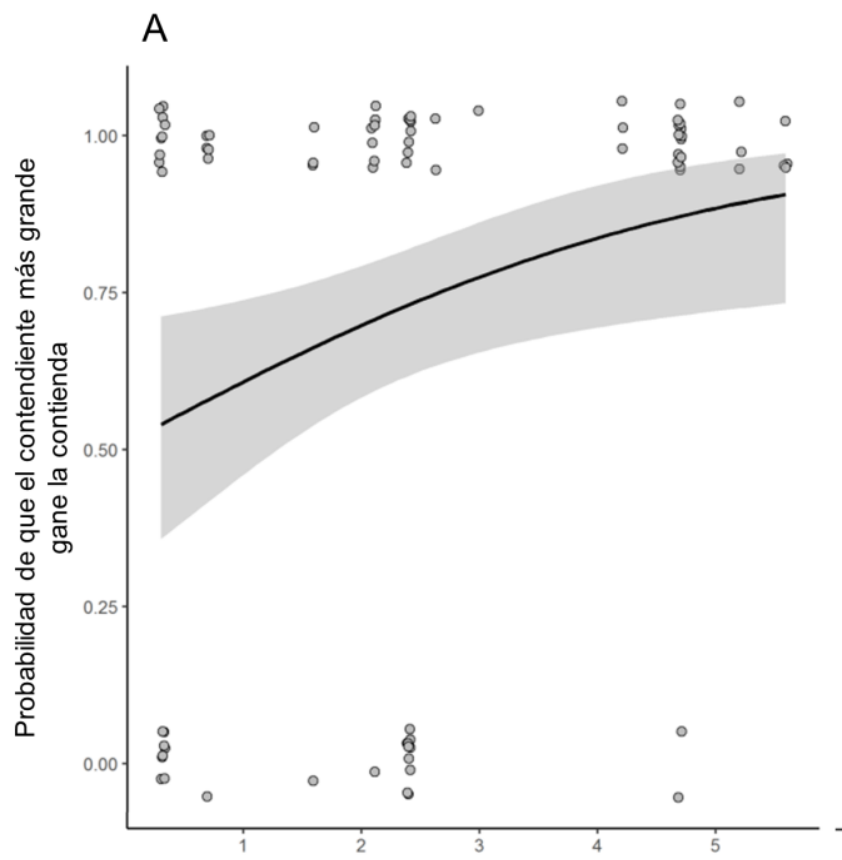

Diferencia entre la masa corporal de los contendientes (g)
B
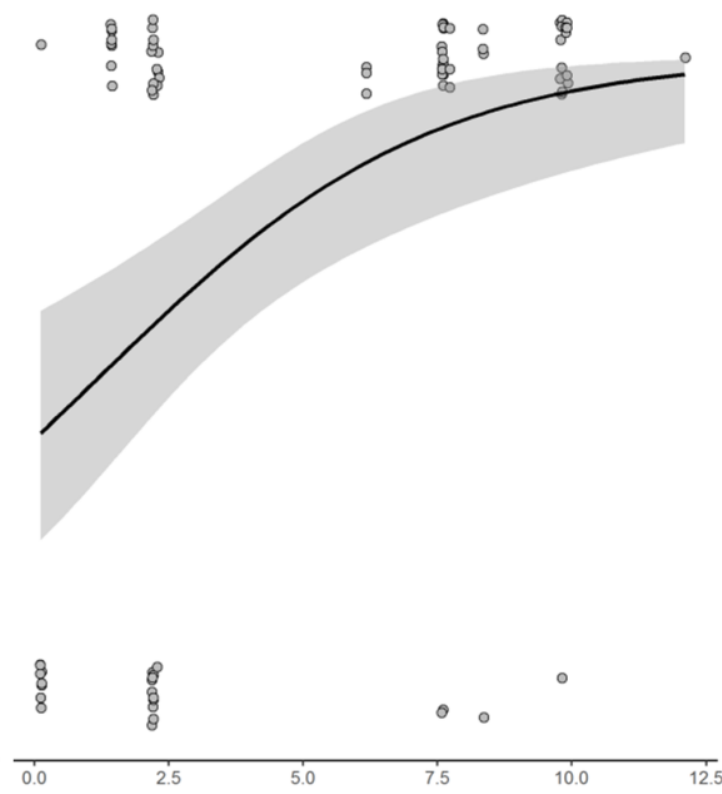

Diferencia entre la longitud del pico de los contendientes ( $\mathrm{mm}$ )
C

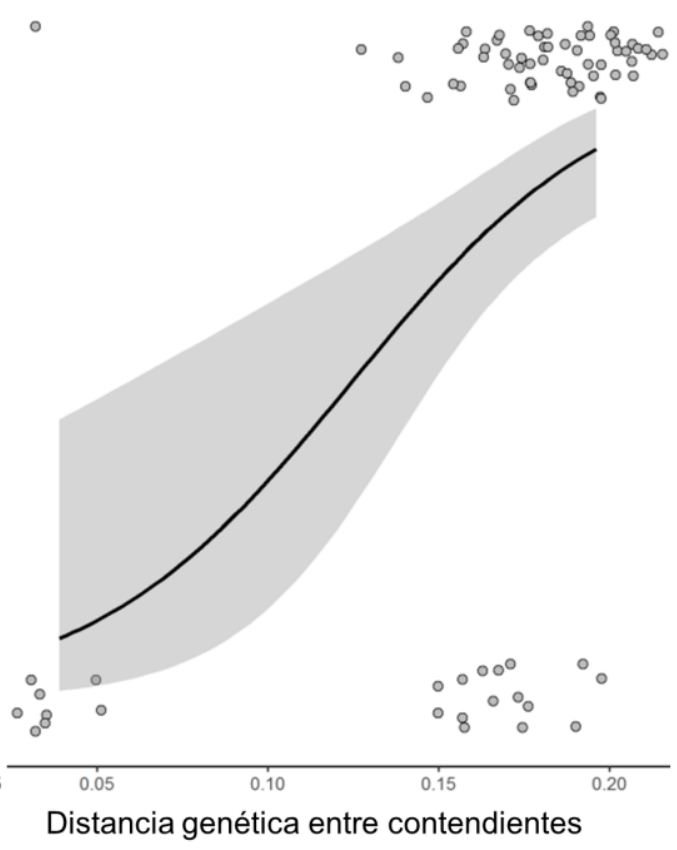

Distancia genética entre contendientes

Figura 2. Contiendas ganadas por el competidor más grande "1" y más pequeño "0" como función de la diferencia entre (A) la masa corporal, (B) la longitud del pico y (C) la distancia genética entre colibríes contendientes. Los puntos grises representan el resultado de cada contienda. Las líneas negras representan la probabilidad de que el competidor con mayor masa corporal de cada interacción agonística gane la contienda. Dicha probabilidad fue estimada a través de un GLM con distribución de error binomial. La sombra gris representa los intervalos de confianza del 95\%.

71 
La probabilidad de que el contendiente de mayor rango dentro la jerarquía de dominancia ganara las contiendas estuvo asociada significativamente al número de flores dentro del territorio $\left(X^{2}=12.76, \mathrm{gl}=1, P<0.01\right.$; Figura 3 ). Por el contrario, las diferencias morfológicas de masa corporal $\left(X^{2}=0.13, \mathrm{gl}=1, P=0.71\right)$, longitud del pico $\left(X^{2}=2.65, \mathrm{gl}=1, \mathrm{P}=0.10\right)$ y distancia genética entre contendientes $\left(X^{2}=0.29\right.$, $\mathrm{gl}=1, P=0.58)$ no estuvieron asociadas a la dominancia de los colibríes de mayor rango sobre contendientes de menor rango.

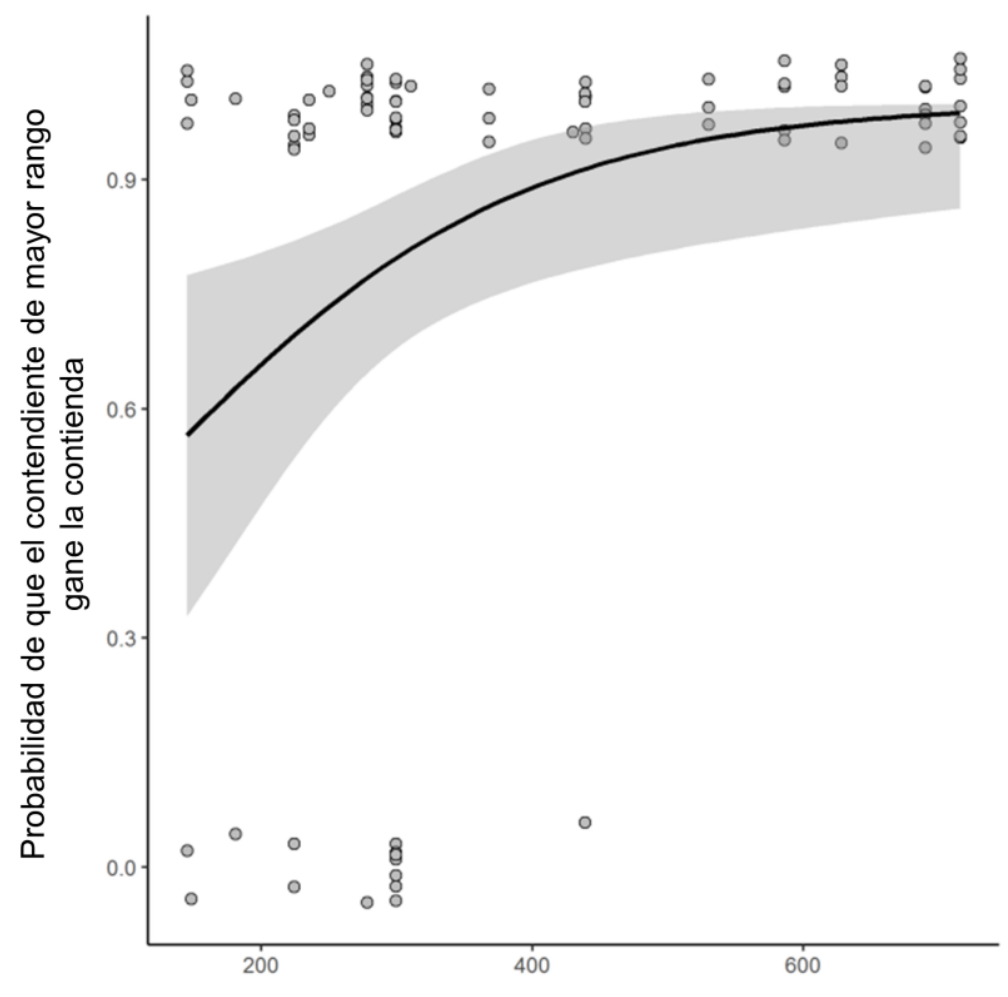

Flores de Palicourea padifolia en el territorio ( $n$ )

Figura 3. Contiendas ganadas por el competidor de mayor rango "1" y por el de menor rango "0" como función del número de flores de $P$. padifolia en el territorio. La línea negra representa la probabilidad de que el competidor de mayor rango gane la contienda. Dicha probabilidad fue estimada a través de un GLM con distribución de error binomial. La sombra gris representa los intervalos de confianza del 95\%.

\section{Discusión}


Nuestros resultados indican que durante la floración de $P$. padifolia se estableció una jerarquía de dominancia entre las distintas especies que conforman el ensamble de colibríes y que compiten por el acceso a este recurso floral. Un mayor rango dentro de la jerarquía de dominancia estuvo asociado positiva y significativamente a especies de colibríes con una mayor longitud del pico y masa corporal. La probabilidad de que el contendiente más grande ganara las contiendas estuvo relacionada significativamente a las diferencias en la masa corporal, la longitud del pico y la distancia genética entre contendientes. Por otro lado, la probabilidad de que el contendiente con mayor rango dentro de la jerarquía de dominancia ganara las contiendas estuvo relacionada positivamente a un mayor número de flores en los territorios.

\section{Jerarquía de dominancia}

La jerarquía de dominancia durante la floración de P. padifolia se conformó principalmente por las especies de colibríes que establecieron y defendieron territorios como su estrategia de forrajeo (C. thalassinus, E. fulgens, $P$. curvipennis, $S$. cyanocephala y $S$. beryllina). Chlorestes candida fue la única especie dentro de la jerarquía que no estableció territorios de forrajeo, sin embargo, participó en más de 10 contiendas contra especies territoriales por lo cual fue posible estimar su rango dentro de la jerarquía de dominancia (sensu Francis et al. 2018). Al determinar jerarquías de dominancia interespecíficas es importante considerar que aunque las especies compitan por el acceso a un recurso específico éstas pueden desarrollar estrategias diferentes que eviten su participación en interacciones agonísticas (e.g., parásitos de territorios, establecimiento de rutas de forrajeo, forrajeo en recursos no defendidos o en recursos asociados a otros polinizadores). La inclusión de estas especies podría generar sesgos en el orden de dominancia, sobre todo si se utilizan métodos que no estimen la incertidumbre del rango que ocupan las especies dentro de la jerarquía. En el caso de los colibríes, Feinsiger y Colwell (1978) definieron los diferentes roles que las especies pueden ocupar dentro de una comunidad (i.e. territoriales, ruteros, parásitos de territorio, generalistas). De estos roles, los ruteros y los parásitos de territorio no suelen participar en contiendas agonísticas por el 
acceso a recursos florales (Feinsinger y Colwell 1978). Los ruteros establecen un plan de vuelo en el cual visitan diferentes localidades de alimentación de forma secuencial (Ohashi y Thomson 2009), evitando así las contiendas por el acceso a las flores. De forma similar algunas especies de colibríes, regularmente pequeñas, parasitan los territorios de forrajeo y suelen no ser detectados por el colibrí dueño del territorio, por lo cual no es frecuente su participación en contiendas agonísticas (Feinsinger y Colwell 1978). En el presente estudio observamos que S. heloisa parasitó de forma exitosa territorios de forrajeo. Esta especie aprovechó los momentos donde el colibrí dueño del territorio salía a expulsar a algún intruso para forrajear en las flores dentro del territorio y solamente fue detectado y expulsado en una ocasión. Consideramos que al inferir una jerarquía de dominancia interespecífica se deben incluir especies que utilicen estrategias de forrajeo similares o que accedan a los recursos florales a través del uso de contiendas agonísticas, con el fin de evitar sesgos en el rango que ocupan las especies dentro de la jerarquía.

Un mayor rango dentro de la jerarquía de dominancia estuvo asociado positivamente a especies con una mayor masa corporal y una mayor longitud del pico. La especie que ocupó el rango más alto dentro de la jerarquía de dominancia fue Eugenes fulgens (rango =1.73), esta especie tiene el pico más largo del ensamble (masa corporal $=6.9 \pm 0.04 \mathrm{~g}$, longitud del pico $=29.4 \pm 0.03 \mathrm{~mm}$ ), mientras Pampa curvipennis (rango $=1.87$ ) que es la especie con mayor masa corporal del ensamble (masa corporal $=9.5 \pm 0.03 \mathrm{~g}$, longitud del pico $=27.2 \pm 0.02 \mathrm{~mm}$ ) ocupó un rango ligeramente menor que $E$. fulgens. En el caso de los colibríes, se ha reportado que las especies de mayor masa corporal tienden a desplazar a las especies más pequeñas del acceso a los recursos florales, es decir, una mayor masa corporal se asocia a un rango mayor de dominancia (Márquez-Luna et al. 2018, Bribiesca et al. 2019). Este patrón se ha encontrado en otras localidades, donde las especies más grandes dominaron al resto de las especies del ensamble de colibríes. Por ejemplo, Amazilia tzacatl $(5.1 \mathrm{~g})$ ganó contiendas contra el resto de las especies que competían por el acceso a flores de Hamelia patens en Costa Rica (Thalurania colombica, 4.6 g; Amazilia amabilis $4.1 \mathrm{~g}$; Klais guitmeti 2.95 g; y Microchera albocoronota $2.52 \mathrm{~g}$; Dearborn 1998) o Eupetomena macroura $(8.5 \mathrm{~g})$ que fue la 
especie más dominante en un ensamble de 8 especies de colibríes en Brasil (e.g., Colibri serrirostris $7 \mathrm{~g}$; Amazilia fimbriata $4.6 \mathrm{~g}$; Chlorostilbon lucidus $3.4 \mathrm{~g}$ o Heliactin bilophus $2.5 \mathrm{~g}$; Justino et al. 2012).

Con base en nuestros resultados y a los de otros autores la masa corporal podría ser considerada como un buen indicador del rango que las especies pueden ocupar dentro de las jerarquías de dominancia (López-Segoviano et al. 2017, Francis et al. 2018). Sin embargo, la masa corporal podría enmascarar otros factores importantes asociados a las habilidades competitivas que influyen el resultado de las contiendas y, por lo tanto, el rango que ocupan las especies en la jerarquía de dominancia. Por ejemplo, la aceleración en el vuelo confiere ventajas competitivas a los colibríes y recientemente fue atribuida a una mayor capacidad muscular más que a la masa corporal de las especies (Dakin et al. 2018). Además de lo anterior, la masa corporal de los colibríes puede variar drásticamente alcanzando un incremento de entre 0.25 - 0.50 gramos/día durante la migración en sitios de reabastecimiento (e.g., Selasphorus rufus; Carpenter et al. 1983). Adicionalmente, se ha reportado que en condiciones controladas Calypte anna y Calypte costae pueden llegar a incrementar su peso hasta 0.69 y 0.53 gramos respectivamente durante el día. Sin embargo, durante la noche presentan una pérdida de peso constante de entre 0.042 - 0.053 gramos/hora (Powers 1991). Esto sugiere que los colibríes en vida libre también podrían presentar estas fluctuaciones diarias en la masa corporal. Sin embargo, es necesario desarrollar investigación al respecto, ya que esta variación en la masa corporal podría afectar las habilidades competitivas de las especies (Dakin et al. 2018).

Por otro lado, una mayor longitud del pico también podría conferir ventajas competitivas en contiendas interespecíficas. Se ha reportado que durante las contiendas los colibríes pueden usar el pico para apuñalar, sujetar y arrancar plumas a los intrusos (Rico-Guevara y Araya-Salas 2015, Rico-Guevara et al. 2019). Inclusive algunas especies desarrollan estructuras en los picos como puntas afiladas parecidas a dagas, ganchos y aserraciones, que aunque han sido relacionadas con la perforación de las corolas para el robo de néctar (Lara y Ornelas 2001), también 
pueden tener un papel en las contiendas. Estas estructuras son dimórficas y se desarrollan como caracteres sexuales secundarios (i.e., presentes en machos adultos; Rico-Guevara y Araya-Salas 2015, Rico-Guevara y Hurne 2019, RicoGuevara et al. 2019). Es importante considerar que algunos rasgos morfológicos (e.g., longitud y ancho del pico) pueden presentar variaciones significativas entre poblaciones de la misma especie. Se ha reportado que esta variabilidad morfológica

puede ser el resultado de las diferentes condiciones y recursos a las que han estado expuestas las poblaciones a lo largo del tiempo (e.g., Saucerottia cyanocephala, Rodríguez-Gómez et al. 2013; Eugenes fulgenes, Zamudio-Beltrán et al. 2020). Se debe continuar explorando el papel que juega el pico de los colibríes y sus características en el resultado de las contiendas interespecíficas y las jerarquías de dominancia en diferentes ensambles.

\section{Diferencia entre el tamaño corporal y longitud del pico entre contendientes}

La probabilidad de que los contendientes más grandes ganaran las contiendas estuvo relacionada a las diferencias en la masa corporal, la longitud del pico y la distancia genética entre contendientes. Nuestros resultados indican que cuando la diferencia entre la masa corporal de los contendientes es igual o menor a un gramo; ambos contendientes (el más grande y el más pequeño) tienen probabilidades similares de ganar la contienda (Figura 2 A). Por otro lado, mientras mayor sea la diferencia en la masa corporal de los contendientes incrementa la probabilidad de que el contendiente con mayor masa corporal gane la contienda. Este patrón es similar al reportado en otros grupos animales (e.g., peces poecilidos Xiphophorus helleri, Beaugrand y Cotnoir 1996; el anolis verde Anolis carolinensis, Bush et al. 2016; el ratón doméstico Mus musculus, Varholick et al. 2018). Estos estudios sugieren que el efecto del tamaño corporal se diluye cuando se enfrentan contendientes con masas corporales similares y el orden en la jerarquía de dominancia se vuelve inestable o es explicado por otras características morfológicas (Bush et al. 2016) o por la experiencia previa de los contendientes (Beaugrand y Cotnoir 1996). 
La diferencia en la longitud del pico entre contendientes tuvo el mismo patrón que la masa corporal. Cuando la diferencia entre el pico de los contendientes fue menor o igual a $2.5 \mathrm{~mm}$, ambos contendientes tuvieron la misma probabilidad de ganar. Dicha probabilidad incrementó a medida que la diferencia entre el pico de los contendientes lo hizo. El contendiente con una mayor longitud de pico podría tener ventajas competitivas ya que durante las persecuciones podría arrancar plumas e inclusive provocar lesiones en el colibrí que está persiguiendo. Además del riesgo de lesión, la pérdida de plumas podría generar un costo energético para el colibrí perdedor al tener que invertir energía en la síntesis de queratina para remplazar las plumas pérdidas (King y Murphy 1990). Sin embargo, es complicado documentar estas conductas en campo ya que regularmente duran unos segundos y las persecuciones suelen terminar fuera de la vista del observador (pers. obs.). Estas agresiones difícilmente dejarían una marca visible para el observador por lo cual una alternativa sería el uso de nuevas tecnologías (e.g., cámaras de alta velocidad) bajo condiciones controladas (e.g., ensayos en cautiverio; Rico-Guevara et al. 2019). Los resultados de estas observaciones podrían brindar información para describir estas conductas y su impacto en la resolución de las contiendas. En el presente estudio la especie más dominante fue Eugenes fulgens (masa corporal $=6.9 \mathrm{~g}$, longitud del pico $=29.4 \mathrm{~mm}$ ), incluso tuvo un rango mayor que Pampa curvipennis (masa corporal $=9.5 \mathrm{~g}$, longitud del pico $=27.2 \mathrm{~mm}$ ), la especie con mayor masa corporal del ensamble. Registramos 18 contiendas entre ambas especies de las cuales 10 fueron ganas por $E$. fulgens, mientras que las restantes ocho fueron ganadas por $P$. curvipennis. López-Segoviano et al. (2017) reportan que E. fulgens también fue la especie más dominante de su ensamble de estudio, incluso por encima de Lampornis clemenciae, una especie con mayor masa corporal. Estos resultados podrían ser evidencia del papel de la longitud del pico como una ventaja competitiva en las contiendas agonísticas entre colibríes, sin embargo, es necesaria mayor investigación al respecto.

Chase y Seitz (2011) definieron dos grandes grupos de variables que pueden influir en el resultado de las contiendas agonísticas, 1) las diferencias en atributos y 2) las diferencias en condiciones conductuales o estadios. Los atributos son 
características morfológicas (e.g., tamaño corporal), fisiológicas (e.g., niveles hormonales) o incluso genéticas (e.g., expresión de genes asociados con las conductas sociales), mientras que las condiciones conductuales o estadios están asociados a procesos de aprendizaje, por ejemplo, la experiencia de haber ganado o perdido contiendas anteriores o la residencia previa en un territorio. En el caso de los colibríes se han documentado procesos de aprendizaje observacional y relacionados a la experiencia. Por ejemplo, se sabe que conforme aumenta el tiempo de exposición a nuevos recursos (e.g., bebederos) con néctar con diferente concentración de azúcar, las hembras de Calothorax lucifer aumentan la frecuencia de contiendas agonísticas en torno a los recursos de mayor calidad energética (Márquez-Luna et al. 2017). Asimismo, en Basilinna leucotis se ha obtenido evidencia del efecto que tiene la residencia previa en territorios de forrajeo sobre el resultado de las contiendas agonísticas (Mendiola-Islas et al. 2016). Estos factores podrían ser relevantes cuando las diferencias morfológicas (e.g., masa corporal, longitud del pico) sean mínimas entre las especies contendientes o en contiendas intraespecíficas.

\section{Distancia genética entre contendientes}

La distancia genética entre contendientes estuvo relacionada significativamente a la probabilidad de que el contendiente más grande ganara las contiendas. El patrón muestra que, a una menor distancia genética, los contendientes de menor tamaño corporal tienen mayor probabilidad de ganar las contiendas. Esto contrasta con lo planteado por Martin y Ghalambor (2014), quienes postulan que los contendientes de menor tamaño corporal tendrán más probabilidad de ganar contiendas contra competidores más grandes cuando exista una mayor distancia genética entre los contendientes. Sin embargo, este resultado contrastante puede ser explicado por la influencia de la composición de especies del ensamble estudiado. El rango de distancia genética entre las especies de colibríes de este ensamble fue amplio (0.037 a 0.193) en comparación al rango reportado en otros ensambles de colibríes (e.g., 0.15 a 0.24 en el PNLM, Márquez-Luna et al. 2019). Sin embargo, el 68\% de las contiendas (i.e., 55 contiendas) ocurrió entre colibríes con una distancia genética de 
0.164 a 0.193 . Por otro lado, el $11 \%$ de las contiendas registradas (i.e., 9 contiendas) ocurrieron entre especies del mismo género ( $S$. beryllina y $S$. cyanocephala) con una distancia genética entre ellas muy baja $(0.037)$ y características morfológicas muy similares $(S$. beryllina, masa corporal $=4.08 \mathrm{~g}$, longitud del pico $=19.48 \mathrm{~mm} ; S$. cyanocephala, masa corporal $=4.6 \mathrm{~g}$, longitud del pico $=19.6 \mathrm{~mm}$ ). Como se mencionó previamente, en las contiendas entre especies similares morfológicamente factores como la experiencia o la residencia previa pueden ser factores determinantes para definir a la especie ganadora de una contienda. La importancia y tendencia que tendrá la distancia genética entre los contendientes en la resolución de contiendas agonísticas estará determinada por la composición de especies del ensamble e inclusive por la historia de diversificación del grupo. En este estudio $E$. fulgens y $P$. curvipennis fueron las especies que se enfrentaron más frecuentemente (18 contiendas entre ambas especies). La distancia genética entre estas especies fue de 0.164 y ganó más frecuentemente $E$. fulgens (10 contiendas), que en este caso fue la especie más pequeña de la interacción. Si bien el resultado anterior apoya a la hipótesis propuesta por Martin y Ghalambor (2014), hubo interacciones entre especies de colibríes que no se ajustan a este patrón. Por ejemplo, se estimó la mayor distancia genética (0.193) entre Colibri thalassinus y Pampa curvipennis y entre $C$. thalassinus y Saucerottia beryllina. Entre C. thalassinus y P. curvipennis registramos 3 contiendas, con base en la hipótesis de Martin y Ghalambor (2014) C. thalassinus tendría que haber ganado dichas contiendas, sin embargo las 3 contiendas fueron ganadas por $P$. curvipennis. Por otro lado, no registramos contiendas entre $C$. thalassinus y $S$. beryllina. Adicionalmente, se ha reportado que los colibríes pertenecientes al clado de las Esmeraldas suelen ser dominantes en comparación a otros grupos de colibríes (Márquez-Luna et al. 2018, Bribiesca et al. 2019). Sin embargo, los resultados de este estudio indican que Eugenes fulgens (Gema de Montaña) fue la especie más dominante de este ensamble incluso por encima de Pampa curvipennis (Esmeralda).

\section{Rango dentro de la jerarquía y flores en el territorio}


La probabilidad de que el contendiente con mayor rango ganara las contiendas estuvo asociada positivamente al número de flores de $P$. padifolia en los territorios de forrajeo. Los colibríes con un menor rango solo ganaron algunas contiendas cuando el número de flores en el territorio fue menor a 439 flores. Este patrón podría reflejar el valor intrínseco de los territorios con mayor número de flores y la relación costo benéfico de defender un territorio de forrajeo. Un territorio de forrajeo deberá cubrir el costo energético asociado a establecer y defender el territorio de intrusos, inclusive se ha asociado la conducta territorial de los colibríes a umbrales energéticos dentro de los cuales las especies establecen territorios de forrajeo (Kodric-Brown y Brown 1978, Justino et al. 2012, Márquez-Luna et al. 2015). En los territorios con más de 500 flores de $P$. padifolia, las contiendas fueron ganadas en su totalidad por el contendiente de mayor rango. Dichos territorios serían de mayor calidad al contener más energía disponible para el colibrí dueño, por lo cual podría incrementar la intensidad y el tiempo invertido de la defensa del territorio. Se ha reportado que la intensidad de la defensa está determinada por la precepción del valor que el colibrí dueño tiene del territorio defendido (Kuban et al. 1983, Dearborn 1998).

Las jerarquías de dominancia en ensambles de colibríes son dinámicas y diferentes factores pueden modificar el orden que las especies ocupan dentro de la jerarquía (Márquez-Luna et al. 2019). Se ha reportado que uno de los factores más relevantes en determinar el orden que las especies ocupan dentro de la jerarquía de dominancia es la masa corporal (Bribiesca et al. 2019, López-Segoviano et al. 2018). Nuestros resultados indican que cuando las especies de colibríes contendientes son similares morfológicamente (e.g., masa corporal o longitud del pico) ambos contendientes tendrán probabilidades semejantes de ganar la contienda. Por otro lado, la importancia de la distancia genética entre los contendientes dependerá de la composición de especies del ensamble. Además de lo anterior, la abundancia y disponibilidad floral afectará la conducta de los colibríes, desde el establecimiento de territorios de forrajeo y la intensidad de su defensa hasta las estrategias de forrajeo que utilizará cada especie de acuerdo a sus requerimientos energéticos. Estudiar y comprender los mecanismos que determinan el rango que las especies ocupan dentro de las jerarquías de dominancia permitirá entender de mejor manera los 
patrones de coexistencia de diferentes especies y su respuesta conductual a los cambios en la composición de especies. Dichos cambios se dan en ambos grupos de interactuantes, como por ejemplo la llegada de colibríes migratorios o la introducción de especies de plantas exóticas en la red de interacción colibrí-planta, lo cual debe ser considerado en futuros estudios. 


\section{DISCUSIÓN GENERAL}

Los principales resultados de este trabajo permiten entender que las relaciones de dominancia entre especies de colibríes derivan de la interacción de múltiples factores. En esta tesis determinamos que los siguientes factores intervienen en las contiendas por el acceso a recursos y por lo tanto contribuyen en la determinación del rango que las especies ocupan dentro de las jerarquías de dominancia: 1) El contexto ecológico, es decir, la disponibilidad de recursos florales en el ambiente y la composición del ensamble de colibríes compitiendo por el acceso a esos recursos, 2) Las relaciones filogenéticas entre las especies en un ensamble que compiten por el acceso a los recursos alimenticios, y 3) Ciertos rasgos morfológicos que brinden ventajas competitivas durante las contiendas, como son la masa corporal y la longitud del pico.

En el capítulo I determinamos que la dominancia de las especies de colibríes de mayor masa corporal sobre especies de menor masa corporal no es absoluta. Los colibríes de especies de mayor masa corporal dominaron a las especies más pequeñas cuando compitieron por el acceso a recursos alimenticios en el $74 \%$ de las contiendas analizadas (119 casos de estudio). Por otro lado, el $26 \%$ de estas interacciones agonísticas (41 casos de estudio) fue ganado por especies de menor masa corporal en relación a su contendiente. Esta proporción se mantuvo en Norte, Centro y Sudamérica, con un porcentaje de encuentros ganados por el contendiente de menor masa corporal de $26 \%$ (18 casos de estudio), 26\% (5 casos de estudio) y $25 \%$ (18 casos de estudio) respectivamente. Estos resultados contrastan con la idea de que una mayor masa corporal otorga una ventaja absoluta sobre el resto de las especies (Stiles y Wolf 1970; Hainsworth y Wolf 1972) y sugieren que otros factores, además de la masa corporal, pueden influir sobre el resultado de las contiendas entre especies de colibríes cuando compiten por el acceso a recursos alimenticos. Los resultados de este capítulo también nos permitieron determinar que de los nueve clados de colibríes definidos por McGuire et al. (2014), las Esmeraldas dominaron el $45 \%$ de las interacciones agonísticas analizadas en este capítulo (72 casos de estudio). Esto evidencia que algunos clados de colibríes han desarrollado rasgos 
morfológicos, fisiológicos o conductuales que les brindan ventajas para competir por el acceso a recursos alimenticios a través de interacciones agonísticas. Finalmente, no encontramos diferencias significativas en la distancia genética entre las especies de colibríes que ganaron contiendas contra competidores de mayor tamaño. Este patrón se mantuvo en Norte, Centro y Sudamérica. No obstante, parece existir una tendencia latitudinal en la cual la distancia genética entre contendientes incrementa de norte a sur del continente. Esto podría ser resultado de la historia de diversificación del grupo en el continente, ya que los procesos de diversificación de 7 de los 9 clados de colibríes ocurrieron principalmente en Sudamérica (McGuire et al. 2014).

En el capítulo II reportamos que el rango de las especies de colibríes dentro de la jerarquía de dominancia es dinámico y determinamos algunos de los factores que pueden modificarlo. El rango jerárquico de dominancia que ocuparon las especies de colibríes cambió en cada uno de los periodos de floración de los tres principales recursos florales (Bouvardia ternifolia, Salvia elegans y Penstemon roseus) en nuestro sitio de estudio (Parque Nacional La Malinche, Tlaxcala). Las especies de colibríes mostraron cambios conductuales y modificaron sus estrategias de forrajeo dependiendo de la disponibilidad de recursos y de la presencia de competidores heteroespecíficos. Nuestros resultados también demuestran que la especie con mayor masa corporal del ensamble no siempre es la más dominante. Por ejemplo, Colibri thalassinus fue la especie más dominante durante la floración de $P$. roseus, a pesar de que una especie más grande de colibrí (Lampornis clemenciae) también competía por el acceso al néctar de esa planta.

Los resultados obtenidos en nuestro estudio contrastan con lo reportado en otros ensambles de colibríes donde la especie más grande dominó al resto de los competidores (Dearborn 1998; Araújo-Silva y Bessa 2010; Justino et al. 2012). Sin embargo, encontramos que el incremento en la distancia genética entre los contendientes estuvo asociado positivamente con una mayor frecuencia de encuentros dominados por especies más pequeñas que su competidor. Este resultado sustenta la hipótesis propuesta por Martin y Ghalambor (2014), quienes postulan que las especies pequeñas de colibríes tendrán más probabilidad de ganar 
contiendas contra especies más grandes si ambas especies son filogenéticamente distantes. En este sentido, Dakin et al. (2018) demostraron que las diferencias morfológicas o fisiológicas generan divergencia conductual entre las especies de colibríes. Por lo tanto, especies cercanamente emparentadas serán morfológicamente similares y expresarán capacidades de maniobrabilidad similares (Skandalis et al. 2017; Dakin et al. 2018). A lo largo de su historia de diversificación las especies de colibríes han estado expuestas a diferentes presiones de selección, condiciones ambientales y recursos de diferentes tipos. Lo anterior, ha promovido que las especies desarrollen diferentes características que les permitan garantizar su acceso a los recursos. Por ejemplo, las especies pequeñas de colibríes podrían haber desarrollado características que les permitirían competir por el acceso a recursos contra especies de mayor tamaño corporal (e.g., mayor desarrollo muscular, mayor aceleración y maniobrabilidad durante el vuelo, un incremento en la producción de testosterona, estradiol o deshidroepiandrosterona). Por otro lado, las especies de mayor tamaño pudieron desarrollar otras características como la especialización en el uso de recursos particulares (e.g., los colibríes ermitaños del género Phaethornis tienen el pico curvo y visitan plantas del género Heliconia con corolas curvas). El desarrollo diferencial de rasgos morfológicos, fisiológicos y conductuales para competir por el acceso a recursos podría favorecer la coexistencia de especies y por lo tanto disminuir la frecuencia de contiendas interespecíficas. Los resultados de este capítulo confirman que las relaciones filogenéticas entre las especies de un ensamble pueden tener una influencia sobre el resultado de las contiendas y por lo tanto en el orden jerárquico de dominancia.

Finalmente, en el capítulo III demostramos que las especies de colibríes con una mayor masa corporal y una mayor longitud de pico están asociadas positiva y significativamente a un mayor rango dentro de la jerarquía de dominancia durante el periodo de floración de Palicourea padifolia en un bosque mesófilo Veracruzano. Este resultado coincide con el patrón reportado para otros ensambles de colibríes donde las especies con mayor masa corporal dominaron al resto de las especies del ensamble (Dearborn 1998; Justino et al. 2012; López-Segoviano et al. 2017). Sin embargo, se debe considerar que en colibríes la masa corporal puede ser muy 
variable, incluso durante un mismo día (Carpenter et al. 1983). Esta variabilidad en la masa corporal podría afectar las habilidades competitivas de las especies (Dakin et al. 2018). Por lo tanto, es importante considerar y analizar el papel de otros rasgos morfológicos menos variables en el tiempo y que pueden representar ventajas competitivas durante las contiendas por el acceso a recursos alimenticos. Los colibríes pueden utilizar su pico para pinchar, punzar y arrancar plumas a los intrusos durante las contiendas (Rico-Guevara y Araya-Salas 2015; Rico-Guevara et al. 2019). Bajo este contexto una mayor longitud de pico podría representar una ventaja durante las contiendas. Sin embargo, es necesario continuar investigando el papel de diferentes rasgos morfológicos durante las contiendas agonísticas entre colibríes y su efecto sobre las jerarquías de dominancia interespecíficas.

Asimismo, determinamos que la probabilidad de que el contendiente más grande gane las contiendas está relacionada significativamente con las diferencias en la masa corporal, la longitud del pico y la distancia genética entre contendientes. Nuestros resultados indican que, cuando la diferencia entre la masa corporal de los contendientes es menor a un gramo o cuando la diferencia entre la longitud del pico de los contendientes es menor o igual a $2.5 \mathrm{~mm}$, ambos contendientes (el más grande y el más pequeño; el del pico más largo y el del pico más corto) tuvieron probabilidades similares de ganar la contienda. Por otro lado, especies de menor tamaño corporal tuvieron una mayor probabilidad de ganar las contiendas cuando existió una menor distancia genética entre los contendientes. Esto contrasta con lo planteado por Martín y Ghalambor (2014), quienes postulan que los contendientes de menor tamaño corporal tendrán más probabilidad de ganar contiendas contra competidores más grandes cuando exista una mayor distancia genética entre ellos. Sin embargo, este resultado contrastante puede ser explicado por la influencia de la composición de especies del ensamble estudiado. El rango de distancia genética entre las especies de colibríes de este ensamble fue amplio (0.039 a 0.196) en comparación al rango reportado en otros ensambles de colibríes (e.g., 0.15 a 0.24 en el PNLM, Márquez-Luna et al. 2019). Sin embargo, el 68\% de las contiendas (i.e., 55 contiendas) ocurrió entre colibríes con una distancia genética de 0.169 a 0.196 . Es decir, ocurrieron entre contendientes con una distancia genética de cercana a media 
(Johns y Avise 1998). Además, el $11 \%$ de las contiendas registradas (i.e., 9 contiendas) ocurrieron entre especies del mismo género ( $S$. beryllina y $S$. cyanocephala) con una distancia genética muy baja (0.039) y características morfológicas muy similares $(S$. beryllina, masa corporal $=4.2 \mathrm{~g}$, longitud del pico $=19.5 \mathrm{~mm}$; . . cyanocephala, masa corporal $=4.7 \mathrm{~g}$, longitud del pico $=19.7 \mathrm{~mm}$ ). Este resultado evidencia que la relevancia y tendencia que tendrán las relaciones filogenéticas entre los contendientes (e.g., distancia genética) en la resolución de contiendas agonísticas estará determinada en gran medida por la composición de especies del ensamble e inclusive por la historia de diversificación del grupo en la región de estudio.

En resumen, los principales resultados de este trabajo confirman que los colibríes establecen jerarquías de dominancia interespecíficas cuando compiten por el acceso a recursos alimenticios (Capítulo II y III). El orden que las especies ocupan dentro de las jerarquías de dominancia es dinámico y es influenciado por los ciclos fenológicos anuales de los recursos disponibles en el ambiente y por la identidad de los colibríes que compiten por su acceso (Capítulo II). Las diferencias entre los rasgos morfológicos de los colibríes contendientes (masa corporal y longitud del pico) representan ventajas competitivas y pueden influir en el resultado de las contiendas y por lo tanto en el orden que las especies ocupan dentro de la jerarquía de dominancia (Capítulo III). Sin embargo, la dominancia de los colibríes más grandes sobre contendientes más pequeños no es absoluta (Capítulo I). En relación a los nueve clados de colibríes, las especies pertenecientes al clado de las Esmeraldas participan con más frecuencia en contiendas agonísticas por el acceso a recursos alimenticios (Capítulo I). La distancia genética entre las especies de colibríes que conforman un ensamble específico puede ser un factor importante en la resolución de las contiendas ya que de manera indirecta puede reflejar procesos de divergencia morfológica y conductual entre dos especies contendientes. Sin embargo, la importancia de este factor y su relación con la resolución de contiendas dependerá de la composición de especies del ensamble de estudio (Capítulo II y III).

La fragmentación y pérdida de hábitats, la introducción de especies vegetales exóticas y la subsecuente pérdida de especies nativas podrían alterar las redes de 
interacción biótica poniendo en peligro los servicios ecosistémicos que nos brindan los colibríes. Bajo el presente escenario de cambio global es fundamental continuar con el estudio de las relaciones de dominancia entre los colibríes. Conocer los mecanismos bajo los cuales funcionan estas relaciones de dominancia nos permitirá determinar su resiliencia y respuesta a cambios en el ambiente. Además nos permitirá inferir acciones que permitan mantener los servicios ecosistémicos y las relaciones bióticas en las que están involucrados los colibríes. 


\section{Literatura citada}

Abrahamczyk, S., y M. Kessler. (2015). Morphological and behavioural adaptations to feed on nectar: how feeding ecology determines the diversity and composition of hummingbird assemblages. Journal of Ornithology, 156, 333347.

Altshuler, D. L., Stiles, F. G., y Dudley, R. (2004). Of Hummingbirds and Helicopters: Hovering Costs, Competitive Ability, and Foraging Strategies. The American Naturalist, 163, 16-25.

Araujo, A. C., y Sazima, M. (2003). The assemblage of flowers visited by hummingbirds in the "capões" of Southern Pantanal, Mato Grosso do Sul, Brazil. Flora-Morphology, Distribution, Functional Ecology of Plants, 198, (6):427-435.

Araújo, M. B., y Rozenfeld, A. (2014). The geographic scaling of biotic interactions. Ecography, 37, (5):406-415.

Araújo-Silva, L. E., y Bessa, E. (2010). Territorial behaviour and dominance hierarchy of Anthracothorax nigricollis Vieillot 1817 (Aves:Trochilidae) on food resources. Revista Brasileira de Ornitologia, 18, 89-96.

Arizmendi, M. C., y Berlanga, H. (2014). Colibríes de México y Norteamérica. CONABIO. México, 160 pp.

Baptista, L. F., Schuchmann, K. L. (1990). Song learning in the Anna Hummingbird (Calypte anna). Ethology, 84, 15-26.

Beaugrand, J. P., y Cotnoir, P. A. (1996). The role of individual differences in the formation of triadic dominance orders of male Green Swordtail Fish (Xiphophorus helleri). Behavioural Processes, 38, (3):287-296.

Berlanga, H., Gómez de Silva, H., Vargas-Canales, V. M., Rodriguez-Contreras, V., Sánches-Gonzales, L. A., Ortega-Álvares, R y Calderón-Parra R. 2015. Aves 
de México: Lista actualizada de especies y nombres comunes. CONABIO, Ciudad de México 122 pp.

Bleiweiss, R., Kirsch, J. A., y Matheus, J. C. (1997). DNA hybridization evidence for the principal lineages of hummingbirds (Aves: Trochilidae). Molecular biology and evolution, 14, (3):325-343.

Bribiesca, R., Herrera-Alsina, L., Ruiz-Sanchez, E., Sánchez-González, L. A., y Schondube, J. E. (2019). Body mass as a supertrait linked to abundance and behavioral dominance in hummingbirds: A phylogenetic approach. Ecology and Evolution, 9, (4):1623-1637.

Bush, J. M., Quinn, M. M., Balreira Cabral, E., y Johnson, M. A. (2016). How do lizards determine dominance? Applying ranking algorithms to animal social behavior. Animal Behaviour, 118, 65-74.

Camfield, A. F. (2006). Resource value affects territorial defense by Broad-tailed and Rufous Hummingbirds. Journal of Field Ornithology, 77, 120-125.

Carpenter, F. L., Hixon, M. A., Russell, R. W., Paton, D. C., y Temeles, E. J. (1993). Interference asymmetries among age-sex classes of rufous hummingbirds during migratory stopovers. Behavioral Ecology and Sociobiology, 33, 297304.

Carpenter, L. F., Paton, D. C., y Hixon, M. A. (1983). Weight gain and adjustment of feeding territory size in migrant hummingbirds. Proceedings of the National Academy of Sciences of the United States of America, 80, 7259-7263.

Cazelles, K., Mouquet, N., Mouillot, D., y Gravel, D. (2016). On the integration of biotic interaction and environmental constraints at the biogeographical scale. Ecography, 39, (10):921-931.

Chase, I. D., y Seitz, K. (2011). Self-structuring properties of dominance hierarchies: a new perspective. Advances in Genetics, 75, 51-81. 
Chesser, R. T., Billerman, S. M., Burns, K. J., Cicero, C., Dunn, J. L., Kratter, A. W., Lovette, I. J., Mason, N. A., Rasmussen, P. C., Remsen, Jr. J. V., Stotz, D. F., y Winker, K. (2020). Sixty-first Supplement to the American Ornithological Society's Check-list of North American Birds. The Auk, ukaa030, DOI: https://doi.org/10.1093/auk/ukaa030

Contreras, P. S., y Ornelas, J. F. (1999). Reproductive conflicts of Palicourea padifolia (Rubiaceae) a distylous shrub of a tropical cloud forest in Mexico. Plant Systematics and Evolution, 219, 225-241.

Cotton, P. A. (2007). Seasonal resource tracking by Amazonian hummingbirds. Ibis, $149,135-142$.

Dakin, R., Segre, P. S., Straw, A. D., y Altshuler, D. L. (2018). Morphology, muscle capacity, skill and maneuvering ability in hummingbirds. Science, 359, 653657.

David, H. A. (1987). Ranking from unbalanced paired-comparison data. Biometrika, $74,432-436$.

Dearborn, D. C. (1998). Interspecific territoriality by a Rufous-Tailed Hummingbird (Amazilia tzacat): effects of intruder size and resource value. Biotropica, 30, 306-313.

Elo, A. E. (1978). The rating of chess players, past and present. New York, NY: Arco.

Ewald, P. W. (1985). Influence of asymmetries in resource quality and age on aggression and dominance in black-chinned hummingbird. Animal Behaviour, 33, 705-719.

Farine, D. R., y Sánchez-Tójar, A. (2017). aniDom: Inferring dominance hierarchies and estimating uncertainty. URL https://cran.r-project.org/package=aniDom.

Feinsinger, P., y Colwell, R. K. (1978). Community organization among Neotropical nectar-feeding birds. Amercian Zoologist, 18, 779-795. 
Feinsinger, P., Swarm, L. A., y Wolfe, J. A. (1985). Nectar-feeding birds on Trinidad and Tobago: comparison of diverse and depauperate guilds. Ecological Monographs, 55, (1):1-28.

Francis, M. L., Plummer, K. E., Lythgoe, B. A., Macallan, C., Currie, T. E., y Blount, J. D. (2018). Effects of supplementary feeding on interspecific dominance hierarchies in garden birds. PlosOne, 13, (9):e0202152.

Goldberg, T. L., y Ewald, P. W. (1991). Territorial song in the Anna's hummingbird, Calypte anna: costs of attraction and benefits of deterrence. Animal Behaviour, 42, 221-226.

Gotelli, N. J., Graves, G. R., y Rahbek, C. (2010). Macroecological signals of species interactions in the Danish avifauna. Proceedings of the National Academy of Sciences, 107, (11):5030-5035.

Graham, C. H., Parra, J. L., Rahbek, C., y McGuire, J. A. (2009). Phylogenetic structure in tropical hummingbird communities. Proceedings of the National Academy of Sciences, 106, 19673-19678.

Hainsworth, F. R., y Wolf, L. L. (1972). Power for hovering flight in relation to body size in hummingbirds. The American Naturalist, 106, 589-596.

Hernández-Ramírez, A. M. (2018). Buscando al polinizador eficiente: variación temporal en el gremio de visitantes florales y carga polínica estigmática en la especie distílica Palicourea padifolia (Rubiaceae). Revista Mexicana de Biodiversidad, 89, (2), 412-420.

Jiménez, L., Negrete-Yankelevich, S., y Macías-Ordóñez, R. (2012). Spatial association between floral resources and hummingbird activity in a Mexican tropical montane cloud forest. Journal of Tropical Ecology, 28, (5):497-506.

Johns, G. C., y Avise, J. C. (1998). A comparative summary of genetic distances in the vertebrates from the mitochondrial cytochrome b gene. Molecular Biology and Evolution, 15, 1481-1490. 
Justino, D. G., Maryama, P. K., y Oliveira, P. E. (2012). Floral resource availability and hummingbird territorial behaviour on a Neotropical savanna shrub. Journal of Ornithology, 153, 189-197.

King, J. R., y Murphy, M. E. (1990). Estimates of the mass structures other than plumage produced during molt by White-Crowned Sparrows. The Condor, 92, 839-843.

Kodric-Brown, A., y Brown, J. H. (1978). Influence of economics, interspecific competition and sexual dimorphism on territoriality of migrant rufous hummingbirds. Ecology, 59, 285-296.

Kuban, J. F., Lawley, J., y Neill, R. L. (1983). The Partitioning of Flowering Century Plants by Black-Chinned and Lucifer Hummingbirds. The Southwestern Naturalist, 28, 143-148.

Kumar, S., Stecher, G., y Tamura, K. (2016). MEGA7: molecular evolutionary genetics analysis version 7.0 for bigger datasets. Molecular Biology and Evolution, 33, 1870-1874.

Lara, C. (2006). Temporal dynamics of flower use by hummingbirds in a Highland temperate forest in Mexico. Ecoscience, 13, 23-29.

Lara, C., y Ornelas, J. (2001). Preferential nectar robbing of flowers with long corollas: experimental studies of two hummingbird species visiting three plant species. Oecologia, 128, (2):263-273.

Lara, C., Martinez-Garcia, V., Ortiz-Pulido, R., Bravo-Cadena, J., Loranca, S., y Cordoba-Aguilar, A. (2011). Temporal-spatial segregation among hummingbirds foraging on honeydew in a temperate forest in Mexico. Current Zoology, 57, 56-62.

López-Segoviano, G., Bribiesca, R., y Arizmendi, M. C. (2017). The role of size and dominance in the feeding behaviour of coexisting hummingbirds. Ibis, 160, 283-292. 
Magrach, A., Lara, C., Márquez-Luna, U., Díaz-Infante, S., y Parker, I. (2020). Community-level reorganizations following migratory pollinator dynamics along a latitudinal gradient. Proceedings of the Royal Society B, 287, (1930): 20200649.

Márquez-Luna, U., Lara, C., Corcuera, P., y Valverde, P. (2018). Efecto del tamaño corporal y distancia evolutiva en las interacciones agonísticas de colibríes (Trochilidae). Revista Mexicana de Biodiversidad, 89, (1):149-162.

Márquez-Luna, U., Lara, C., Corcuera, P., y Valverde, P. (2019). Factors affecting the dominance hierarchy dynamics in a hummingbird assemblage. Current Zoology, 65, (3):261-268.

Márquez-Luna, U., Lara, C., Ortiz-Pulido, R. (2015). La conducta territorial del Zafiro Oreja Blanca (Hylocharis leucotis) es afectada por la disponibilidad de energía. Ornitología Neotropical, 26, 13-23.

Márquez-Luna, U., Lara, C., Ortiz-Pulido, R. (2017). La calidad del néctar afecta la conducta territorial y de forrajeo en hembras del colibrí Lucifer (Calothorax lucifer): Un experimento. Ornitología Neotropical, 28, 67-75.

Martin, P. R., y Ghalambor, C. K. (2014). When David beats Goliath: the advantage of large size in interspecific aggressive contests declines over evolutionary time. PLOS ONE, 9, e108741.

McGuire, J. A., Witt, C. C., Remsen, J. V., Corl, A., Rabosky, D. L., Altshuler, D. L. y Dudley, R. (2014). Molecular phylogenetics and the diversification of Hummingbirds. Current Biology, 24, 910-916.

Mendiola-Islas, V., Lara, C., Corcuera, P., Valverde, P. L. (2016). Residency in WhiteEared Hummingbirds (Hylocharis leucotis) and its effect in territorial contest resolution. PeerJ, 4:e2491

Montgomerie, R. D., y Gass, C. L. (1981). Energy Limitation of Hummingbird Population in Tropical and Temperate Communities. Oecologia, 50, 162-165. 
Nabholz, B., Lanfear, R., y Fuchs, J. (2016). Body mass-corrected molecular rate for bird mitochondrial DNA. Molecular Ecology, 25, (18):4438-4449.

Navarro, A. G. y Peterson, A. T. (2007). Mapas de las aves de México basados en WWW. Museo de Zoología, Facultad de Ciencias, UNAM y University of Kansas, Museum of Natural History. CONABIO. México.

Ohashi, K., y Thomson, J. D. (2009). Trapline foraging by pollinators: its ontogeny, economics and possible consequences for plants. Annals of Botany, 103, (9):1365-1378.

Ornelas, J. F., González, C., Jiménez, L., Lara, C., y Martínez, A. J. (2004a). Reproductive ecology of distylous Palicourea padifolia (Rubiaceae) in a tropical montane cloud forest. II. Attracting and rewarding mutualistic and antagonistic visitors. American Journal of Botany, 91, (7), 1061-1069.

Ornelas, J. F., Jiménez, L., González, C., y Hernández, A. (2004b). Reproductive ecology of distylous Palicourea padifolia (Rubiaceae) in a tropical montane cloud forest. I. Hummingbirds' effectiveness as pollen vectors. American Journal of Botany, 91, (7):1052-1060.

Paine, R. T. (1976). Size-limited predation: an observational and experimental approach with the Mytilus-Pisaster interaction. Ecology, 57, (5): 858-873.

Pimm, S. L., Rosenzweig, M. L., y Mitchell, W. (1985). Competition and food selection: field test of a theory. Ecology, 66, (3):798-807.

Piñero, D., Barahona, A., Eguiarte, L., Olivares, A. R., Lizana, R. S. (2008). La variabilidad genética de las especies: aspectos conceptuales y sus aplicaciones y perspectivas en México. En Capital natural de México, vol. I: Conocimiento actual de la biodiversidad. CONABIO, México, pp.415-435.

Powers, D. R. (1991). Diurnal variation in mass, metabolic rate, and respiratory quotient in Anna's and Costa's hummingbirds. Physiological Zoology, 64, (3):850-870. 
R Core Team. (2019). R: A language and environment for statistical computing. $R$ Foundation for Statistical Computing, Vienna, Austria. URL https://www.Rproject.org/

Rico-Guevara, A., y Araya-Salas, M. (2015). Bills as daggers? A test for sexually dimorphic weapons in a lekking hummingbird. Behavioral Ecology, 26, (1):2129.

Rico-Guevara, A., y Hurme, J. (2019). Intrasexually selected weapons. Biological Reviews, 94, (1):60-101.

Rico-Guevara, A., Rubega, M. A., Hurme, J., y Dudley, R. (2019). Shifting paradigms in the mechanics of nectar extraction and Hummingbird bill morphology. Integrative Organismal Biology, 1, (1):oby006

Rodríguez-Flores, C. I., y Arizmendi, M. C. (2016). The dynamics of hummingbird dominance and foraging strategies during the winter season in a highland community in Western Mexico. Journal of Zoology, 299, (4):262-274.

Rodríguez-Gómez, F., Gutiérrez-Rodríguez, C., y Ornelas, J. F. (2013). Genetic, phenotypic and ecological divergence with gene flow at the Isthmus of Tehuantepec: the case of the azure-crowned hummingbird (Amazilia cyanocephala). Journal of Biogeography, 40, (7):1360-1373.

Sánchez-Tójar, A., Schroeder, J., Farine, D. R. (2017). A practical guide for inferring reliable dominance hierarchies and estimating their uncertainty. Journal of Animal Ecology, 87, (3):594-608.

Schemske, D. W., Mittelbach, G. G., Cornell, H. V., Sobel, J. M., y Roy, K. (2009). Is there a latitudinal gradient in the importance of biotic interactions?. Annual Review of Ecology, Evolution, and Systematics, 40, 245-269.

Schuchmann, K. L. (1999). Family Trochilidae (Hummingbirds). En J. del Hoyo, A. Elliott, y J. Sargatal (Eds.), Handbook of Birds of the World. Volumen 5: BarnOwls to Hummingbirds. (pp. 468-535). Lynx Edicions, Barcelona, España. 
Shurin, J. B., y Allen, E. G. (2001). Effects of competition, predation, and dispersal on species richness at local and regional scales. The American Naturalist, 158, (6):624-637.

Skandalis, D. A., Segre, P. S., Bahlman, J. W., Groom, D. J. E., Welch, Jr, K. C., Witt, C. C., McGuire, J. A., Dudley, R., Lentink, D., y Altshuler, D. L. (2017). The biomechanical origin of extreme wing allometry in hummingbirds. Nature communications, 8, 1047.

SMN. (2019). Normales climatológicas por Estado. Servicio Meteorológico Nacional. Consultado 21 octubre, 2019 de http://smn.cna.gob.mx/es/.

Stachowicz, J. J. (2001). Mutualism, Facilitation, and the Structure of Ecological Communities Positive interactions play a critical, but underappreciated, role in ecological communities by reducing physical or biotic stresses in existing habitats and by creating new habitats on which many species depend. Bioscience, 51, (3):235-246.

Stiles, G. F. (1995). Behavioral, Ecological and Morphological Correlates of Foraging for Arthropods by the Hummingbirds of a Tropical Wet Forest. The Condor, 97, 853-878.

Stiles, F. G., y Wolf, L. L. (1970). Hummingbird territoriality at a tropical flowering tree. The Auk, 87, 467-491.

Tamura, K., Nei, M. (1993). Estimation of the number of nucleotide substitutions in the control region of mitochondrial DNA in humans and chimpanzees. Molecular Biology and Evolution, 10, 512-526.

Taylor, C. M. (1989). Revision of Palicourea (Rubiaceae) in Mexico and Central America. Systematic Botany Monographs, 26, 1-102.

Varholick, J. A., Bailoo, J. D., Palme, R., y Würbel, H. (2018). Phenotypic variability between social dominance ranks in laboratory mice. Scientific Reports 8:6593. 
Whittaker, R. J., Willis, K. J., y Field, R. (2001). Scale and species richness: towards a general, hierarchical theory of species diversity. Journal of biogeography, 28 , (4):453-470.

Wickhamn, H. (2016). ggplot2: Elegant graphics for data analysis. Springer-Verlag. New York, USA.

Wolf, L. L. (1969). Female territoriality in a tropical hummingbird. The Auk, 86, (3):490-504.

Wolf, L. L., Stiles, F. G., Hainsworth, F. R. (1976). Ecological organization of a tropical, highland hummingbird community. Journal of Animal Ecology, 45, 349-379.

Wootton, J. T. (1994). The nature and consequences of indirect effects in ecological communities. Annual Review of Ecology and Systematics, 25, 443-466.

Zamudio-Beltrán, L. E., Ornelas, J. F., Malpica, A., y Hernández-Baños, B. E. (2020). Genetic and morphological differentiation among populations of the Rivoli's Hummingbird (Eugenes fulgens) species complex (Aves: Trochilidae). The Auk, 137, 1-20. 